\title{
Taming the beast: a revised classification of Cortinariaceae based on genomic data
}

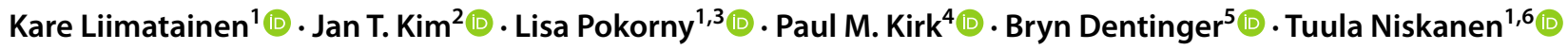

Received: 20 October 2021 / Accepted: 20 January 2022 / Published online: 23 February 2022

(c) The Author(s) 2022

\begin{abstract}
Family Cortinariaceae currently includes only one genus, Cortinarius, which is the largest Agaricales genus, with thousands of species worldwide. The species are important ectomycorrhizal fungi and form associations with many vascular plant genera from tropicals to arctic regions. Genus Cortinarius contains a lot of morphological variation, and its complexity has led many taxonomists to specialize in particular on infrageneric groups. The previous attempts to divide Cortinarius have been shown to be unnatural and the phylogenetic studies done to date have not been able to resolve the higher-level classification of the group above section level. Genomic approaches have revolutionized our view on fungal relationships and provide a way to tackle difficult groups. We used both targeted capture sequencing and shallow whole genome sequencing to produce data and to perform phylogenomic analyses of 75 single-copy genes from 19 species. In addition, a wider 5-locus analysis of 245 species, from the Northern and Southern Hemispheres, was also done. Based on our results, a classification of the family Cortinariaceae into ten genera-Cortinarius, Phlegmacium, Thaxterogaster, Calonarius, Aureonarius, Cystinarius, Volvanarius, Hygronarius, Mystinarius, and Austrocortinarius-is proposed. Seven genera, 10 subgenera, and four sections are described as new to science and five subgenera are introduced as new combinations in a new rank. In addition, 41 section names and 514 species names are combined in new genera and four lecto- and epitypes designated. The position of Stephanopus in suborder Agaricineae remains to be studied. Targeted capture sequencing is used for the first time in fungal taxonomy in Basidiomycetes. It provides a cost-efficient way to produce -omics data in species-rich groups. The -omics data was produced from fungarium specimens up to 21 years old, demonstrating the value of museum specimens in the study of the fungal tree of life. This study is the first family revision in Agaricales based on genomics data and hopefully many others will soon follow.
\end{abstract}

Keywords Agaricales · Fungariomics · Fungi · HybPiper · Museomics · Targeted capture sequencing · Whole genome sequencing

Handling Editor: Ruilin Zhao.

Kare Liimatainen

k.liimatainen@kew.org

Jan T. Kim

j.t.kim@herts.ac.uk

Lisa Pokorny

1.pokorny@kew.org

Paul M. Kirk

p.kirk@kew.org

Bryn Dentinger

bdentinger@nhmu.utah.edu

Tuula Niskanen

tuula.niskanen@cortinarius.fi

1 Jodrell Laboratory, Royal Botanic Gardens, Kew,

Surrey TW9 3AB, UK
2 Department of Computer Science, School of Physics, Engineering and Computer Science, University of Hertfordshire, Hatfield, Hertfordshire AL10 9AB, UK

3 Present Address: Institut Botànic de Barcelona (IBB, CSIC-Ajuntament de Barcelona), 08038 Barcelona, Catalonia, Spain

4 Biodiversity Informatics and Spatial Analysis, Jodrell Laboratory, Royal Botanic Gardens, Kew, Surrey TW9 3AB, UK

5 Natural History Museum of Utah and School of Biological Sciences, University of Utah, Salt Lake City, UT, USA

6 Botanical Museum, University of Helsinki, P.O. Box 7, 00014 Helsinki, Finland 


\section{Introduction}

Genomic-level data have revolutionized our views on fungal relationships and helped us create better phylogenies for previously unresolved lineages (e.g., Chang et al. 2021; Li et al. 2021). These data have been used to tackle macroevolutionary events, e.g., mushroom morphological evolution (Varga et al. 2019, Sánchez-García et al. 2020) or the evolution of symbiotic traits (Miyauchi et al. 2020). High-throughput sequencing (HTS) techniques have also allowed genomic data to be generated from fungarium specimens (Dentinger et al. 2016).

Fungal genomes are small, ranging from 7.67 to 720.2 $\mathrm{Mbp} / 1 \mathrm{C}$ (Kullman et al. 2005), with an average size of $\sim 63$ $\mathrm{Mbp} / 1 \mathrm{C}$ in Ascomycota (Hill et al. 2021) and $~ 50 \mathrm{Mbp} / 1 \mathrm{C}$ in Basidiomycota (Mohanta and Bae 2015; Li et al. 2018), compared to those of plants and animals, e.g., ranging 64 $\mathrm{Mbp} / 1 \mathrm{C}$ to $140 \mathrm{Gbp} / 1 \mathrm{C}$ in angiosperms (Pellicer et al. 2018) and 1.6 to $6.3 \mathrm{Gbp} / 1 \mathrm{C}$ in mammals (Kapusta et al. 2017). Therefore, in phylogenomics studies of fungi, in depth or shallow whole genome sequencing (WGS) have been an affordable option to generate HTS data, with the vast majority of the fungal genomic studies to date having relied on this approach. However, for species-rich groups where hundreds to thousands of samples might be included, targeted capture sequencing provides a more cost-effective alternative (Hale et al. 2020). Enrichment methods have been widely used to study the systematics of plants and animals (e.g., Johnson et al. 2019; Faircloth 2017) and they have recently been applied in fungal systematics to study lichen-forming Ascomycota families Lobariaceae (Widhelm et al. 2019) and Parmeliaceae (Grewe et al. 2020), as well as the Peltigeralean backbone (Widhelm et al. 2021).

The family Cortinariaceae belongs to suborder Agaricineae, which contains mainly the brown and dark-spored Agaricales with thick-walled and pigmented basidiospores (Matheny et al. 2015; Dentinger et al. 2016). According to the most recent phylogenetic studies, the family Cortinariaceae only includes one genus, Cortinarius (Pers.) Gray. Several genera formerly placed in the Cortinariaceae, e.g., Phaeocollybia R. Heim, Hebeloma (Fr.) P. Kumm., and Galerina Earle, have been moved to other families in the Agaricineae (Matheny et al. 2015). On the other hand, many taxa previously treated as separate genera are currently included into Cortinarius: Bulbopodium Earle, Cuphocybe R. Heim, Dermocybe (Fr.) Wünsche, Inoloma (Fr.) Wünsche, Myxacium (Fr.) P. Kumm., Phlegmacium (Fr.) Wünsche, Rapacea E. Horak, Rozites P. Karst., and Telamonia (Fr.) Wünsche, as well as sequestrate genera Gigasperma E. Horak, Hymenogaster Vittad. p.p., Protoglossum Massee, Quadrispora Bougher \& Castellano, and
Thaxterogaster Singer (Peintner et al. 2001, 2002, 2004; Garnica et al. 2005; Soop et al. 2019; Nouhra et al. 2021). Other than Cortinarius, the only genus currently placed in the family Cortinariaceae is the South American Stephanopus M.M. Moser \& E. Horak, a small genus with five described species associated with Nothofagaceae, but it is lacking any sequence data and thus its position in the suborder Agaricineae remains unresolved.

As currently delimited, Cortinarius is by far the largest genus of Agaricales, and its representatives are found from the tropics to arctic habitats in the Northern and Southern Hemispheres. To date, over 5000 taxa, including subspecies and varieties, have been recorded in Index Fungorum (2021). ITS sequence data exist for close to 3000 species (UNITE 2021, using an SH threshold of 1.5\%), including both described and undescribed taxa. However, sequence data from many regions of the world are still lacking and, thus, many more species are in urgent need of sequencing and/or description.

Cortinariaceae species are important ectomycorrhizal fungi and form associations with many vascular plants, including mainly woody species (trees and some shrubs) in the gymnosperms (Pinaceae) and the rosid angiospermsorders Fabales (Fabaceae), Fagales (Betulaceae, Fagaceae, Nothofagaceae), and Rosales (Rhamnaceae, Rosaceae), in the so-called nitrogen fixing clade; core Malvales (Malvaceae, plus the Cistaceae, Dipterocarpaceae, and Sarcolaenaceae clade); and, even, orders Malpighiales (Phyllanthaceae, Salicaceae) and Myrtales (Myrtaceae)_as well as some herbaceous angiosperms, both in the monocots (Cyperaceae and Orchidaceae) and in the caryophyllids eudicots (Polygonaceae) (Moser and Horak 1975; Harrington and Mitchell 2002; Frøslev et al. 2005; Garnica et al. 2005; Jacquemyn et al. 2010; Tedersoo et al. 2011; Harrower et al. 2015a; Thoen et al. 2019). The species of Cortinariaceae provide access to nitrogen for vascular plants in nutrient poor habitats, and their role in carbon cyling has been studied for northern European (Bödeker et al. 2014; Lindahl et al. 2021) and North American (Fernandez et al. 2020) boreal forests.

The first study based on molecular data (Høiland \& HolstJensen 2000) indicated that many of the traditional infrageneric groupings of Cortinarius were unnatural (e.g., Moser 1983; Brandrud et al. 1989; Bidaud et al. 1994). During the following 20 years many studies were conducted to gain a better understanding of their natural relationships. Most of these datasets were based only on sequences from the ITS and LSU regions (Høiland \& Holst-Jensen 2000; Peintner et al. 2004; Garnica et al. 2005; Harrower et al. 2011; Liimatainen et al. 2014, 2020a; Stensrud et al. 2014), and only two extensive studies of the genus also included data from RPB1 and/or RPB2 regions (Garnica et al. 2016; Soop et al. 2019). So far, the only study to include more than a handful 
of DNA markers (ITS, nLSU, GPD, MCM7, RPB1, RPB2, and TEF1) was conducted by Stefani et al. (2014) for the delimitation of Australian dermocyboid Cortinarius species. Despite these efforts, no genus-wide, revised subgeneric classification of Cortinarius has been presented because it has not been possible to resolve the backbone of the phylogeny. Existing sequence data have, however, allowed the revision of various sections within Cortinarius, with studies by Soop et al. (2019), Liimatainen et al. (2020a), Ammirati et al. (2021), and Niskanen and Liimatainen (2021) presenting the most updated morpho-genetic, section-level classification of Cortinarius, including a total of 172 sections.

The aim of this study was to conduct the first phylogenomic study of family Cortinariaceae to resolve higherlevel relationships and allow for a revised genus-level classification of the group.

\section{Materials and methods}

\section{Molecular sampling}

Sampling was designed to cover as many of the major lineages of Cortinariaceae as possible, based on the latest phylogenetic trees published for the family (Garnica et al. 2016; Soop et al. 2019). Vouchers of 19 dried fungarium specimens sampled for genomics work are deposited in the collections of the Royal Botanic Gardens, Kew, United Kingdom (K) and/or (H) University of Helsinki, Finland.

\section{DNA extraction and genomic library preparation}

DNA was extracted from 2 to $4 \mathrm{mg}$ of dried grounded lamella with the DNeasy Plant Mini kit (Qiagen, Germantown, USA). Extracted DNA was quantified using a Quantus $^{\mathrm{TM}}$ fluorometer and the Quantifluor dsDNA system kit (Promega Corporation, Madison, WI, USA). To get an estimation of the average fragment size, samples were assessed on a 2100 Bioanalyzer (Agilent Technologies, Santa Clara, CA, USA), using the appropriate DNA chips and reagents, or a 4200 TapeStation System (Agilent Technologies), using the corresponding Genomic DNA ScreenTapes and reagents. The DNA was then fragmented using an M220 Focusedultrasonicator $^{\mathrm{TM}}$ (Covaris, Woburn, MA, USA) with varied shearing times (30-45 s) depending on the DNA fragment size profile. The average fragment size in the specimens that were used for WGS ranged from 680 to $745 \mathrm{bp}$, and from 660 to $880 \mathrm{bp}$ for the specimens used for the targeted capture sequencing.

Dual-indexed libraries for WGS were prepared using a TruSeq ${ }^{\circledR}$ Nano DNA LT (Illumina Inc.) sample kit following the manufacturer's protocols. Dual-indexed libraries for the targeted capture sequencing were prepared using the NEBNext巴 Ultra ${ }^{\mathrm{TM}}$ II Library Prep kit and the NEBNext ${ }^{\circledR}$ Multiplex Oligos for Illumina ${ }^{\circledR}$ (Dual Index Primer Set 1), according to the manufacturer's protocols (New England BioLabs, Ipswich, MA, USA), although at half the recommended volumes. The resulting genomic libraries were quantified and qualified as above (i.e. Quantus and Bioanalyzer/TapeStation).

\section{WGS, genome assembly, and extraction of single-copy orthologs}

For WGS, five to six libraries were pooled following Dentinger et al. (2016). The sequencing was performed on an Illumina MiSeq with v3 $(2 \times 300$ bp paired-end reads $)$ chemistry (Illumina, San Diego, CA, USA) at Jodrell Laboratory, Royal Botanic Gardens, Kew.

Demultiplexed reads were quality-checked with FastQC (Andrews 2010) before trimming with Trimmomatic v0.39 (Bolger et al. 2014) with settings: LEADING:3 TRAILING:3 SLIDINGWINDOW:4:15 MINLEN:36. The genomes were then assembled using ABySS (Simpson et al. 2009) with a $k$-mer size ranging $51-96 \mathrm{bp}$, depending on the quality of the sequence data.

Next, the 208 single-copy genes identified by Dentinger et al. (2016) were extracted from the nine assembled genomes using exonerate v2.2.0 (Slater and Birney 2005) with Cortinarius glaucopus (Miyauchi et al. 2020) amino acid (AA) sequences (for the 208 single-copy genes) as queries in searches against our nine assemblies. The top-scoring hit was retained in each case. Additionally, we included the AA sequences of the five single-copy loci currently used in phylogenetic studies of family Cortinariaceae, which were not part of the 208-gene queries in the exonorate search: RPB1 (RNA polymerase II largest subunit B220; also RPO21; C. odorifer GenBank no. DQ083857), RPB2 (RNA polymerase II second largest subunit B150; also RPO22; Coprinopsis cinerea, GenBank no. XM_001829088), MCM7 (component of the Mcm2-7 hexameric helicase complex; also CDC47; C. basirubescens Genbank no. JN985546), GPD (glyceraldehyde-3-phosphate dehydrogenase (GAPDH), isozyme 3; also TDH3; C. austrosanguineus JX675721), and TEF1 (Translational elongation factor EF-1 alpha; also eEF1A; C. sodagnitus GenBank no. DQ061275) to also retrieve sequences of those regions from the genome assemblies. These regions were compared against the assemblies to verify that they were truly single-copy ones in our species.

\section{Enrichment panel probe design}

Our goal was to design a 20,000-probe custom myBaits ${ }^{\circledR}$ enrichment panel for target capture of phylogeneticallyinformative, single-copy nuclear orthologs. Four out of 
nine Cortinarius species (C. victoriaensis, $C$. neofurvolaesus, C. scaurus, and C. typicus), for which most single-copy orthologs recovered by exonorate and representing different lineages across Cortinariaceae, were selected for probe design. The size of the dataset exceeded the limits of the 20,000 probe enrichment panel and we therefore discarded 20 target genes with the most missing data from all four species. The final dataset included 188 targets, from those identified by Dentinger et al. (2016), with the addition of the currently used loci (RPB1, RPB2, MCM7, GPD, and TEF1), resulting in a total of 193 targets. For the probe design, nucleotide sequences containing both intron and exon regions were used. Based on the visual inspection of the alignments of each target, the intron regions were generally short $(<50 \mathrm{bp})$ and largely conserved within the family making it possible to include them in the enrichment panel. The design and production of the probes was done by Arbor Biosciences (Ann Arbor, Michigan, USA) based on the sequence data provided. The probes were 120 nucleotides long and designed with $\sim 2 \times$ tiling density.

\section{Hybridisation and targeted capture sequencing}

Dual-indexed genomic libraries were pooled and hybridised with our custom myBaits ${ }^{\circledR}$ enrichment panel, following v3.0 manufacturer's protocols, with the exception of pooling four or nine libraries per hybridisation reaction and each reaction having a total of $1 / 4$ of the recommended volume. Hybridisations were performed at $65^{\circ} \mathrm{C}$ for $20 \mathrm{~h}$ in Vapo Protect Mastercycler 6325 thermocycler (Eppendorf, Arlington, UK). Captured targets were amplified with a KAPA HiFi $2 \times$ HotStart ReadyMix PCR kit (Roche, Basel, Switzerland) for 10 cycles, and the PCR products were cleaned using Agencourt AMPure XP magnetic beads. Final products were quantified and qualified as above. Thirteen enriched libraries were further pooled for sequencing on an Illumina MiSeq platform (Illumina, San Diego, CA, USA) using v2 Nano chemistry ( $2 \times 250$ bp paired-end reads) at the Jodrell Laboratory, Royal Botanic Gardens, Kew.

\section{Target retrieval and sequence assembly}

Demultiplexed reads were quality-checked as above before trimming with Trimmomatic v0.39 (Bolger et al. 2014) with settings: LEADING:20 TRAILING:20 SLIDINGWINDOW:4:20 MINLEN:36. The HybPiper v1.3.1 (Johnson et al. 2019) pipeline was used for downstream analyses. First, quality-filtered, trimmed reads were mapped to amino acid (AA) sequences corresponding to our target loci using BLASTx (Altschul et al. 1990). Second, paired, mapped reads were assembled into contigs using SPAdes v3.13.1 (Bankevich et al. 2012), using default settings with the exception of minimum coverage, which was set to $4 \mathrm{x}$.
Third, the intronate.py script was used to generate supercontigs (scaffolded merged SPAdes contigs containing both complete exon and intron sequences) and retrieve sequences.py was used to retrieve the final supercontig sequences (of the target loci from each of our specimens) to build the data matricess required for subsequent phylogenetic analyses. Finally, summary statistics (e.g., percent of reads mapped to target) were generated using SAMtools (Li et al. 2009) and the hybpiper_stats.py script.

\section{Data mining and data matrix generation}

Two different data matrices were assembled for downstream phylogenetic analyses. The first consisted of the single-copy orthologs from both the shallow WGS and the targeted capture sequencing data, for a total of 19 species. Of the original 193 single-copy orthologs targeted, 75 of them (including RPB1, RPB2, MCM7, GPD, and TEF1), present at least in $>50 \%$ of the species sampled and with $>500 \mathrm{bp}$ of average length recovered, were selected for further analysis. For Cortinarius crassus, the data matrices originating from WGS versus targeted capture sequencing were kept separate to allow direct comparison of these two approaches.

For the second data matrix, we mined NCBI GenBank for RPB1 sequences from Cortinariaceae species, which we combined with 17 newly generated RPB1 sequenced from the WGS and targeted capture sequencing data. When available, we also mined RPB2 (from 18 genomes), MCM7 (9), GPD (12), and TEF1 (10) for these same samples. The final data matrix included 245 species.

\section{Multiple sequence alignment and phylogenetic analyses}

For both data matrices, all loci were individually aligned using MAFFT v7 with iterative refinement (i.e., E-INS-i algorithm; Katoh and Standley 2013) and, then, manually adjusted in SeaView (Galtier et al. 1996) following the guidelines summarized in Morrison (2006). The individual alignments were then concatenated in Mesquite v3.2 (Maddison and Maddison 2017). Phylogenetic trees were generated from the two concatenated data matrices, with model parameter estimation partitioned by loci, using RAxML v8.2.12 with 1000 traditional bootstrap (BS) replicates under the GTR $+\Gamma$ model (Stamatakis 2014), as advised by Young \& Gillung (2020). For the first data matrix, Crepidotus sp. (Dentinger et al. 2016) and Hebeloma cylindrosporum (Kohler et al. 2015) were used as outgroups. For the second data matrix, the backbone topology inferred from the first data matrix was used as a topological constraint. 


\section{Data availability}

The nine new Cortinariaceae genomes sequenced for the present study are deposited in the European Nucleotide Archive (Study ID PRJEB49625) and the raw reads resulting from the targeted capture sequencing in the NCBI GenBank Sequence Read Archive, SRA (BioProject PRJNA791499). The DNA sequences used to design the enrichment panel probes are available on Dryad (https://doi.org/10.5061/ dryad.0p2ngf238).

\section{Molecular results}

\section{WGS and targeted capture sequencing performance}

Summary statistics for the WGS, targeted capture sequencing, and locus mining used in the phylogenomic analysis are presented in Tables 1 and 2. There was substantial variation in the quality of the assemblies from WGS data and, thus, in the recovery rate of the targeted single-copy orthologs. Anywhere from 33 to $100 \%$ of the 75 target markers chosen for the final phylogenomics analysis were recovered and the recovery rate was $>70 \%$ for only four out of nine specimens. The recovery rate for the targeted capture sequencing was far better: it was $>85 \%$ (of the 75 loci) for nine out of eleven specimens and substantially less (35\% and $45 \%$ ) in only two specimens. Reads mapped to the initial 193 targets ranged from 10,101 to 93,312 . On average, over 23,000 reads were needed to reach $>85 \%$ coverage for the 75 loci, and over 33,000 reads were needed to reach $>95 \%$ coverage. Pooling nine specimens in one baiting reaction generally produced good results: in 8 out of 9 specimens $>88 \%$ of the 75 target loci were recoved, only in one specimen the recovery rate was low, $<35 \%$.

\section{Phylogenomic inference and systematic rearrangements}

The phylogeny inferred from 75 single-copy nuclear orthologs for 20 accessions is shown in Fig. 1. The results of the wider 5-locus analysis, containing 245 species, are presented in Fig. 2. Nodal support BS values below $85 \%$ are considered weak, between 85 and $95 \%$ moderate, between 95 and $99 \%$ BS strong, and lastly, 100\% denotes full support. Based on the results, the division of the family Cortinariaceae into ten putative genera is proposed and these names are used hereon.

In the phylogenomics tree (Fig. 1), Thaxterogaster (BS $68 \%$ ) is sister to a clade encompassing all other genera (BS $79 \%$ ), both weakly supported. This latter clade is further divided into a strongly supported Cortinarius (BS 95\%) and a weakly supported clade containing the remaining genera
(BS 82\%). The strongly supported (BS 95\%) crown of this latter clade is composed of fully supported Aureonarius (BS 100\%), Phlegmacium (BS 100\%), as well as Calonarius, here represented by just one species. Austrocortinarius, also represented by one accession, and fully supported Cystinarius (BS $100 \%$ ) are in a grade leading to the aforementioned crown clade. From the sampled genera represented by more than one species, only one, Thaxterogaster, received a suboptimal BS value $(<95 \%)$.

The results of the phylogenetic analysis, based on the five most-used single-copy marker genes in Cortinarius from 245 taxa, are presented in Fig. 2. All genera represented by more than one accession in this analysis received moderate to full support: Aureonarius (BS 100\%), Austrocortinarius (BS 100\%), Calonarius (BS 100\%), Cystinarius (BS 99\%), Hygronarius (BS 92\%), Phlegmacium (BS 88\%), Thaxterogaster (BS 99\%), Volvanarius (BS 100\%). The only exception was genus Cortinarius s. str. that received lower support (BS $70 \%$ ). The diversity, distribution, and selected morphological characters for the proposed genera are summarized in Table 3.

The infrageneric relationships were variably resolved in different genera (Fig. 2). In genus Calonarius, three weakly to moderately supported subgenera were recognized: $C$. subgen. Calonarius (BS 63\%), C. subgen. Calochroi (BS 87\%), and C. subgen. Fulvi (BS 75\%). Genus Aureonarius was divided into two strongly to fully supported subgenera: $A$. subgen. Aureonarius (BS 100\%) and A. subgen. Callistei (BS 98\%). In genus Phlegmacium, four moderately to strongly supported subgenera were recognized: $P$. subgen. Phlegmacium (BS 91\%), P. subgen. Carbonella (BS 98\%), P. subgen. Bulbopodium (BS 96\%), and $C$. subgen. Cyanicium (represented by just one species in our analysis). The genus Cystinarius has two subgenera: $C$. subgen. Crassi (BS 100\%) and $C$. subgen. Cystinarius (represented by one species in the analysis). The infrageneric relationships in the genus Cortinarius remained mostly unresolved but the following lineages with more than one species in our analysis received moderate to full support: C. subgen. Dermocybe (BS 93\%), C. subgen. Leprocybe (BS 93\%), C. subgen. Iodolentes (BS 100\%), C. subgen. Telamonia (BS 100\%), C. subgen. Myxacium (BS 97\%), and C. subgen. Cortinarius (BS 100\%). In the genus Thaxterogaster many relationships remained unresolved, although the following subgenera received weak to full support: T. subgen. Multiformes (BS 83\%), T. subgen. Cretaces (BS 96\%), T. subgen. Thaxterogaster (BS 99\%), T. subgen. Scauri (BS 92\%), and T. subgen. Riederorum (BS 100\%).

\section{Taxonomy}

New and emended generic descriptions are presented below, as well as descriptions of new subgenera and short notes on the previously existing subgenera. The diversity, distribution 


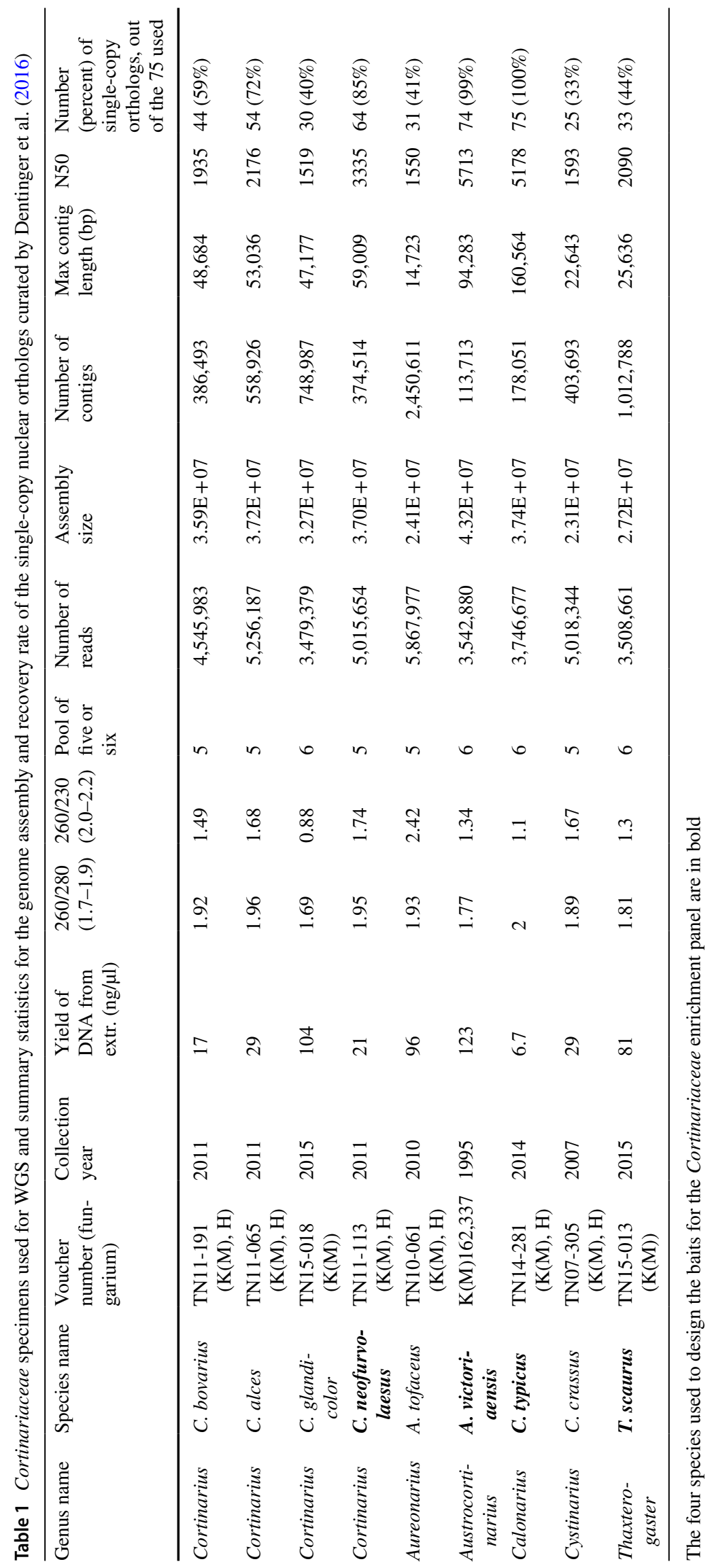




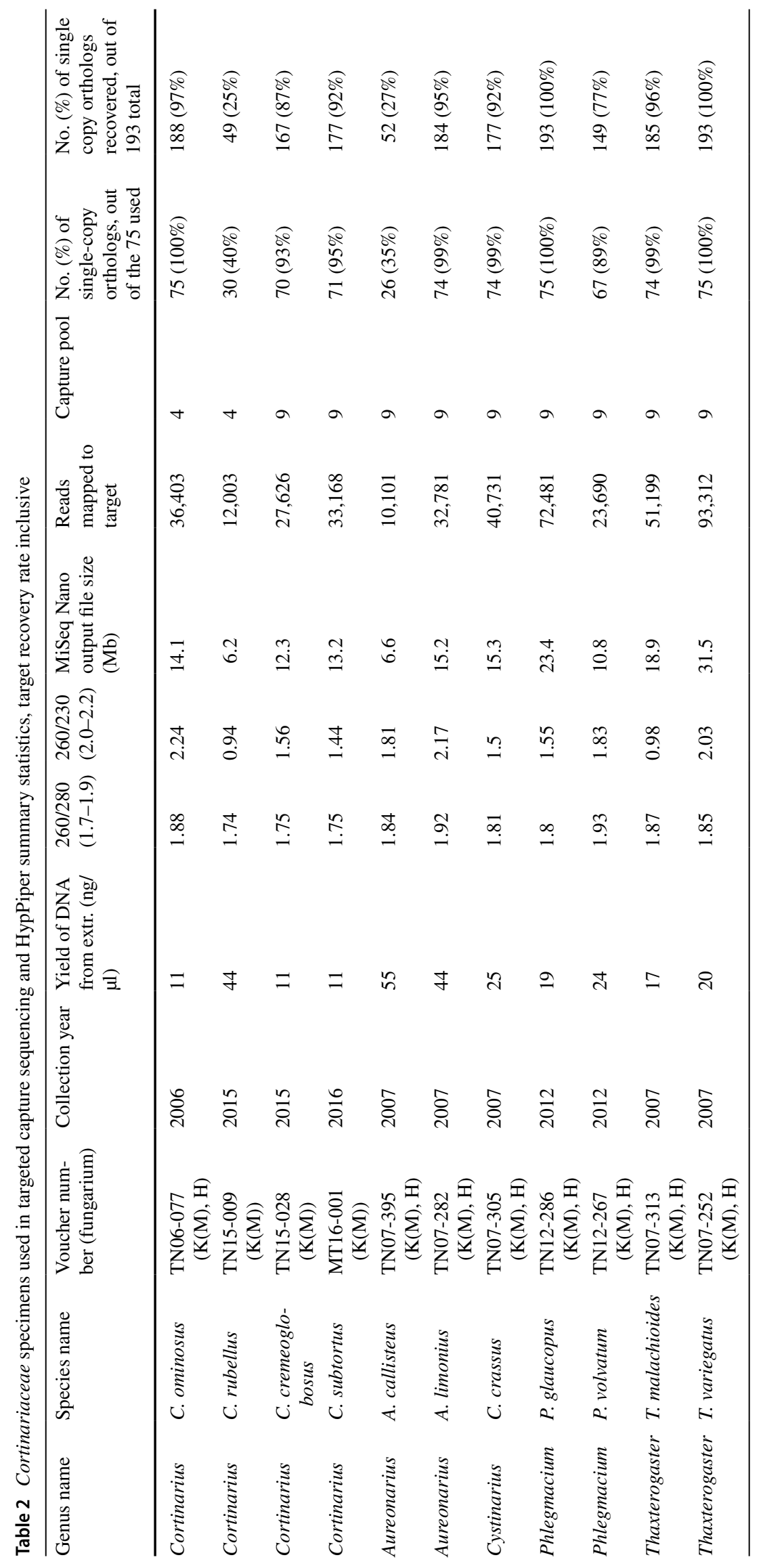




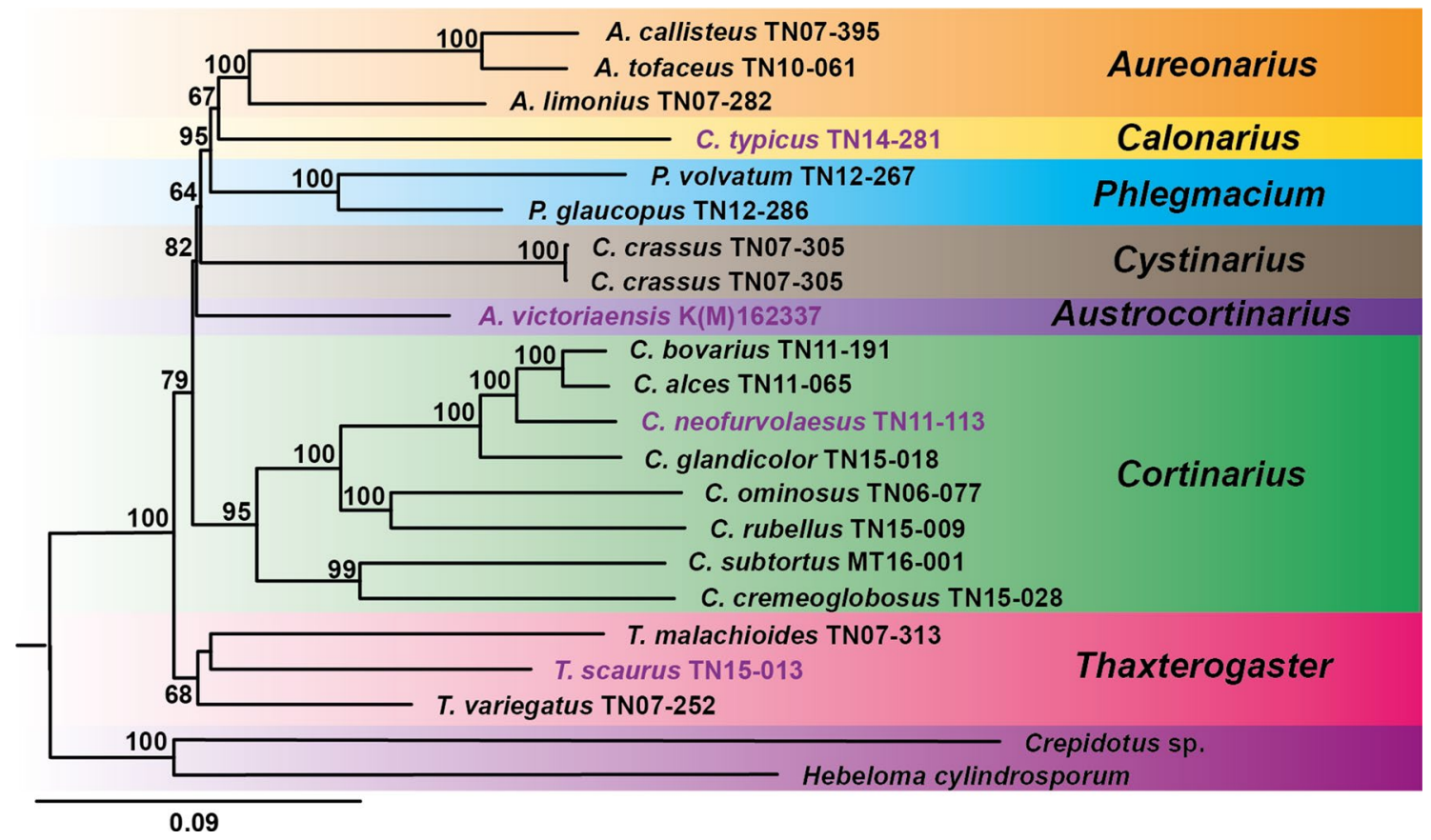

Fig. 1 Topology resulting from the RAxML analysis of 75 singlecopy nuclear orthologs. The tree is rooted with Crepidotus sp. and Hebeloma cylindrosporum as the outgroup. Bootstrap (BS) val-

and selected morphological characteristics of the proposed genera are summarized in Table 3.

Cortinariaceae R. Heim ex Pouzar, Česká Mykol. 37(3): 174 (1983) em. Niskanen \& Liimat.

Nom. cons. (Art. 14)

Current name of the type species: Cortinarius violaceus (L.) Gray, Nat. Arr. Brit. Pl. (London) 1: 628 (1821). Sanctioned in Fr., Syst. mycol. 1: 217 (1821). Basionym of the type species: Agaricus violaceus L., Sp. pl. 2: 1173 (1753). Lectotype: Bulliard, Herbier de la France: pl. 598 Fig. 2A, 1793 (lectotypus hic designatus, IF551873, as Agaricus araneosus). Epitype: Sweden, Ångermanland, Härnösand, Geresta, 25 Aug 1993, coll. H. Lindström et al. CFP 1197 (S, epitypus hic designatus IF551874), GenBank No. OL958654 (ITS).

Synonyms: Gigaspermaceae Jülich, Biblthca Mycol. 85: 367 (1982) [1981]. Nom. illegit., Art. 53.1. Type genus: Gigasperma E. Horak, N.Z. J1 Bot. 9(3): 491 (1971). Current name of the type species: Thaxterogaster crypticus (E. Horak) Niskanen \& Liimat., comb. nov. IF551875. Basionym of the type species: Gigasperma cryptica E. Horak, N.Z. J1 Bot. 9(3): 491 (1971). Holotype: 27002 (PDD).

Currently included genera: Cortinarius, Aureonarius, Austrocortinarius, Calonarius, Cystinarius, Hygronarius, Mystinarius, Phlegmacium, Thaxterogaster, and Volvanarius. ues $>50 \%$ are indicated above branches. The four species used to design the baits for the targeted capture sequencing are in purple

Description: Basidiomata small- to large-sized, agaricoid or sequestrate, development type stipitocarpic or pileocarpic. Pileus at first conical to hemispherical, then low conical to low convex to plane, with or without an umbo; surface smooth, innately fibrillose, tomentose or \pm scaly; \pm brown, \pm yellow/ochraceous, white, \pm grey, more or less purple or blackish brown to black, more rarely orange, red, or green/olivaceous; dry, viscid or glutinous, hygrophanous, with hygrophanous spots or streaks or nonhygrophanous. Lamellae crowded to distant; adnate, adnexed or emarginate; when young greyish white, pale grey, pale to dark brown, or with a purplish tint or purple, more rarely yellow, green/olivaceous, orange or red. Stipe cylindrical, clavate, bulbous or rooting; usually silky-fibrillose, white, pale to dark brown, with purplish tints or purple or \pm yellow/ochraceous, more rarely green/olivaceous, orange, red or blackish; dry to glutinous. Universal veil white, yellow/ ochraceous, purple, grey/brown, pink/red, or green/olivaceous, in some species changing colour with age or on exposure; sparse to abundant, in pileocarpic species found from the margin of the bulb, in species of the genus $\mathrm{Vol}$ vanarius often forming a volva at the base of the stipe. In stipitocarpic species forming incomplete and/or complete girdles on the stipe, or a sock-like sheet on the lower part of the stipe, more rarely forming a ring at the upper part of the stipe; dry or viscid. Odour in many species indistinct, when present in most species then best observed in 
Fig. 2 Topology resulting from the RAxML analysis of RPB1, RPB2, MCM7, GPD, and TEF1. The tree is rooted with Thaxterogaster as the outgroup. Bootstrap (BS) values $>50 \%$ are indicated above branches. The new subgenera described are in dark blue

lamellae and then raphanoid, fruity, earthy, cellar-like, cedar tree-like, perfume-like, yeast-like, farinaceous, grassy, rubbery, pelargonium-like, curry-like, anise or unpleasant. The honey-like odour, typical to part of the species of Cortinarius subgen. Myxacium, Thaxterogaster subgen. Multiformes and $T$. subgen. Scauri, is best observed in the context of the stipe. In part of the species of $C$. subgenus Iodolentes the base of the stipe has an odour of iodorm that is best observed when the basidiomata are slightly dried and in Aureonarius subgen. Callistei the odour of the surface of the pileus in some species is like a recently extinguished candle (ozone) or apple-like. $\mathrm{KOH} / \mathrm{NaOH}$ reaction useful in identification of the species of Calonarius and Phlegmacium. Basidiospores $4.5-20 \times 3-10 \mu \mathrm{m}$, in vast majority of the species \pm amygdaloid, \pm ellipsoid, \pm citriform or \pm subglobose, less commonly obovoidly ellipsoid, fusoid, lacrymoid, or boletoid, finely to strongly verrucose, somewhat to strongly dextrinoid in Melzer's reagent, some species non-dextrinoid. Cystidia present in genus Cystinarius, Cortinarius subgen. Cortinarius, $C$. sect. Camphorati, C. sect. Subtorti, and some species of $C$. subgen. Iodolentes, $C$. sect. Bicolores and genus Volvanarius. Pileipellis in vast majority of the taxa \pm duplex with a more or less developed hypoderm, simplex in Calonarius, Austrocortinarius, Phlegmacium subgen. Cyanicium, Cortinarius subgen. Cortinarius and $C$. sect. Subtorti and in part of the species of Phlegmacium subgen. Phlegmacium, Cortinarius sect. Delibuti. In genus Cystinarius somewhat duplex-like, the hypoderm is poorly developed but the hyphae beneath the epicutis are hypoderm-like (elements that are short and wide).

Ecology and Distribution: With a world-wide distribution; species occur both in Northern and Southern Hemisphere from tropical to arctic-alpine habitats. The species of Cortinariaceae are ectomycorrhizal and form associations with the trees and shrubs from Fagales, Salicaceae, Cistaceae, Dipterocarpaceae, Myrtaceae, Fabaceae (e.g., Dicymbe), Rhamnaceae, Rosaceae, and Pinaceae, as well as with some herbaceous angiosperms in the Cyperaceae, Orchidaceae, and Polygonaceae.

Notes: Typical for the species of the family Cortinariaceae are ornamented basidiospores that are cinnamon brown in deposit. Most species also have a cobweb-like inner veil covering the young lamellae and the remnants of it can often still been found at the upper part of the stipe in older basidiomata. Characteristic is also the silky-fibrillose stipe, at least easily observed at the top of the stipe. Majority of the species lack cheilo- and/or pleurocystidia which are only found in genus Cystinarius and some lineages of genera

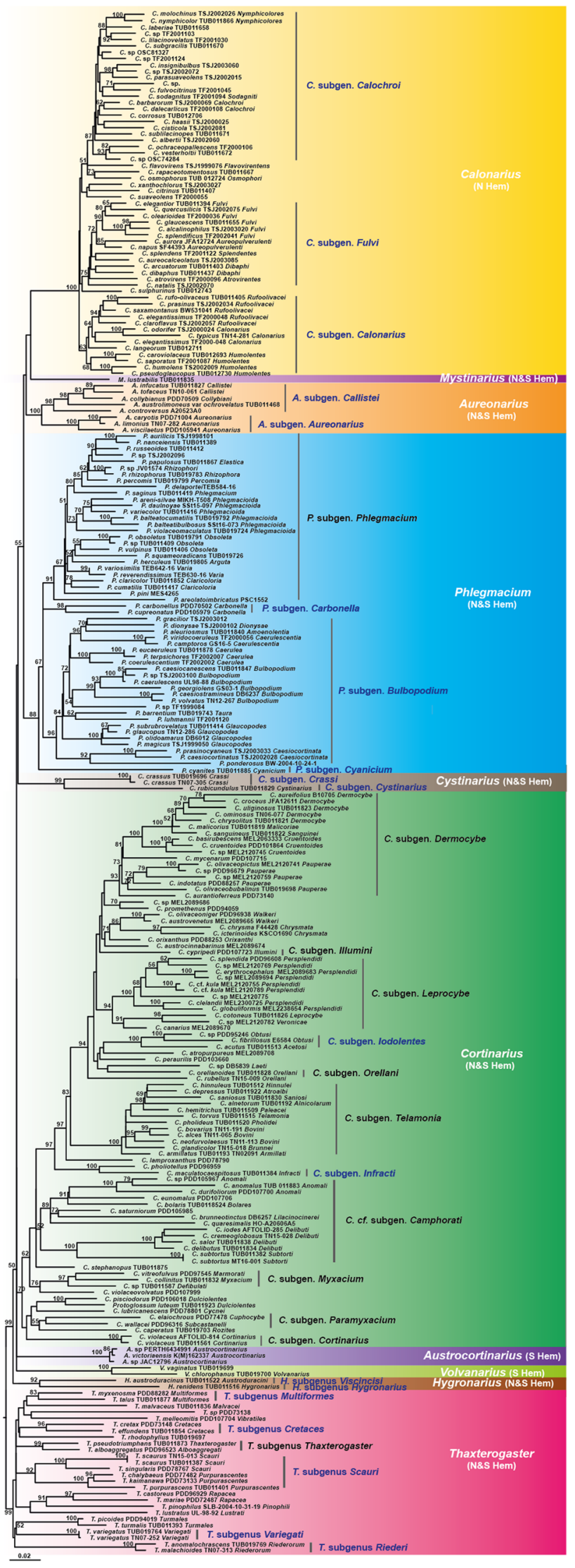




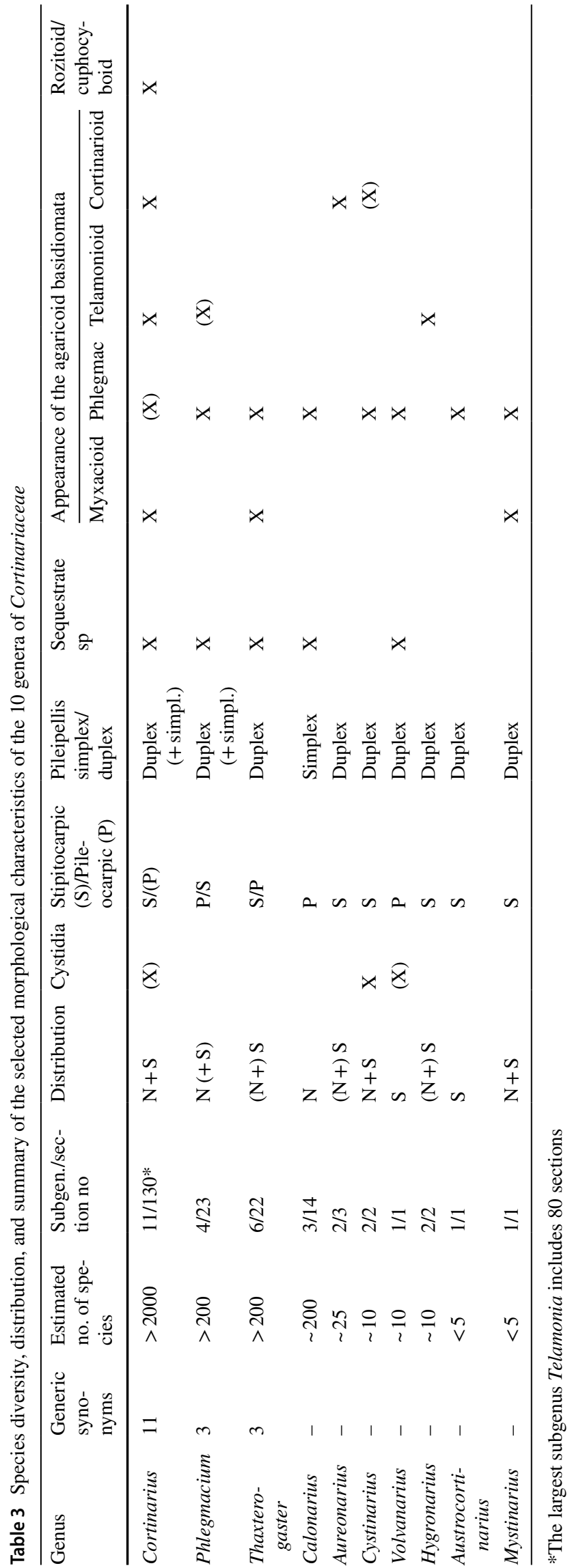

Cortinarius and Volvanarius. The structure of the pileipellis in the majority of genera and subgenera is duplex with a more or less developed hypoderm.

Variation in size and coloration of basidiomata is large. One of the smallest species, Cortinarius bibulus, has a pileus of $0.3-1.5 \mathrm{~cm}$ in diam. and a stipe $1.5-5 \times 0.1-0.3 \mathrm{~cm}$, and one of the largest, Phlegmacium praestans, has a pileus up to $20 \mathrm{~cm}$ in diam. and a stipe up to $20 \times 3 \mathrm{~cm}$. A wide variety of colored pigments can be found from the basidiomata although brownish, ochrceous/yellow, greyish, whitish, and purplish colours are most common.

Cortinarius (Pers.) Gray, Nat. Arr. Brit. Pl. (London) 1: 627 (1821) em. Niskanen \& Liimat.

Nom. cons. (Art. 14)

Basionym: Agaricus sect. Cortinaria Pers., Syn. meth. fung. (Göttingen) 2: 276 (1801).

Current name of the type species: Cortinarius violaceus (L.) Gray, Nat. Arr. Brit. Pl. (London) 1: 628 (1821). Basionym of the type species: Agaricus violaceus L., Sp. pl. 2: 1173 (1753).

Synonyms: Cuphocybe R. Heim, Revue Mycol., Paris 16: 8 (1951). Current name of the type species: Cortinarius elaiochrous E. Horak, M.M. Moser, Peintner \& Vilgalys, Mycotaxon 83: 449 (2002). Basionym of the type species: Cuphocybe olivacea R. Heim, Revue Mycol., Paris 16: 8 (1951).

Dermocybe (Fr.) Wünsche, Die Pilze: 87, 125 (1877). Basionym: Agaricus trib. Dermocybe Fr., Syst. mycol. (Lundae) 1: 10, 227 ['217'] (1821). Current name of the type species: Cortinarius cinnamomeus (L.) Gray [as 'Cortinaria'], Nat. Arr. Brit. Pl. (London) 1: 630 (1821). Basionym of the type species: Agaricus cinnamomeus L. 1753.

Hydrocybe (Fr. ex Rabenh.) Wünsche, Die Pilze: 87, 119 (1877). Basionym: Cortinarius a Hydrocybe Fr. ex Rabenh., Deutschl. Krypt.-Fl. (Leipzig) 1: 488 (1844). Current name and basionym of the type species: Cortinarius duracinus Fr., Epicr. syst. mycol. (Upsaliae): 304 (1838) [1836-1838].

Inoloma (Fr.) Wünsche, Die Pilze: 87, 126 (1877). Basionym: Agaricus trib. Inoloma Fr., Syst. mycol. (Lundae) 1: 216 (1821). Current name of the type species: Cortinarius violaceus (L.) Gray, Nat. Arr. Brit. Pl. (London) 1: 628 (1821). Basionym of the type species: Agaricus violaceus L., Sp. pl. 2: 1173 (1753).

Myxacium (Fr.) P. Kumm., Führ. Pilzk. (Zerbst): 22 (1871). Basionym: Agaricus trib. Myxacium Fr., Syst. mycol. (Lundae) 1: 247 (1821). Current name of the type species: Cortinarius collinitus (Sowerby) Gray [as 'Cortinaria collinita ], Nat. Arr. Brit. Pl. (London) 1: 628 (1821). Basionym of the type species: Agaricus collinitus Sowerby, Col. fig. Engl. Fung. Mushr. (London) 1(no. 2): tab. 9 (1796).

Myxopholis Locq., Fl. Mycol., 3. Cortinariales-A.: 146 (1979) [1977]. Basionym and current name of the type 
species: Cortinarius mucifluus Fr., Epicr. syst. mycol. (Upsaliae): 274 (1838) [1836-1838].

Protoglossum Massee, Grevillea 19(no. 92): 97 (1891). Current name of the type species: Cortinarius atratus (Rodway) Gasparini, Mycosphere 5(4): 542 (2014). Basionym of the type species: Protoglossum luteum Massee, Grevillea 19(no. 92): 97 (1891).

Quadrispora Bougher \& Castellano, Mycologia 85(2): 285 (1993). Current name of the type species: Cortinarius oblongisporus (G.W. Beaton, Pegler \& T.W.K. Young) Gasparini, IOSR Journal of Pharmacy 6(4): 3 (2014). Basionym of the type species: Hymenogaster oblongisporus G.W. Beaton, Pegler \& T.W.K. Young, Kew Bull. 40(1): 188 (1985).

Rozites P. Karst., Bidr. Känn. Finl. Nat. Folk 32: XX (1879). Current name of the type species: Cortinarius caperatus (Pers.) Fr., Epicr. syst. mycol. (Upsaliae): 256 (1838) [1836-1838]. Basionym of the type species: Rozites caperatus (Pers.) P. Karst., Bidr. Känn. Finl. Nat. Folk 32: 290 (1879).

Sericeocybe Rob. Henry, Bull. trimest. Soc. mycol. Fr. 109(1): 19 (1993). Current name of the type species: Cortinarius caninus (Fr.) Fr., Epicr. syst. mycol. (Upsaliae): 285 (1838) [1836-1838]. Basionym of the type species: Agaricus anomalus var. caninus Fr. 1821.

Telamonia (Fr.) Wünsche, Die Pilze: 87, 122 (1877). Basionym: Agaricus trib. Telamonia Fr., Syst. mycol. (Lundae) 1: 10, 210 (1821). Current name of the type species: Cortinarius torvus (Fr.) Fr., Epicr. syst. mycol. (Upsaliae): 293 (1838) [1836-1838]. Basionym of the type species: Agaricus torvus Fr., Observ. mycol. (Havniae) 2: 80 (1818).

Currently included subgenera: Cortinarius, Camphorati, Dermocybe, Illumini, Infracti, Iodolentes, Leprocybe, Myxacium, Orellani, Paramyxacium, and Telamonia (Fig. 3).

Description: Basidiomata small- to large-sized, agaricoid or sequestrate, development type stipitocarpic, very rarely pileocarpic. Pileus $0.3-13 \mathrm{~cm}$, at first conical to hemispherical, then low conical, to low convex to plane, with or without an umbo; surface smooth, innately fibrillose, tomentose or \pm scaly; in the vast majority of the species pale to dark red-, ochraceous- or grey- brown, in other species \pm yellow/ orange, \pm white, \pm red, greenish/olivaceous, purple, umber to blackish; dry, viscid or glutinous, hygrophanous, with hygrophanous spots or streaks or non-hygrophanous. Lamellae in most species medium spaced, in others crowded or distant; adnate, adnexed or emarginate; when young greyish white, pale grey, pale to dark brown, or with a purplish tint or purple, more rarely yellow, green/olivaceous, orange or red. Stipe $1.5-13 \mathrm{~cm}$ long, $0.1-2.5 \mathrm{~cm}$ wide at the apex, up to $5 \mathrm{~cm}$ at the base; in the vast majority of the species cylindrical to clavate, less often rooting or bulbous; silkyfibrillose, white, pale to dark brown, with purplish tints or purple, more rarely yellow, green/olivaceous, orange or red; dry to viscid. Universal veil in the majority of the species white, in others yellow/ochraceous, purple, green/olivaceous, pink or red, in some species at first white and then turning pink; sparse to abundant, forming incomplete and/ or complete girdles on the stipe, or a sock-like sheet on the lower part of the stipe, more rarely forming a ring at the upper part of the stipe; dry or viscid. Context in the vast majority of the species brownish white, pale to dark red-, ochraceous- or grey-brown, sometimes with a purplish tint, in other species \pm yellow/orange, \pm red, greenish/olivaceous, purple, umber or blackish. Odour in many species indistinct or raphanoid, usually best observed in lamellae, in certain groups pelargonium-like, cedar tree-like, fruity, perfumelike, iodoform-like, earthy or unpleasant: in some taxa best observed in the context of the stipe and honey-like, sweet or raphanoid; in most species of $C$. sect. Obtusi and Acetosi the odour is iodoform-like and best observed at the base of the stipe when somewhat dried. $\mathrm{KOH}$ reaction in most species negative in pileus, context and/or stipital veil, in some groups red, yellow to orange-yellow, brown or black. Basidiospores $4.5-20 \times 3-10 \mu \mathrm{m}$, in vast majority of the species \pm amygdaloid, \pm ellipsoid or \pm subglobose, less commonly obovoidly ellipsoid, fusoid, lacrymoid, citriform or boletoid, finely to strongly verrucose. Cystidia absent in vast majority of the species, cheilo- and/or pleurocystidia present in some groups. Pileipellis \pm duplex, hypoderm usually more or less developed, lacking from $C$. subgen. Cortinarius.

Ecology and Distribution: In the Northern and Southern Hemisphere with a wide range of hosts.

Notes: The species of this globally distributed, exceptionally species-rich genus of Cortinariaceae are characterized by mainly stipitocarpic development and a pileipellis duplex with a more or less developed hypoderm. The basidiomata range from very small to large, from dry to glutinous, and are of varied colours although brown colours are the most common. Secondary metabolites containing nitrogen are currently only known from this genus of the family and are present in the subgenera Cortinarius, Infracti, Orellani, and section Subtorti (Stensrud et al. 2014).

Morphologically similar species, previously included in this entity but phylogenetically distinct from the genus $\mathrm{Cor}$ tinarius, are found in the genera Aureonarius, Cystinarius, Hygronarius, Thaxterogaster sect. Vibratiles and Phlegmacium subgen. Carbonella.

\section{Cortinarius subgen. Cortinarius}

Synonym: Inoloma (Fr.) Wünsche, Die Pilze: 87, 126 (1877). Basionym: Agaricus trib. Inoloma Fr., Syst. mycol. (Lundae) 1: 216 (1821).

Currently included sections: Cortinarius.

Notes: The species of this small bihemispheric subgenus have a unique combination of characters and are easy to identify at the subgeneric level. The basidiomata are medium to rather large-sized, deep violet to almost blackish 


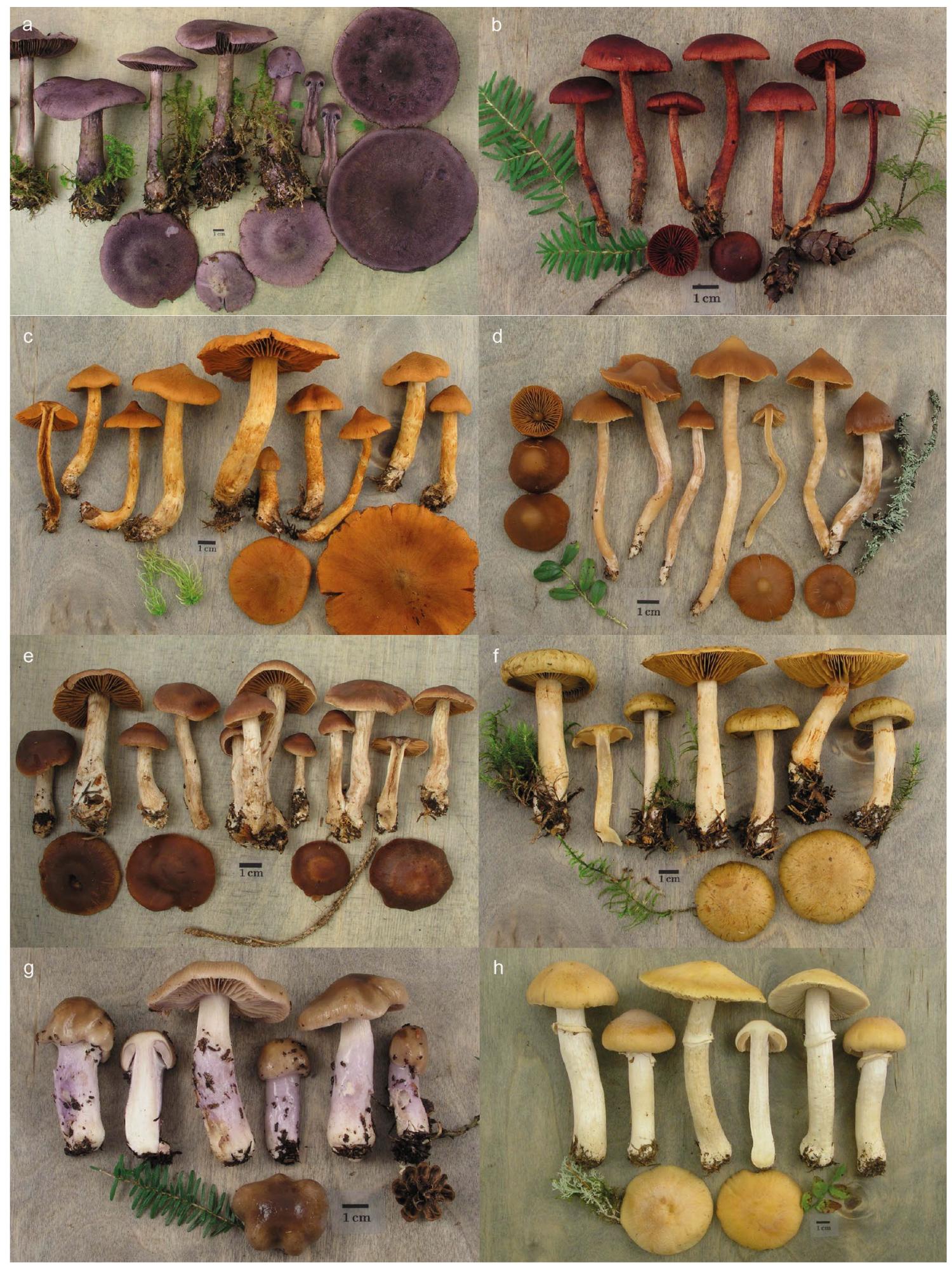

Fig. 3 Photos of the representatives of genus Cortinarius. A. C. subgen. Cortinarius, C. harcynicus TN 04-525 (H), B. C. subgen. Dermocybe, $C$. neosanguineus TN 09-130 (H), C. subgen. Orellani, $C$. rubellus TN 05-024 (H), D. C. subgen. Iodolentes, C. mammillatus
TN 06-249, E. C. subgen. Telamonia, C. badiolaevis TN 04-960 (H), F. C. sect. Subtorti, C. subtortus TN 05-021 (H), G. C. subgen. Myxacium, C. seidliae TN09-063 (H), and H. C. subgen. Paramyxacium, C. caperatus TN 06-149 (H). Photos K. Liimatainen 
violet, stipitocarpic, agaricoid (cortinarioid) with a dry pileus and a dry stipe. The pileus is tomentose to scaly and non-hygrophanous, and the $\mathrm{KOH}$ reaction on any surface of the basidiomata is red. Pleurocystidia and cheilocystidia are present and the pileipellis lacks a well-developed hypoderm. For a recent morpho-genetic revision see Harrower et al. (2015a, b).

\section{Cortinarius subgen. Camphorati Liimat., Niskanen \&} Ammirati, Index Fungorum 256: 2 (2015)

Current name of the type species: Cortinarius camphoratus (Fr.) Fr., Epicr. syst. mycol. (Upsaliae): 280 (1838) [1836-1838]. Basionym of the type species: Agaricus camphoratus Fr., Syst. mycol. (Lundae) 1: 218 (1821). Neotype: S F-14265, in Brandrud et al., Cortinarius Flora Photographica I, pl. A12 (1989).

Possible synonym: Sericeocybe Rob. Henry, Bull. trimest. Soc. mycol. Fr. 109(1): 19 (1993). Current name of the type species: Cortinarius caninus (Fr.) Fr., Epicr. syst. mycol. (Upsaliae): 285 (1838) [1836-1838]. Basionym of the type species: Agaricus anomalus var. caninus Fr. 1821.

Currently included sections: Camphorati.

Notes: The core group of this subgenus, the small bihemispheric $C$. sect. Camphorati, is easy to delimit based on morphology: The basidiomata are medium to large-sized, blue/purple, white to pale yellowish brown, stipitocarpic, agaricoid (telamonioid) with a dry pileus and dry stipe. The odour in many species is strong and unpleasant. Cheilocystidia are present and the pileipellis is somewhat duplex, but the hypoderm is not that well-developed. In the phylogenetic analysis of Soop et al. (2019) this group was placed within a larger entity including sections Anomali, Spilomei, Bolares, Delibuti and Subtorti but without support. Further studies will be needed to define the limits of the subgenus.

Cortinarius subgen. Dermocybe (Fr.) Trog, Mitt. naturf. Ges. Bern 15-23: 43 (1844)

Basionym: Agaricus trib. Dermocybe Fr., Syst. mycol. (Lundae) 1: 10, 227 ['217'] (1821).

Current name of the type species: Cortinarius cinnamomeus (L.) Gray [as 'Cortinaria'], Nat. Arr. Brit. Pl. (London) 1: 630 (1821). Basionym of the type species: Agaricus cinnamomeus L., Sp. pl. 2: 1173 (1753). Neotype: S F-44851, in Niskanen, Index Fungorum 221: 1 (2015).

Synonym: Dermocybe (Fr.) Wünsche, Die Pilze: 87, 125 (1877). Basionym: Agaricus trib. Dermocybe Fr., Syst. mycol. (Lundae) 1: 10, 227 ['217'] (1821).

Currently included sections: Dermocybe, Aureifolii, Cruentoides, Malicoriae, Pauperae and Sanguinei.

Notes: This bihemispheric subgenus includes agaricoid (dermocyboid), stipitocarpic, small- to medium-sized species with yellow, orange, red or olive colours. The stipe is dry, and the pileus is dry, hygrophanous or not, and felty, squamulose or glabrous. The pileipellis is somewhat duplex with a poorly developed hypoderm.

Cortinarius subgen. Illumini Liimat., Niskanen \& Kytöv., Index Fungorum 256: 2 (2015)

Current name and basionym of the type species: Cortinarius illuminus Fr., Epicr. syst. mycol. (Upsaliae): 305 (1838) [1836-1838] (Lundae) 1: 218 (1821). Neotype: S F-44877, in Niskanen et al., Index Fungorum 256: 1 (2015).

Currently included sections: Illumini.

Notes: This is a small bihemispheric subgenus that includes agaricoid (telamonioid), stipitocarpic, mediumsized species with a vivid red-brown to brown, dry, hygrophanous pileus, dry stipe, subglobose basidiospores and a pileipellis duplex.

Cortinarius subgenus Infracti Niskanen \& Liimat., subgen. nov.

IndexFungorum IF551876

Current name and basionym of the type species: Cortinarius infractus (Pers.) Fr., Epicr. syst. mycol. (Upsaliae): 261 (1838) [1836-1838]. Neotype: S F-41138, in Liimatainen et al., Persoonia 33: 120, (2014).

Etymology: Named after the type species of the subgenus.

Currently included sections: Infracti.

Description: Basidiomata medium-sized to large-sized, agaricoid (phlegmacioid), development type stipitocarpic. Pileus $3-10 \mathrm{~cm}$, at first hemispherical, then low convex to almost plane, sometimes with a very low and broad umbo, innately fibrillose; olivaceous grey, olivaceous brown or umber brown, some species becoming yellow/ochraceous brown with age; viscid or glutinous; not hygrophanous. Lamellae crowded, adnate, adnexed to emarginate, dark olivaceous brown to dark olivaceous grey at least when young, sometimes with a purplish tint. Stipe $3-9 \mathrm{~cm}$ long, $0.8-1.5 \mathrm{~cm}$ wide at the apex, up to $2.5 \mathrm{~cm}$ at base, cylindrical to clavate; whitish grey to olivaceous grey, sometimes with a purplish tint at the apex, dry. Universal veil yellow to yellow brown, in some species white when young, rather sparse, fibrillose. Context in pileus and stipe whitish to olivaceous grey, sometimes purple at the apex of the stipe, marbled hygrophanous. Odour in lamellae indistinct. Taste bitter. $\mathrm{NaOH}$ reaction yellow to orange-yellow (Soop et al. 2018). Basidiospores 7-9.5 $\times 5-7 \mu \mathrm{m}$, subglobose to broadly ellipsoid, moderately verrucose. Lamellar trama preparation with abundant small red granules in Melzer's. Cystidia absent. Pileipellis duplex, hypoderm present but poorly developed.

Ecology and Distribution: In the Northern Hemisphere with Fagaceae and Pinaceae.

Notes: A small subgenus of about 10 to 15 agaricoid (phlegmacioid) species occurring in the Northern Hemisphere. The species of this subgenus can be distinguished by the combination of bitter taste, olivaceous tints, viscid 
to glutinous, innately fibrillose pileus, clavate to sometimes almost cylindrical stipe and subglobose to broadly ellipsoid spores. The development type is stipitocarpic.

\section{Cortinarius subgenus Iodolentes Niskanen \& Liimat.,} subgen. nov.

IndexFungorum IF552140

Current name and basionym of the type species: Cortinarius aurae Niskanen \& Liimat., in Hyde et al., Fungal Diversity 100: 247 (2020). Holotype: K(M) 200315.

Etymology: The name refers to the iodoform-like odour that many of the species of this subgenus have.

Currently included sections:Acetosi, Fragrantiores and Obtusi.

Description: Basidiomata small- to medium-sized, agaricoid (telamonioid) or sequestrate, development type stipitocarpic. Pileus $1-7 \mathrm{~cm}$, at first conical to hemispherical, then low conical to low convex to plane, with an acute or broader umbo, pileus margin in many smaller species more or less pellucid-striate, surface often somewhat rimy; yellow brown, red brown to dark brown; dry; hygrophanous. Lamellae medium spaced to distant, adnate, adnexed or emarginate, yellow brown to strong brown, often with a white edge. Stipe $2.5-11 \mathrm{~cm}$ long, $0.15-1.4 \mathrm{~cm}$ wide at the apex, cylindrical or rooting; at first white fibrillose, later very pale brown to yellow brown. Universal veil white, sparse, or forming complete and/or incomplete girdles on stipe. Context in pileus \pm brown, usually somewhat paler in stipe. Odour in lamellae indistinct or in some species raphanoid or cellar-like, at the base of stipe indistinct, raphanoid or iodoform-like, the latter best observed when slightly dried. Basidiospores 6.5-10.5 ×4.5-6.5 $\mu \mathrm{m}$, ovoid, amygdaloid to ellipsoid, in $C$. fragrantior ovoid-subglobose, finely to strongly verrucose. Cheilocystidia present in part of the species, clavate to balloon-shaped. Pileipellis duplex, hypoderm developed.

Ecology and Distribution: In Northern and Southern Hemisphere with a wide range of hosts plants.

Notes: Cortinarius subgenus Iodolentes includes small- to medium-sized telamonioid species with dry, \pm brown pileus and dry, initially white stipe. The context of the stipe is often somewhat paler than in the pileus and does not become darker towards the base of the stipe. Many species have an iodoform-like odour at the base of the stipe and clavate to balloon-shaped cheilocystidia.

The species of this subgenus were traditionally included in the $C$. subgen. Telamonia due to their dry pileus and dry stipe, but the first molecular studies showed that they should be recognized as a separate taxon (Høiland and Holst-Jensen 2000; Peintner et al 2004; Garnica et al. 2005), which is also supported by our phylogenetic analysis. Iodolentes belongs to a well-supported branch (BS 94\%) in genus Cortinarius that also includes subgenera Dermocybe, Leprocybe,
Illumini and Orellani. Since the species of Iodolentes morphologically differ from the species of other related subgenera we here describe the subgenus as new.

Cortinarius subgen. Leprocybe M.M. Moser, Z. Pilzk. 35(3 + 4): 232 (1969) em. Niskanen \& Liimat

Current name and basionym of the type species: Cortinarius cotoneus Fr., Epicr. syst. mycol. (Upsaliae): 289 (1838) [1836-1838]. Neotype: S F-44846, in Ammirati et al., Persoonia 46: 221 (2021).

Currently included sections: Leprocybe, Fuscotomentosi, Melanoti, Persplendidi, Squamiveneti, Veneti, and Veronicae.

Notes: The species of this subgenus occur in both the Northern and Southern Hemispheres. The basidiomata are small- to medium-sized (occasionally large-sized), agaricoid (leprocyboid/dermocyboid) or sequestrate, and with a dry pileus and dry stipe and with yellow, red, or greenish-olive colours. At least some parts of the basidiomata are fluorescent. For a recent morpho-genetic revision of Northern Hemispheric Leprocybe see Ammirati et al. (2021) and Bidaud et al. (2021).

Cortinarius subgen. Myxacium (Fr.) Trog, Mitt. naturf. Ges. Bern 15-23: 42 (1844)

Basionym: Agaricus trib. Myxacium Fr., Syst. mycol. (Lundae) 1: 247 (1821)

Current name of the type species: Cortinarius collinitus (Sowerby) Gray [as 'Cortinaria collinita'], Nat. Arr. Brit. Pl. (London) 1: 628 (1821). Basionym of the type species: Agaricus collinitus Sowerby, Col. fig. Engl. Fung. Mushr. (London) 1(no. 2): tab. 9 (1796). Lectotype: Sowerby, Col. Fig. Engl. Fungi 1: pl. 9. 1795, in Gómez \& CadiñanosAguirre, J des JEC 2: 135, (2018).

Synonyms: Myxacium (Fr.) P. Kumm., Führ. Pilzk. (Zerbst): 22 (1871). Basionym: Agaricus trib. Myxacium Fr., Syst. mycol. (Lundae) 1: 247 (1821).

Myxopholis Locq., Fl. Mycol., 3. Cortinariales-A.: 146 (1979) [1977]. Basionym and current name of the type species: Cortinarius mucifluus Fr., Epicr. syst. mycol. (Upsaliae): 274 (1838) [1836-1838].

Quadrispora Bougher \& Castellano, Mycologia 85(2): 285 (1993). Current name of the type species: Cortinarius oblongisporus (G.W. Beaton, Pegler \& T.W.K. Young) Gasparini, IOSR Journal of Pharmacy 6(4): 3 (2014). Basionym of the type species: Hymenogaster oblongisporus G.W. Beaton, Pegler \& T.W.K. Young, Kew Bull. 40(1): 188 (1985).

Currently included sections: Myxacium, Cuphomorphi, Defibulati, Marmorati, and Quadrispora.

Notes: This is a bihemispherical subgenus with about 50 species. The basidiomata are medium-sized to small, agaricoid (cuphocyboid, myxacioid) or sequestrate with a viscid to glutionous pileus and glutinous to dry stipe with 
white, brown and/or purplish colours. Cylindrical stipes and relatively large (up to $20 \mu \mathrm{m}$ long), mainly amygdaloid to citriform basidiospores are also typical. For a recent morpho-genetic revision of the subgenus see Soop et al. (2021).

The type species of the subgenus, $C$. collinitus, is described from Britain. Recently, a lectotype for the species was designated by Gómez and Cadiñanos-Aguirre (2018). They also challenged the current interpretation of the name and concluded the species to be more $C$. trivialis-like. We agree with this conclusion and materials from Britain will need to be sequenced for selection of a suitable epitype. However, since both the current species called as $C$. collinitus as well as $C$. trivialis-like fungi belong to this subgenus, we conclude that the subgeneric name Myxacium can be confidently used for this clade although the fixing of the name $C$. collinitus still requires a selection of an epitype.

\section{Cortinarius subgen. Orellani (M.M. Moser) Gasparini,} Australas. Mycol. 23(2): 69 (2004)

Basionym: Cortinarius sect. Orellani M.M. Moser, Z. Pilzk. 35(3+4): 224 (1969)

Current name and basionym of the type species: Cortinarius orellanus Fr., Epicr. syst. mycol. (Upsaliae): 288 (1838) [1836-1838]. Lectotype: Junghuhn, Observationes Mycologicae in species fungorum tam novas tam male cognitas, Linnaea V, t. 6, f. 9. 1830 (lectotypus hic designatus, IF552141). Epitypus: Norway, Agder; Tvedestrand, Eidbo, in forest with Tilia, Quercus and Corylus, 21 Sep 2014, coll. I-L. Fonneland \& D. Pettersen (O F-251482, epitypus hic designatus IF552142), UNITE No. UDB036242 (ITS).

Currently included sections: Orellani.

Notes: This small bihemispherical subgenus is characterized by the lethal nephrotoxin bipyridine orellanine that has caused severe poisonings and deaths in humans (Schumacher \& Høiland 1983; Danel et al. 2001) and is not found in any other lineage in Cortinariaceae. The basidiomata of the species of $C$. subgen. Orellani are medium-sized, stipitorcarpic, agaricoid (cortinarioid) with yellow, orange-brown and saturated reddish-brown colours, and with a dry pileus and stipe. A tomentose to finely scaly pileus and cylindrical to somewhat clavate stipe is also typical. The pileipellis is duplex with a well-developed hypoderm.

Cortinarius subgen. Paramyxacium M.M. Moser \& E. Horak, Beih. Nova Hedwigia 52: V, 263 (1975) em. Niskanen \& Liimat.

Current name of the type species: Cortinarius paradoxus M.M. Moser \& E. Horak, Beih. Nova Hedwigia 52: 264 (1975). Holotype: IB 19650506.

Synonyms: Cuphocybe R. Heim, Revue Mycol., Paris 16: 8 (1951). Current name of the type species: Cortinarius elaiochrous E. Horak, M.M. Moser, Peintner \& Vilgalys, Mycotaxon 83: 449 (2002). Basionym of the type species:
Cuphocybe olivacea R. Heim, Revue Mycol., Paris 16: 8 (1951).

Rozites P. Karst., Bidr. Känn. Finl. Nat. Folk 32: XX (1879). Current name of the type species: Cortinarius caperatus (Pers.) Fr., Epicr. syst. mycol. (Upsaliae): 256 (1838) [1836-1838]. Basionym of the type species: Rozites caperatus (Pers.) P. Karst., Bidr. Känn. Finl. Nat. Folk 32: 290 (1879).

Currently included sections: Cuphocybe, Paramyxacium, Rozites, Subcastanelli and clade/Achroi.

Notes: The centre of the diversity of this subgenus is in the Southern Hemisphere with only a few species occurring in the Northern Hemisphere. This subgenus contains agaricoid (rozitoid, cuphocyboid) and sequestrate species and the development type of agaricoid species is stipitocarpic. Typical for the agaricoid species of this subgenus is the membraneous veil that in most species forms a distinct ring or collar on the stipe, or in a few species, thick girdles or scales on the stipe. The pileus is viscid/glutinous to dry, and many species also have squamules or scales on the pileus, or the pileus is innately fibrillose, radially wrinkled and/or rimy. The basidiomata are usually medium- to large-sized. The basidiospores are medium to large-sized (8-16 $\times 5.5-9.5 \mu \mathrm{m})$, usually ovoid, amygdaloid or citriform, more rarely ellipsoid to very short and broadly ellipsoid.

Cortinarius subgen. Telamonia (Fr.) Trog, Mitt. naturf. Ges. Bern 15-23: 43 (1844) em. Niskanen \& Liimat.

Basionym: Agaricus trib. Telamonia Fr., Syst. mycol. (Lundae) 1: 10, 210 (1821)

Current name of the type species: Cortinarius torvus (Fr.) Fr., Epicr. syst. mycol. (Upsaliae): 293 (1838) [1836-1838]. Basionym of the type species: Agaricus torvus Fr., Observ. mycol. (Havniae) 2: 80 (1818). Lectotype: Bulliard, Herb. Fr. (Paris) 2: Tab. 96, pl. 600, 1782 [1781-82], in Liimatainen et al., Fungal Diversity 104: 323 (2020). Epitype: S F-248482, in Liimatainen et al., Fungal Diversity 104: 323 (2020).

Synonym: Hydrocybe (Fr. ex Rabenh.) Wünsche, Die Pilze: 87, 119 (1877). Basionym: Cortinarius a Hydrocybe Fr. ex Rabenh., Deutschl. Krypt.-Fl. (Leipzig) 1: 488 (1844). Type species Cortinarius duracinus Fr., Epicr. syst. mycol. (Upsaliae): 304 (1838) [1836-1838].

Telamonia (Fr.) Wünsche, Die Pilze: 87, 122 (1877). Basionym: Agaricus trib. Telamonia Fr., Syst. mycol. (Lundae) 1: 10, 210 (1821).

Currently included sections: 80 sections, see Liimatainen et al. (2020a).

Notes: This predominantly Northern Hemispheric lineage is the most species-rich subgenus in Cortinariaceae including hundreds of species. The basidiomata are smallto medium-sized (to large), stipitorcarpic, agaricoid (telamonioid) with a dry pileus and stipe. The basidiomata are 
predominantly with brown, grey, white, and/or purplish colours. The pileipellis is duplex, with a more or less developed hypoderm. For a recent morpho-genetic revision of the subgenus see Liimatainen et al. (2020a).

\section{Aureonarius Niskanen \& Liimat. gen. nov.}

IndexFungorum IF552143

Current name of the type species: Aureonarius kroegeri (Niskanen, Liimat., E. Harrower, Berbee, Garnica \& Ammirati) Niskanen \& Liimat. comb. nov. IF552144. Basionym of the type species: Cortinarius kroegeri Niskanen, Liimat., E. Harrower, Berbee, Garnica \& Ammirati, Index Fungorum 294: 1 (2016). Holotype: UBC F15952.

Etymology: Derived from the latin word aureus meaning golden, since species of this genus have yellow colours in their basidiomata, and the generic name Cortinarius.

Currently included subgenera: Aureonarius and Callistei (Fig. 4).

Description: Basidiomata small- to medium-sized (rather large-sized), agaricoid, development type stipitocarpic. Pileus $1-11 \mathrm{~cm}$, at first hemispherical or conical, then low convex or low conical to almost plane, some species with an umbo; smooth, finely scaly, innately fibrillose or almost tomentose yellow; orange, orange-red, orange-brown, brownish red, yellow-brown, red-brown, umber or blackish brown; dry or viscid, hygrophanous or not. Lamellae rather crowded, medium spaced to distant, adnate, adnexed to emarginate, white, \pm yellow, bright orange, yellow-brown or \pm red. Stipe $2-11 \mathrm{~cm}$ long, $0.2-1.8 \mathrm{~cm}$ wide at the apex, up to $2.5 \mathrm{~cm}$ wide at the base, clavate, cylindrical or tapering downwards, yellowish white, yellow, yellow-brown to orange-brown, in some species becoming more brownish when pressed with the thumb or with age, dry to somewhat viscid. Universal veil yellow, ochraceous, yellow-brown, orange-red, orange-brown, brown-red or purple-brown, sparse or more abundant and then forming complete and incomplete girdles on the stipe. Context in pileus white, pale yellow, yellow-brown, orange, orange-brown, redbrown to umber, in stipe yellow, yellow-brown, orange or red-orange. Odour of pileus surface or context indistinct or like a recently extinguished candle (ozone) or apple-like, odour in lamellae indistinct, raphanoid, cellar-like or raw potato-like. $\mathrm{KOH}$ reaction \pm red in stipital veil, pileus and/or context, or negative. UV fluorescence somewhat yellow or absent. Basidiospores 5-10.5 $\times 4.5-7 \mu \mathrm{m}$, subglobose, ovoid, broadly ellipsoid, ellipsoid or amygdaloid, finely, moderately to coarsely verrucose. Chrysobasidia present in two species, A. rubrocastaneus and A. rubrimarginatus. Cystidia absent. Pileipellis duplex, hypoderm at least somewhat developed.

Ecology and Distribution: In the Northern and Southern Hemispheres, with a centre of the diversity in the Southern Hemisphere. In coniferous (Pinaceae) and deciduous forests (Nothofagaceae, Fagaceae, Betulaceae).
Notes: The species of the bihemispheric genus Aureonarius are characterised by vivid yellow, orange, or red colours, at least in some parts of the basidiomata. The basidiomata are small- to rather large-sized, agaricoid (cortinarioid/leprocyboid), and the development type is stipitocarpic. No sequestrate species are yet known to belong to this genus. Some species have a weak yellow UV fluorescence, and some species exhibit a \pm red $\mathrm{KOH}$-reaction in stipital veil, pileus, or context. This taxon is well supported in our phylogenomic analyses, and we here describe it as a new genus.

\section{Aureonarius subgenus Aureonarius}

IndexFungorum IF552145

Etymology: Derived from the latin word aureus meaning golden, since species of this genus have yellow colours in their basidiomata, and the generic name Cortinarius.

Currently included sections: Aureonarius (= Cortinarius sect. Limonii Nezdojm).

Description: Basidiomata small- to medium-sized, agaricoid (cortinarioid/leprocyboid), development type stipitocarpic. Pileus $1-8 \mathrm{~cm}$, at first hemispherical or conical, then low convex or low conical to almost plane, often with an umbo, yellow, orange, orange-red, orange-brown, brownish red, yellow-brown, red-brown, umber, or blackish brown, dry or viscid, hygrophanous or not. Lamellae rather crowded, medium spaced to somewhat distant, adnate, adnexed to emarginate, \pm yellow, bright orange, pale yellow-brown or \pm red. Stipe $2-11 \mathrm{~cm}$ long, $0.2-1.8 \mathrm{~cm}$ wide at the apex, cylindrical to fusoid, often tapering downwards, yellowish white, yellow, yellow-brown to orange-brown, dry to somewhat viscid. Universal veil yellow, ochraceous, yellow-brown, orange-brown, or brown-red, sparse or more abundant and then forming complete and incomplete girdles on the stipe. Context in pileus yellow-brown, orange, orange-brown, red-brown to umber, in stipe yellow, yellow-brown, orange or red-orange. Odour in lamellae or pileus surface indistinct. $\mathrm{KOH}$ reaction red to dark red in stipital veil, pileus and/or context, or negative. UV fluorescence weak or absent (Soop et al. 2018). Basidiospores 5-10.5 $\times 4.5-7 \mu \mathrm{m}$, subglobose, broadly ellipsoid, ellipsoid or amygdaloid, finely, moderately to coarsely verrucose. Chrysobasidia present in two species, A. rubrocastaneus and $A$. rubrimarginatus. Cystidia absent. Pileipellis duplex, hypoderm developed, some species with a thin gelatinous layer at the top of the epicutis.

Ecology and Distribution: The centre of the diversity of this lineage is in New Zealand where the species occur in Myrtaceae and Nothofagaceae forests. The three species known from the Northern Hemisphere, associated with Fagaceae and Pinaceae, are clustered in one monophyletic lineage within one of the New Zealand lineages.

Notes: The species of this small, bihemispheric subgenus have small- to medium-sized, stipitocarpic, agaricoid 
(cortinarioid/leprocyboid) basidiomata with yellow, orangered and reddish-brown colours. The pileus is dry to viscid, and the stipe is cylindrical to fusoid and dry. The lamellae are \pm yellow, bright orange, pale yellow-brown or \pm red and the basidiospores are subglobose, broadly ellipsoid, ellipsoid or amygdaloid. A distinct odour in the lamellae or at the pileus surface is lacking. The species of the sister subgenus Callistei differ from the species of subgenus Aureonarius by having white, pale yellow or greyish ochraceous lamellae at least when young and somewhat yellow UV fluorescence. In addition, some species of the subgenus Callistei have a clavate stipe and a distinct smell at the pileus surface, context or lamellae, and none of the species have amygdaloid or ellipsoid spores.

\section{Aureonarius subgenus Callistei (Liimat., Niskanen \&} Ammirati) Niskanen \& Liimat., comb. nov.

IndexFungorum IF552146

Basionym: Cortinarius subgen. Callistei Liimat., Niskanen \& Ammirati, in Niskanen, Liimatainen, Kytövuori \& Ammirati, Index Fungorum 256: 2 (2015).

Current name of the type species: Aureonarius callisteus (Fr.) Niskanen \& Liimat. comb. nov. IF552147. Basionym of the type species: Agaricus callisteus Fr., Observ. mycol. (Havniae) 2:51. 1818. Neotype: S CFP1219, in Brandrud et al., Cortinarius flora photographica 5: pl. E30, (2012).

Currently included sections: Callistei and Collybiani.

Description: Basidiomata small- to medium-sized, agaricoid (cortinarioid/leprocyboid), development type stipitocarpic. Pileus $2-11 \mathrm{~cm}$, at first hemispherical to somewhat conical, then low convex to almost plane, some species with an umbo, smooth, finely scaly, innately fibrillose or almost tomentose, yellow, yellow-orange, yellow-brown, orangebrown, brownish red to mahogany-red, dry, hygrophanous or not. Lamellae medium spaced to distant, adnate to emarginate, at first almost white, pale yellow or yellowish brown, later brownish yellow to brown. Stipe $3.5-11 \mathrm{~cm}$ long, $0.5-1.5 \mathrm{~cm}$ wide at the apex, up to $2.5 \mathrm{~cm}$ wide at the base, clavate, cylindrical to somewhat tapering; yellowish white, pale yellow, yellow-brown, becoming more brownish when pressed with the thumb and with age. Universal veil yellow, yellow-brown, orange-red or purple-brown, forming complete and/or incomplete zones on the stipe, or sparse. Context in pileus white to pale yellow, in stipe pale yellow, yellow-brown to orange-brown, in many species becoming darker with age. Odour of pileus surface or context like a recently extinguished candle (ozone), apple-like or indistinct, odour in lamellae indistinct, raphanoid, cellar-like or raw potato-like. $\mathrm{KOH}$ reaction in pileus and/or stipital veil brownish red to red. UV fluorescence somewhat yellow. Basidiospores 5.5-9 $\times 5-7 \mu \mathrm{m}$, subglobose, ovoid to broadly ellipsoid, finely to moderately verrucose. Cystidia absent. Pileipellis duplex, hypoderm at least somewhat developed.
Ecology and Distribution: In the Northern and Southern Hemispheres in coniferous and deciduous forests.

Notes: The species of this small, bihemispheric subgenus have small- to medium-sized, stipitocarpic, agaricoid (cortinarioid/leprocyboid) basidiomata with yellow, orange and brownish-red colours. The pileus is dry, and the stipe is clavate or cylindrical and dry. The lamellae are at first almost white, pale yellow or yellowish brown and the basidiospores are subglobose, ovoid to broadly ellipsoid. Many species have a distinct odour either at the pileus surface or in the lamellae. The species of the sister subgenus Aureonarius have \pm yellow, bright orange, pale yellow-brown or \pm red lamellae and an indistinct odour in the lamellae or at the pileus surface. In addition, there is no UV fluorescence in the basidiomata of the species of subgenus Aureonarius.

Aureonarius section Callistei Niskanen \& Liimat., sect. nov.

\section{IndexFungorum IF552148}

Current name of the type species: Aureonarius callisteus (Fr.) Niskanen \& Liimat.

Etymology: Named after A. callisteus, a species belonging to this section.

Currently included species: $C$. neocallisteus, C. callisteus, $C$. infucatus, $C$. tofaceus.

Description: Basidiomata medium-sized (to largesized), agaricoid (cortinarioid/leprocyboid), development type stipitocarpic. Pileus $3-11 \mathrm{~cm}$, at first hemispherical, then low convex to almost plane, smooth to finely scaly to almost tomentose, yellow, yellow-orange, yellow-brown to orange-brown, dry, somewhat to not hygrophanous. Lamellae medium spaced to distant, adnate to emarginate, at first almost white, pale yellow or yellowish brown, later brownish yellow to brown. Stipe $3.5-11 \mathrm{~cm}$ long, $0.6-1.5 \mathrm{~cm}$ wide at the apex, up to $2.5 \mathrm{~cm}$ wide at the base, clavate or cylindrical; pale yellow, yellow brown, becoming more brownish when pressed with the thumb and with age. Universal veil yellow to yellow-brown, forming complete and/ or incomplete zones on the stipe, sometimes sparse. Context in pileus white to pale yellow, in stipe yellow-brown to orange-brown, becoming darker with age. Odour of pileus surface like a recently extinguished candle (ozone), applelike or indistinct, odour in lamellae raphanoid, cellar-like or raw potato-like. $\mathrm{KOH}$ reaction in pileus and/or stipital veil brownish red to red. UV fluorescence somewhat yellow. Basidiospores 6.5-9 $\times 5.5-7 \mu \mathrm{m}$, subglobose to ovoid, moderately verrucose. Cystidia absent. Pileipellis duplex, hypoderm somewhat developed.

Ecology and Distribution: In the Northern Hemisphere in coniferous and deciduous forests.

Notes: A Northern Hemispheric lineage in A. subgenus Callistei. The representatives of the sister lineage, A. sect. Collybiani from the Southern Hemispheric Nothofagaceae 
forests, often have a somewhat more reddish-coloured pileus and darker universal veil. The group received full support in the phylogenetic analysis of Soop et al. (2018, 2019).

Aureonarius section Collybiani Niskanen \& Liimat., sect. nov.

IndexFungorum IF552149

Current name of the type species: Aureonarius collybianus (Soop) Niskanen \& Liimat., comb. nov. IF552150. Basionym of the type species: Cortinarius collybianus Soop, Bull. Soc. mycol. Fr. 117(2): 121 (2001). Holotype: PDD 70509.

Etymology: Named after the type species of the section. Currently included species: C. collybianus, C. eucollybianus, C. rubrodactylus.

Description: Basidiomata small- to medium-sized, agaricoid (cortinarioid/leprocyboid), development type stipitocarpic. Pileus $2-8.5 \mathrm{~cm}$, at first hemispherical to somewhat conical, then convex to plano-convex, often with an umbo, smooth to finely innately fibrillose, orangered, apricot-brown, brownish red to mahogany red, dry, hygrophanous or not. Lamellae medium spaced to distant, adnate to emarginate, at first white, pale yellow or greyish ochraceous later more brownish. Stipe $4-9 \mathrm{~cm}$ long, $0.5-1.2 \mathrm{~cm}$ wide at the apex, somewhat clavate, cylindrical to somewhat tapering, yellowish white, pale yellow, yellow or brown-yellow, becoming more brownish at the base with age. Universal veil orange-red, orange-brown, or purple-brown, sparse. Context white or pale yellow. Odour in context like wax-candles. $\mathrm{KOH}$ reaction dark red on pileipellis and stipital veil or trivial. Not UV fluorescent. Basidiospores 5.5-8.5 $\times 5-6 \mu \mathrm{m}$, subglobose to broadly ellipsoid, finely to moderately verrucose. Cystidia absent. Pileipellis duplex, hypoderm developed.

Ecology and Distribution: In the Southern Hemisphere in Nothofagaceae forests.

Notes: A Southern Hemispheric lineage in A. subgenus Callistei. The representatives of the sister lineage, $A$. sect. Callistei from the Northern Hemisphere, often have a somewhat paler, less reddish pileus and a yellow to yellow-brown universal veil. The group received full support in the phylogenetic analysis of Soop et al. $(2018,2019)$.

Austrocortinarius Niskanen \& Liimat., gen. nov. IndexFungorum IF552197

Current name of the type species: Austrocortinarius victoriaensis (Liimat.) Niskanen, comb. nov. IF552198 Basionym of the type species: Cortinarius victoriaensis Liimat., Index Fungorum 506: 2 (2021); Holotype: K(M) 162337

Etymology: A genus of family Cortinariaceae that is currently only known from the Southern Hemisphere.
Currently included subgenera: The genus includes only a few species and no infrageneric classification is proposed at present.

Description: Basidiomata (medium- to) large-sized, agaricoid (phlegmacioid), development type stipitocarpic. Pileus 6-15 cm, at first hemispherical, then convex to planoconvex, margin often with hanging remnants of veil, white to brownish white. Lamellae crowded, adnate to emarginate, at first almost white to very pale brown, later pale brown to brown. Stipe $7-15 \mathrm{~cm}$ long, $1.2-3 \mathrm{~cm}$ wide at the apex, rooting, white. Universal veil white, peronate, often forming a distinct ring at the upper part of the stipe. Context white. Odour not recorded. $\mathrm{KOH}$ reaction not recorded. Basidiospores $10-12 \times 5-6.5 \mu \mathrm{m}$, amygdaloid to citriform, finely verrucose. Cystidia absent. Pileipellis simplex, hypoderm not developed.

Ecology and Distribution: In the Southern Hemisphere in Australia and New Zealand. In Myrtaceae forests.

Notes: Austrocortinarius is a small, Southern Hemispheric genus currently only known from Australia and New Zealand. The representatives of the genus are easy to recognize by the combination of pileipellis simplex, large, \pm white basidiomata and a peronate universal veil often forming a distinct ring at the upper part of the rooting stipe. In addition, the basidiomata are agaricoid (phlegmacioid), stipitocarpic and the spores are rather large and amygdaloid. The sequence data deposited in the public repositories, as well as morphology, indicates that $C$. australiensis would also belong to this genus but the type specimen of the species has not been studied to confirm the placement. The species of genus Austrocortinarius are most reminiscent of those in $P$. subgenus Phlegmacium, sect. Arguti and clades Obsoleti and Caligati but those lineages of Phlegmacium are only known from the Northern Hemisphere. Rooting, phlegmacioid species are also found from genus Thaxterogaster, but none of those species has the same, unique combination of characters than the representatives of the genus Austrocortinarius. Based on the morphological and molecular data we here consider this distinct lineage as its own genus.

Calonarius Niskanen \& Liimat., gen. nov.

IndexFungorum IF552199

Current name of the type species: Calonarius typicus (Liimat.) Niskanen, comb. nov. IF552200. Basionym of the type species: Cortinarius typicus Liimat., in Niskanen \& Liimatainen, Index Fungorum 487: 2 (2021). Holotype: H 7068019.

Etymology: Derived from the section name Calochroi and the generic name Cortinarius.

Currently included subgenera: Calonarius, Calochroi and Fulvi (Fig. 4).

Description: Basidiomata medium- to large-sized, usually agaricoid (phlegmacioid) but a few species sequestrate, 
development type pileocarpic. Pileus $3-15 \mathrm{~cm}$, at first hemispherical, then convex to plano-convex, surface in part of the species with small appressed scales or patches of veil and/or innately fibrillose, often colourful with white, yellow, orange, green, olivaceous, brown, blackish and/or purple colours, glutinous. Lamellae crowded, adnate to adnexed to emarginate, white, pale grey, yellow, greenish, olivaceous, pale brown or purple. Stipe $3-12 \mathrm{~cm}$ long, $0.7-3 \mathrm{~cm}$ wide at the apex, with more or less, usually distinctly, marginated bulb at the base (up to $4.5 \mathrm{~cm}$ wide), bulb in some species flattened; white, pale grey, yellow, olivaceous green or purple. Universal veil white, ochraceous yellow, olivaceous/greenish yellow, orange, brown, brown-olive or purple, found at the bulb margin. Context white, greyish white, yellow or greenish yellow, in some species with a purplish, greenish or olivaceous tint. Odour in lamellae indistinct, earth-like, malty or yeast-like, curry-like, sweet, in one species of anise. $\mathrm{KOH}$ reaction pink, red, yellowish or orangebrown, olivaceous green, black or in some species negative. Basidiospores 8.5-16×5.5-9.5 $\mu \mathrm{m}$, amygdaloid to citriform, distinctly and coarsely verrucose. Cystidia absent. Pileipellis simplex with a well-developed gelatinous layer, hypoderm not developed.

Ecology and Distribution: In the Northern Hemisphere. Forming ectomycorrhizal associations mainly with the trees of Fagaceae (Castanea, Castanopsis, Chrysolepis, Fagus, Notholithocarpus, Quercus) and Pinaceae (Abies, Larix, Picea, Pinus, Pseudotsuga, Tsuga), some species also with Betulaceae (Alnus, Corylus, Carpinus), Cistaceae (Cistus, Helianthemum) and Malvaceae (Tilia) (Garnica et al. 2011). Most species are rare and have narrow ecological preferences (Frøslev et al. 2007), and the majority are calcicolous or calciphilous.

Notes: This species-rich genus is currently only known from the Northern Hemisphere. The species are predominantly calcicolous or calciphilous, many are rare and have narrow ecological preferences and are thus included in national red lists in several countries and/or used as indicator species. One species, C. meinhardii, is also included in the global red list of fungi. Typical for the members of this genus are medium- to large-sized, pileocarpic, agaricoid (phlegmacioid) or sometimes sequestrate, often brightly coloured basidiomata with a more or less, usually distinctly marginated bulb at the base of the stipe. Amygdaloid to citriform coarsely verrucose basidiospores and simplex pileipellis are also typical. Some species have a positive $\mathrm{KOH}$-reaction ( \pm red, yellowish or orange-brown, olivaceous green, black). The species are most reminiscent of those in the genera Phlegmacium and Thaxterogaster, but the combination of simplex pileipellis, marginated bulb and amygdaloid to citriform, coarsely verrucose basidiospores distinguish the members of Calonarius from the other phlegmacioid species. This group has been recognized as a separate, well-supported lineage since early molecular studies (Peintner et al. 2004; Garnica et al. 2005) and is also supported by morphological characteristics, and here were propose a name for it in generic level. For the most recent morpho-genetic study of the group see Frøslev et al. (2007) and Garnica et al. (2009).

\section{Calonarius subgenus Calonarius}

IndexFungorum IF552151

Etymology: Derived from the section name Calochroi and the generic name Cortinarius.

Currently included sections: Calonarius, Humolentes, and Rufoolivacei.

Description: Basidiomata medium- to large-sized, usually agaricoid (phlegmacioid) but at least one species sequestrate, development type pileocarpic. Pileus $4-14 \mathrm{~cm}$, at first hemispherical, then convex to plano-convex, surface in some species with patches or scales of veil or spots, with grey, greenish, olivaceous, yellow, orange-brown, copper brown, red brown, umber brown and purplish colours, rarely creamcoloured, glutinous. Lamellae crowded, adnate to adnexed to emarginate, greyish white, pale ochraceous grey, pale yellow, greenish grey, greyish green, yellowish green or olivaceous, rarely with a purplish tint. Stipe $4-12 \mathrm{~cm}$ long, $0.8-2.5 \mathrm{~cm}$ wide at the apex, with a marginated or more rarely rounded bulb at the base (up to $4.5 \mathrm{~cm}$ wide), bulb in a few species flattened; white, in some species purplish, greyish green or yellowish green or with a purple, yellow or olivaceous tint. Universal veil white, yellow, greyish or yellowish green, brown, brown-olive, purple or purplish red, in some species somewhat glutinous, found at the bulb margin. Context white to grey, rarely greenish yellow, in some species with a purplish, greenish or olivaceous tint at the stipe. Odour in lamellae indistinct, earth-like, malty or yeast-like, curry-like, sweet, in two species of anise. $\mathrm{KOH}$ reaction negative or in some species yellow-brown, orange-brown, olivaceous green, brown-red or purplish, rarely blood-red. Basidiospores 10-16×6-9.5 $\mu \mathrm{m}$, amygdaloid to citriform, distinctly and coarsely verrucose. Cystidia absent. Pileipellis simplex with a well-developed gelatinous layer, hypoderm not developed.

Ecology and Distribution: In the Northern Hemisphere. Forming ectomycorrhizal associations mainly with the species of Fagaceae, Pinaceae, Betulaceae, and Malvaceae. Most species are rare and have narrow ecological preferences, and the majority are calcicolous or calciphilous.

Notes: The species of this subgenus mainly have lamellae without purple tones and the context is white to grey, rarely greenish-yellow, and in some species with a purplish, greenish or olivaceous tint at the stipe. The $\mathrm{KOH}-r e a c t i o n$, if present, is not red for most species. The basidiomata are medium- to large-sized, pileocarpic, agaricoid (phlegmacioid) and the pileipellis is simplex. 
Calonarius section Humolentes Niskanen \& Liimat., sect. nov.

IndexFungorum IF552330

Current name of the type species: Calonarius humolens (Brandrud) Niskanen \& Liimat., comb. nov. IF552331. Basionym of the type species: Cortinarius humolens Brandrud, in Brandrud, Lindström, Marklund, Melot \& Muskos, Cortinarius, Flora Photographica (Matfors) 4: 20. 1998. Holotype: O CFP1281.

Etymology: Named after the type species of the section. Currently included species: C. anaunianus, C. caroviolaceus, C. elotus, C. elotoides, C. glaucoelotus, C. hildegardiae, C. humolens, C. lavandulochlorus, C. mariekristinae, C. osloensis, C. praetermissus, C. pseudoglaucopus, C. rapaceoides, C. saporatus, and C.xanthodryophilus.

Description: Basidiomata medium- to large-sized, agaricoid (phlegmacioid), development type pileocarpic. Pileus 4-14 cm, at first hemispherical, then convex to plano-convex, in some species with small drop-like spots or appressed scales, or more rarely innately fibrillose; with ochraceous/yellow, grey, greenish/olivaceous, and/ or ochraceous brown colours, rarely orange/reddish brown, glutinous. Lamellae crowded (to medium spaced), adnate to adnexed to emarginate, at first pale ochraceous grey, more or less yellow, olivaceous or with a yellow, olivaceous or greenish tint, later more ochraceous brown. Stipe $3-8 \mathrm{~cm}$ long, $0.8-2.5 \mathrm{~cm}$ wide at the apex, with a marginated or rounded bulb at the base (up to $4.5 \mathrm{~cm}$ wide), bulb in some species flattened; white, pale yellow, or with a yellow, olivaceous or purple tint. Universal veil white, yellow, greyish or yellowish green, purple or brown, in some species somewhat glutinous, found at the bulb margin, in some species volva-like when young. Context white, grey, in some species with an olivaceous, yellow or purplish tint. Odour in most species in flesh/lamellae earth-like or raphanoid, in some species malty. $\mathrm{KOH}$ reaction negative. Basidiospores 9-14 $\times 5-8 \mu \mathrm{m}$, amygdaloid to citriform, distinctly and coarsely verrucose. Cystidia absent. Pileipellis simplex with a well-developed gelatinous layer, hypoderm not developed.

Ecology and Distribution: In the Northern Hemisphere. In deciduous and coniferous forests on calcareous or baserich ground. Forming ectomycorrhizal associations mainly with the species of Fagaceae, Pinaceae, Betulaceae and Tilia.

Notes: The species of this section are found from the Norther Hemisphere and grow on calcareous or base-rich ground ground with deciduous or coniferous trees. Basidiomata have ochraceous/yellow, grey, greenish/olivaceous and ochraceous brown colours and most species have an earth-like or raphanoid odour in flesh/lamellae. In addition, the species lack $\mathrm{KOH}$ reaction and they do not have purplish colours in lamellae. The basidiomata are medium- to largesized, pileocarpic, agaricoid (phlegmacioid) and the pileipellis is simplex.

The clade name/Humolentes was first introduced for this group by Brandrud et al. (2019) and includes clades/Pseudoglaucopodes and Caroviolacei recognized by Garnica et al. (2009). For the most recent phylogenetic study of the group see Brandrud et al. (2019) and Fellin et al. (2021).

Calonarius subgenus Calochroi Niskanen \& Liimat., subgen. nov.

IndexFungorum IF552332

Current name of the type species: Calonarius flavipallens (Kytöv., Liimat. \& Niskanen) Niskanen \& Liimat., comb. nov. IF552333. Basionym of the type species: Cortinarius flavipallens Kytöv., Liimat. \& Niskanen, in Liimatainen, Niskanen, Dima, Kytövuori, Ammirati \& Frøslev, Persoonia 33: 125 (2014). Holotype: H 6032745.

Etymology: Named after C. calochrous, a species belonging to this subgenus.

Currently included sections: Calochroi, Nymphicolores, Platypodes, and Sodagniti.

Description: Basidiomata medium- to large-sized, usually agaricoid (phlegmacioid) but at least one species sequestrate development type pileocarpic. Pileus $3-10 \mathrm{~cm}$, at first hemispherical, then convex to plano-convex, surface in most species with small appressed scales or patches of veil, ochraceous white, yellow, ochraceous to brown, in some species with bluish, purplish, greenish or olivaceous tints, in some species completely purple, glutinous. Lamellae crowded, adnate to adnexed to emarginate, greyish white with a purplish tint to pale greyish purple to distinctly purple, in a few species yellow to brown. Stipe 3-12 cm long, $0.7-2.5 \mathrm{~cm}$ wide at the apex, with a distinctly marginated bulb at the base (up to $4 \mathrm{~cm}$ wide), bulb in some species flattened, greyish white, in many species with a purplish tint at the top of the stipe, in some species completely purple at least when young. Universal veil whitish to ochraceous yellow, in some species purple or olivaceous, found at the bulb margin. Context whitish to greyish white, in part of the species pale purple to purple at least at the top of the stipe. Odour in many species in lamellae somewhat earth-like in older basidiomata. $\mathrm{KOH}$ reaction in many species pink, reddish brown or blood red in some parts of the basidiomata, indistinct in part of the species. Basidiospores $8.5-13 \times 5.5-8.5 \mu \mathrm{m}$, amygdaloid to citriform, distinctly and coarsely verrucose. Cystidia absent. Pileipellis simplex with a well-developed gelatinous layer, hypoderm not developed.

Ecology and Distribution: In the Northern Hemisphere. Forming ectomycorrhizal associations mainly with the species of Fagaceae, Pinaceae, Betulaceae, Cistaceae and 
Malvaceae. Most species are rare and have narrow ecological preferences, and the majority are calcicolous or calciphilous.

Notes: This is the most species-rich lineage within the genus Calonarius. Most species are characterized by a combination of lamellae with a purplish tint or completely purplish and lack of anthraquinonoid pigments (Frøslev et al. 2007). The basidiomata are medium- to large-sized, pileocarpic, agaricoid (phlegmacioid) and the pileipellis is simplex. The clade Calochroi was also recovered as a wellsupported lineage in previous studies by Frøslev et al. (2007) and Garnica et al. (2009).

\section{Calonarius section Nymphicolores Niskanen \& Liimat.,} sect. nov.

IndexFungorum IF552334

Current name of the type species: Calonarius molochinus (Bidaud \& Ramm) Niskanen \& Liimat., comb. nov. IF552335. Basionym of the type species: Cortinarius molochinus Bidaud \& Ramm, in Bidaud, Moënne-Loccoz, Reumaux, Carteret \& Eyssartier, Atlas des Cortinaires (Meyzieu) 11: 613. 2001. Holotype: PC 3676.

Etymology: Named after C. nymphicolor, a species belonging to the section.

Currently included species: C. nymphicolor and $C$. molochinus.

Description: Basidiomata medium- to large-sized, agaricoid (phlegmacioid), development type pileocarpic. Pileus $3.5-10 \mathrm{~cm}$, at first hemispherical, then convex to planoconvex, with small patches of whitish veil at centre, entirely pinkish purple or at least margin purple when young, centre cream, pale ochraceous yellow to \pm brownish; glutinous. Lamellae crowded, adnate to adnexed to emarginate, greyish to purple. Stipe $3-7.5 \mathrm{~cm}$ long, $0.7-2 \mathrm{~cm}$ wide at the apex, with a flattened bulb; white, with a purplish tint at the apex. Universal veil white or yellow, becoming yellow to ochraceous brown with age. Context white. Odour indistinct or \pm earthy. $\mathrm{KOH}$ reaction pink on pileus and bulbipellis, somehat rose or negative in context. Basidiospores 8.5-11 $\times 5-6.5 \mu \mathrm{m}$, amygdaloid to ellipsoid, coarsely verrucose. Cystidia absent. Pileipellis simplex with a welldeveloped gelatinous layer, hypoderm not developed.

Ecology and Distribution: In the Northern Hemisphere. In deciduous forests on calcareous ground. Forming ectomycorrhizal associations mainly with the species of Fagaceae.

Notes: The species of the section are found from the Northerh Hemispheric deciduous forests on calcareous ground. Typical are purplish colours in pileus and stipe and often also in lamellae as well as initially white or yellow universal veil. The $\mathrm{KOH}$ reaction is pink on pileus and bulbipellis and the spores are amygdaloid to ellipsoid, coarsely verrucose. The basidiomata are medium- to large-sized, pileocarpic, agaricoid (phlegmacioid) and the pileipellis is simplex. The clade received full support in our phylogenetic analysis.

Calonarius subgenus Fulvi Niskanen \& Liimat., subgen. nov.

IndexFungorum IF552337

Current name of the type species: Calonarius elegantiooccidentalis (Garnica \& Ammirati) Niskanen \& Liimat., comb. nov. IF552338. Basionym of the type species: Cortinarius elegantio-occidentalis Garnica \& Ammirati, in Garnica, Spahn, Oertel, Ammirati \& Oberwinkler, BMC Evol. Biol. 11(213): 13 + Additional file 3: 23 (2011). Holotype: WTU, Ammirati 13226.

Etymology: This subgenus includes part of the species previously included in section Fulvi.

Currently included sections: Fulvi, Atrovirentes, Aureopulverulenti, Dibaphi, and Splendentes.

Description: Basidiomata medium- to large-sized, agaricoid (phlegmacioid), development type pileocarpic. Pileus 3-15 cm, at first hemispherical, then convex to plano-convex, surface in many species with small appressed scales and/or innately fibrillose, \pm yellow, olivaceous green, greyish green, yellow brown, orange-brown, rose brown to red brown, in some species with purplish tints, in one species completely purplish, center saffron orange, brown, chestnut brown, purplish brown to blackish; glutinous. Lamellae crowded, adnate to adnexed to emarginate, greyish white, grey, yellow, greenish yellow, olivaceous yellow, ochraceous brown to olivaceous green, in some species with a purplish tint. Stipe 4-12 cm long, 1-3 cm wide at the apex, with more or less, usually distinctly marginated bulb at the base (up to $4.5 \mathrm{~cm}$ wide), bulb in some species flattened; white, pale yellow, yellow, greenish yellow to olivaceous green, in some species with a purplish tint or completely purplish. Universal veil \pm yellow, orange or purple, found at the bulb margin. Context yellow, greenish yellow, pale yellow or white, in some species with a purplish tint. Odour in lamellae indistinct or malt-like. KOH reaction pink, vinaceous, blood-red, olivaceous green, olivaceous brown, red brown or black. Basidiospores 9-15 $\times 5.5-9 \mu \mathrm{m}$, amygdaloid to citriform, distinctly and coarsely verrucose. Cystidia absent. Pileipellis simplex with a well-developed gelatinous layer, hypoderm not developed.

Ecology and Distribution: In the Northern Hemisphere. Forming ectomycorrhizal associations mainly with the species of Fagaceae, Pinaceae, Betulaceae, and Malvaceae. Most species are rare and have narrow ecological preferences, and the majority are calcicolous or calciphilous.

Notes: Most species of this subgenus are characterized by yellow colours in the lamellae and/or stipe. If the lamellae are purple, then the pileus is not yellow. Part of the species have anthraquinonoid pigments (Frøslev et al. 2007). The basidiomata are medium- to large-sized, pileocarpic, 
agaricoid (phlegmacioid) and the pileipellis is simplex. The group also received good support (BS 96\%) in the analysis by Garnica et al. (2009).

Cystinarius Niskanen \& Liimat., gen. nov.

IndexFungorum IF552491

Current name of the type species: Cystinarius rubiginosus (Ammirati, Bojantchev, Niskanen \& Liimat.) Liimat. \& Niskanen, comb. nov. IF559243. Basionym of the type species: Cortinarius rubiginosus Ammirati, Bojantchev, Niskanen \& Liimat., Index Fungorum 506: 1 (2021). Holotype: H 7072000.

Etymology: Derived from the word cystidia, a property of this genus, and the generic name Cortinarius.

Currently included subgenera: Cystinarius and Crassi (Fig. 4).

Description: Basidiomata medium- to large-sized, agaricoid (phlegmacioid/cortinarioid), development type stipitocarpic. Pileus $1.5-11 \mathrm{~cm}$, at first hemispherical, then convex to plano-convex, surface fibrillose to tomentose, orange yellow, yellow brown, ochraceous brown, greyish brown, red brown to blackish brown, in some species with spots, dry or somewhat viscid. Lamellae crowded to medium spaced, adnate to adnexed to emarginate, white to greyish yellow. Stipe 3-11 cm long, 0.7-2.5 cm wide at the apex, cylindrical, clavate to fusiform, white, pale grey to greyish yellow, in some species staining yellow or pinkish, dry to somewhat viscid. Universal veil white, pale grey, ochraceous yellow to brown, in some species darkening, often sparse, forming thin bands on the stipe. Context in stipe white to yellowish brown, in some species darker in the pileus, in subgenus Rubicunduli staining more or less yellow when exposed. Odour in lamellae indistinct. $\mathrm{KOH}$ reaction negative. Basidiospores 6-9 $\times 3.5-5 \mu \mathrm{m}$, ellipsoid to amygdaloid to subfusoid, almost smooth to very finely and indistinctly verrucose. Lamellae with cylindrical, clavate or capitate cheilo- and pleurocystidia. Pileipellis somewhat duplex-like, the hypoderm is poorly developed but the hyphae beneath the epicutis are hypoderm-like (elements that are short and wide).

Ecology and Distribution: In the Northern and Southern Hemisphere with coniferous and deciduous trees.

Notes: This small bihemispheric genus is easy to recognize by the unique combination of small basidiospores $(6-9 \times 3.5-5 \mu \mathrm{m})$ and presence of cheilo- and pleurocystidia. The basidiomata are medium- to large-sized, stipitocarpic and agaricoid (phlegmacioid/cortinarioid). The pileipellis is somewhat duplex. The species form a well-supported lineage (BS 99\%) distinct from the other genera of Cortinariaceae, a relationship already recovered by the phylogenetic analysis of Stensrud et al. (2014) and Soop et al. (2019), and we here describe the genus as new.

\section{Cystinarius subgen. Cystinarius}

IndexFungorum IF552339

Currently included sections: Cystinarius.

Description: Basidiomata medium- to large-sized, agaricoid (cortinarioid), development type stipitocarpic. Pileus $1.5-8 \mathrm{~cm}$, at first hemispherical, then convex to plano-convex, surface fibrillose, orange yellow, yellow brown, greyish brown, red brown to blackish brown, in some species with spots, dry or viscid. Lamellae crowded to medium spaced, adnate to adnexed to emarginate, white to greyish yellow. Stipe 3-8 cm long, $0.7-2 \mathrm{~cm}$ wide at the apex, cylindrical to clavate, white, pale grey to greyish yellow, staining yellow or pinkish, dry to somewhat viscid. Universal veil white, pale grey to ochraceous yellow, in some species darkening, often sparse, forming thin bands on the stipe. Context in the whole basidiomata white to yellowish brown, in some species darker in the pileus, staining more or less yellow when exposed. Odour in lamellae indistinct. $\mathrm{KOH}$ reaction negative. Basidiospores $6-9 \times 3.5-5 \mu \mathrm{m}$, ellipsoid to amygdaloid to subfusoid, very finely and indistinctly verrucose. Lamellae with cylindrical, clavate or capitate cheilo- and pleurocystidia. Pileipellis somewhat duplex-like, the hypoderm is poorly developed but the hyphae beneath the epicutis are hypoderm-like (elements that are short and wide).

Ecology and Distribution: In the Northern and Southern Hemisphere with coniferous and deciduous trees.

Notes: This small bihemispheric subgenus includes medium- to large-sized, stipitocarpic, agaricoid (cortinarioid) species whose context stains more or less yellow when exposed. Small basidiospores and the presence of cheiloand pleurocystidia is also typical. The pileus is dry to viscid and the stipe is dry and the pileipellis is somewhat duplex with a poorly developed hypoderm. The species of the sister group, $C$. subgen. Crassi, lack bright yellow colours in their basidiomata.

Cystinarius subgen. Crassi Niskanen \& Liimat., subgen. nov.

IndexFungorum IF552493

Current name of the type species: Cystinarius eutactus (Soop) Niskanen \& Liimat., comb. nov. IF552494. Basionym of the type species: Cortinarius eutactus Soop, N.Z. Jl Bot. 43(2): 552. 2005. Holotype: PDD 78807.

Etymology: Named after C. crassus, a species belonging to this subgenus.

Currently included sections: Crassi.

Description: Basidiomata (medium- to) large-sized, agaricoid (phlegmacioid), development type stipitocarpic. Pileus $4-11 \mathrm{~cm}$, at first hemispherical, then convex to plano-convex, surface fibrillose to tomentose, ochraceous brown, greyish brown to dark red brown, dry or somewhat viscid. Lamellae crowded, adnate to adnexed to emarginate, white to yellowish grey. Stipe $4-11 \mathrm{~cm}$ long, 


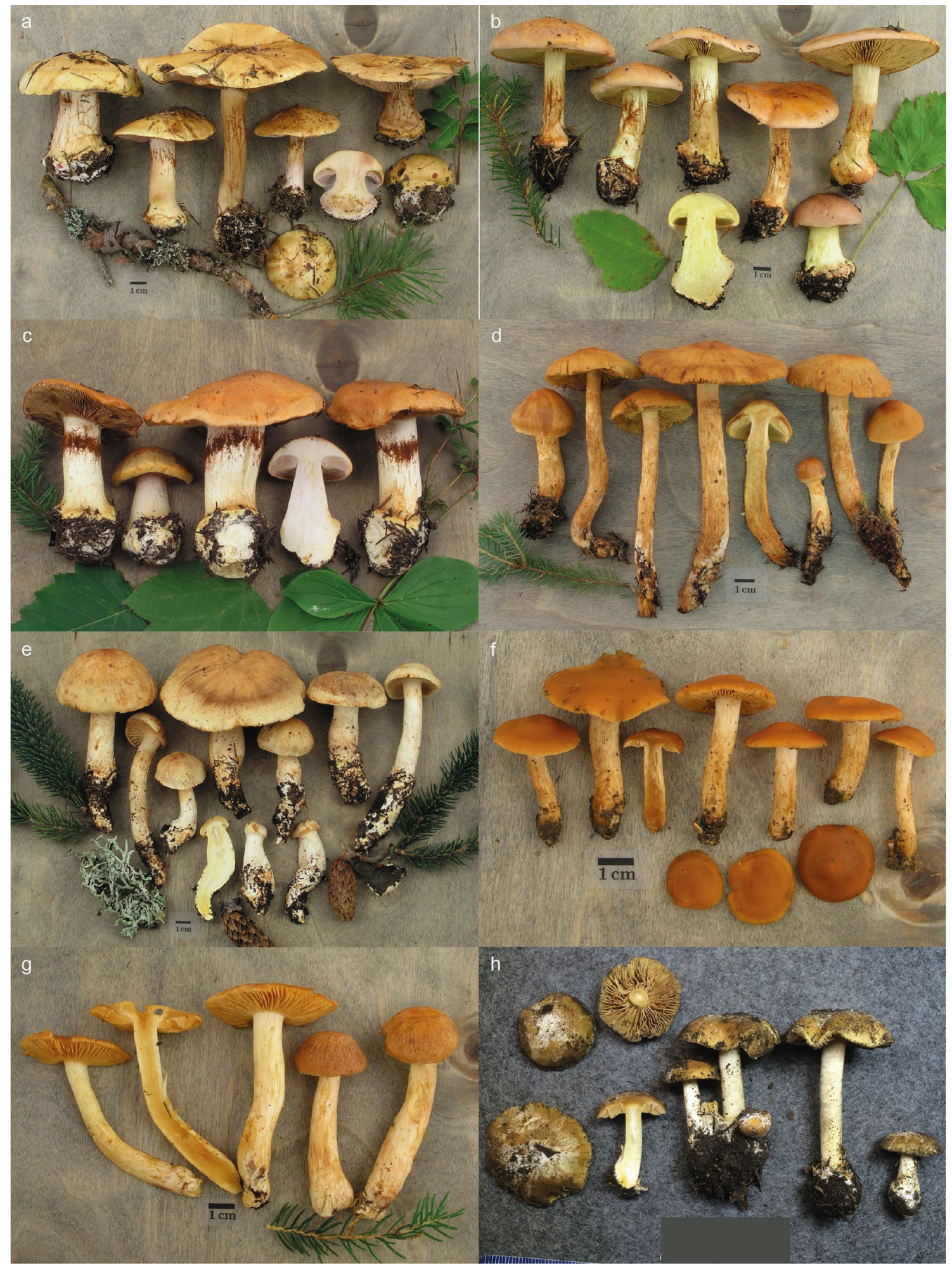

Fig. 4 Photos of the representatives of Cortinariaceae. A Calonarius subgen. Calochroi, C. metarius TN 06-268 (H), B C. subgen. Calonarius, C. odorifer TN 05-138 (H), C C. subgen. Fulvi, C. sp. TN 11-128 (H), D Aureonarius limonius, TN 07-282 (H), E Cystinarius rubiginosus TN 12-223 (H), F Hygronarius renidens TN 05-197 (H), G Mystinarius lustrabilis TN 05-218 (H), H. Volvanarius olivaceovaginatus K235015. Photos A-F K. Liimatainen, H R. Healy 
$1-2.5 \mathrm{~cm}$ wide at the apex, fusiform, cylindrical to clavate, white, in one species becoming brownish red from the apex, dry. Universal veil white, ochraceous to red brown, sparse. Context in stipe white, in pileus very pale brown to brown. Odour in lamellae indistinct. $\mathrm{KOH}$ reaction negative. Basidiospores $6.5-9 \times 3.5-4.5 \mu \mathrm{m}$, ellipsoid to amygdaloid, almost smooth to very finely and indistinctly verrucose. Lamellae with cylindrical or clavate cheilo- and pleurocystidia. Pileipellis somewhat duplex-like, the hypoderm is poorly developed but the hyphae beneath the epicutis are hypoderm-like (elements that are short and wide).

Ecology and Distribution: In the Northern and Southern Hemisphere with coniferous and deciduous trees.

Notes: The members of this small bihemispheric subgenus have medium- to large-sized, stipitocarpic, agaricoid (phlegmacioid) basidiomata with dry to somewhat viscid, \pm brown pileus and a white, dry stipe. Small, narrow basidiospores and the presence of cheilo- and pleurocystidia is also typical. The pileipellis is somewhat duplex with a poorly developed hypoderm. The species of the sister subgenus Cystinarius differ by having bright colours at least in some parts of their basidiomata and a context that stains more or less yellow when exposed.

\section{Hygronarius Niskanen \& Liimat., gen. nov.}

\section{IndexFungorum IF552519}

Current name of the type species: Hygronarius renidens (Fr.) Niskanen \& Liimat., comb. nov. IF552520. Basionym of the type species: Cortinarius renidens Fr., Epicr. syst. mycol. (Upsaliae): 308 (1838) [1836-1838]. Lectotype: Batsch, Elench. Fung., tab. 6: 23.1783 (lectotypus hic designatus, IF552494). Epitypus: Finland, Varsinais-Suomi; Lohja, herb-rich spruce forest, on calcareous ground, 20 Aug 2000, coll. I. Kytövuori 00-021, H 6107047 (epitypus hic designatus IF552495), GenBank No. OL958653 (ITS).

Etymology: Derived from the word hygrophanous, since the species of this genus have a hygrophanous pileus, and the generic name Cortinarius.

Currently included subgenera: Hygronarius and Visincisi (Fig. 4).

Description: Basidiomata small- to medium-sized, agaricoid (telamonioid), development type stipitocarpic. Pileus 1-6 cm, at first somewhat hemispherical or conical, then convex to plano-convex, with or without an umbo, yellow-brown to red-brown, dry to viscid, hygrophanous. Lamellae medium spaced to almost crowded, adnate to emarginate, pale brown to rusty brown. Stipe $2.5-9 \mathrm{~cm}$ long, $0.3-0.8 \mathrm{~cm}$ wide at the apex, cylindrical to somewhat clavate; greyish white, pale brown, brownish yellow to brown, in some species covered by silky-white fibrils when young. Universal veil white to yellow-brown, sparse to distinct. Context \pm brown. Odour in lamellae indistinct or slightly raphanoid. Basidiospores $6-10 \times 4.5-6 \mu \mathrm{m}$, subglobose, broadly ellipsoid to ellipsoid, finely to coarsely verrucose. Cystidia absent. Pileipellis duplex, hypoderm developed.

Ecology and Distribution: In the Northern and Southern Hemisphere with deciduous and coniferous trees.

Notes: This small bihemispheric genus includes small- to medium-sized, stipitocarpic, agaricoid (telamonioid) species with yellow-brown to red-brown colours. The stipe is dry and the pileus is dry or viscid and hygrophanous. The basidiospores are subglobose or ellipsoid and the pileipellis is duplex with a more or less developed hypoderm. The species are morphologically reminiscent of those in Cortinarius subgenus Iodolentes and Telamonia but are genetically distinct from them (Garnica et al. 2005; Stensrud et al. 2014) and for a well-supported clade (BS 92\%) in our phylogenetic analysis. Thus, we here recognize them as their own genus.

\section{Hygronarius subgen. Hygronarius}

IndexFungorum IF552521

Currently included sections: Hygronarius $(=C$. sect. Renidentes Moënne-Locc. \& Reumaux).

Description: Basidiomata small- to medium-sized, agaricoid (telamonioid), development type stipitocarpic. Pileus $1.5-6 \mathrm{~cm}$, at first somewhat hemispherical, then convex to plano-convex, sometimes with an umbo, red-brown, dry to viscid, hygrophanous. Lamellae medium spaced to almost crowded, adnate to emarginate, pale brown to rusty brown. Stipe $2.5-7 \mathrm{~cm}$ long, $0.3-0.6 \mathrm{~cm}$ wide at the apex, cylindrical (to somewhat clavate); greyish white, pale brown to brownish yellow, in some species covered by silky-white fibrils when young. Universal veil absent or very sparse. Context \pm brown. Odour in lamellae indistinct or slightly raphanoid. Basidiospores 6-7 ×4.5-6 $\mu \mathrm{m}$, subglobose to broadly ellipsoid, finely verrucose. Cystidia absent. Pileipellis duplex, hypoderm developed.

Ecology and Distribution: In the Northern and Southern Hemisphere with deciduous and coniferous trees.

Notes: Typical for this small bihemispheric subgenus are small- to medium-sized, stipitocarpic, agaricoid (telamonioid) basidiomata with red-brown colours, absent or sparse universal veil and subglobose to broadly ellipsoid basidiospores. They can most easily be distinguished from the species of $H$. subgen. Viscincisi by the size of the basidiospores: the basidiospores of Viscincisi species are larger, $7-10 \times 4.5-6 \mu \mathrm{m}$.

Hygronarius subgen. Viscincisi Niskanen \& Liimat., subgen. nov.

IndexFungorum IF552522

Current name of the type species: Hygronarius viscincisus (Soop) Niskanen \& Liimat., comb. nov. IF552523 Basionym of the type species: Cortinarius viscincisus Soop, Australas. Mycol. 31: 6 (2013). Holotype: PDD 97544. 


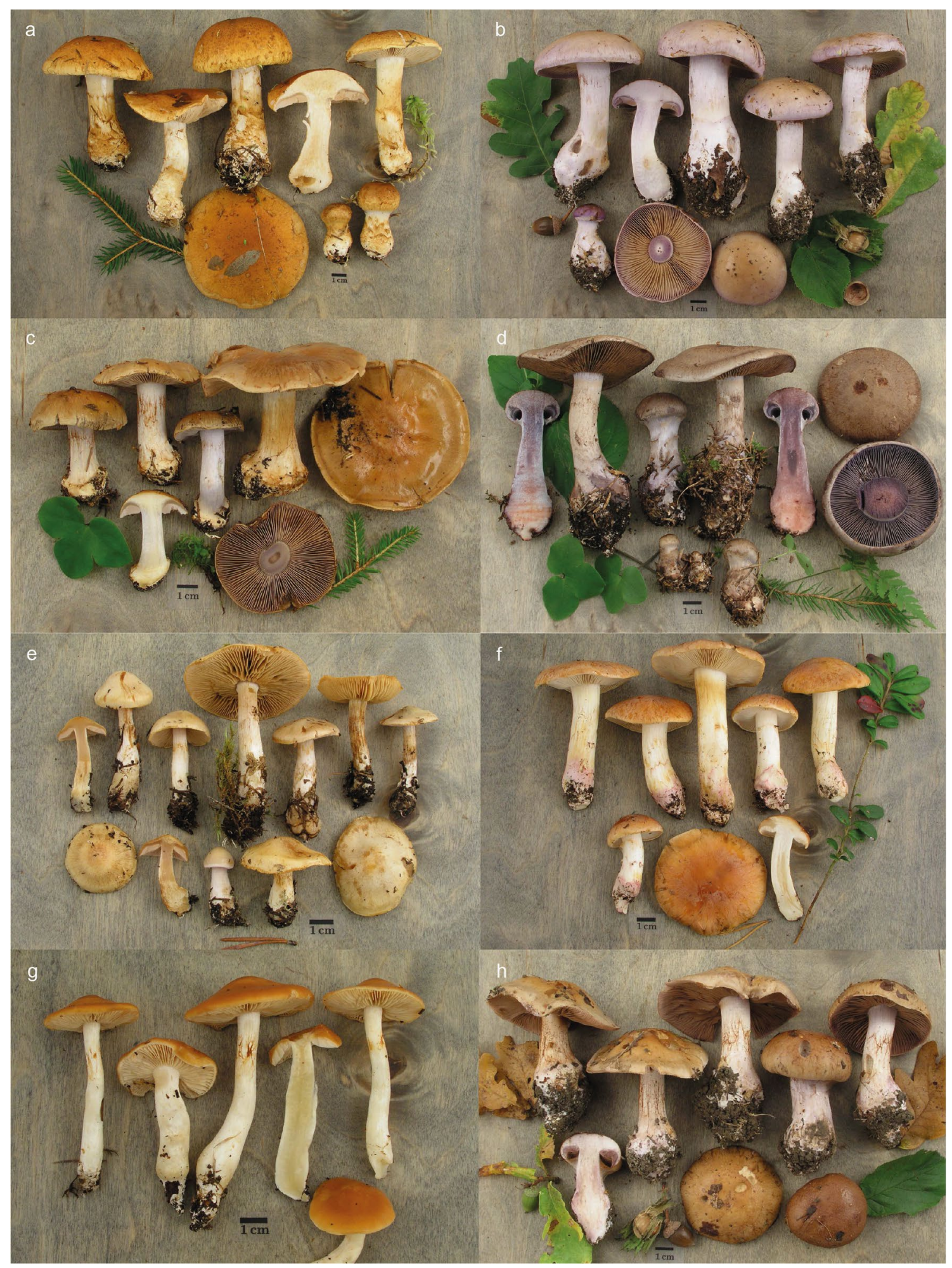

Fig. 5 Photos of the representatives of genera Phlegmacium and Thaxterogaster. A Phlegmacium subgen. Phlegmacium, $P$. saginum TN 05-232 (H), B P. subgen. Phlegmacium, P. largum TN 08-060 (H), C. P. subgen. Bulbopodium, P. olivaceodionysae TN 06-311 (H), D $P$. subgen. Cyanicium, $P$. violaceorubens TN 07-062 (H), E T. sect.
Lustrati, T. leucophanes TN 05-161 (H), F T. subgen. Variegati, T. variegatus TN 05-182 (H), G T. sect. Vibratiles, T. sp TN 05-210 (H), H T. subgen. Scauri, T. subpurpurascens TN 08-059 (H). Photos K. Liimatainen 
Etymology: Named after the type species of this genus. Currently included sections: Austroduracini, Viscincisi.

Description: Basidiomata small- to medium-sized, agaricoid (telamonioid), development type stipitocarpic. Pileus 1-6 cm, at first somewhat hemispherical or conical, then convex to plano-convex, with or without an umbo, yellow-brown to red-brown, dry to viscid, hygrophanous. Lamellae medium spaced to almost crowded, adnate to emarginate, pale brown to rusty brown. Stipe $2.5-9 \mathrm{~cm}$ long, $0.3-0.8 \mathrm{~cm}$ wide at the apex, cylindrical to somewhat clavate; greyish white, pale brown, brownish yellow to brown, in some species covered by silky-white fibrils when young. Universal veil white to yellow-brown, sparse to distinct. Context \pm brown. Odour in lamellae indistinct or slightly raphanoid. Basidiospores 7-10×4.5-6 $\mu \mathrm{m}$, ellipsoid, moderately to coarsely verrucose. Cystidia absent. Pileipellis duplex, hypoderm developed.

Ecology and Distribution: In the Southern Hemisphere in forests of Nothofagaceae.

Notes: The members of this small subgenus only occur in the Southern Hemisperic Nothofagaceae forests. The basidiomata are small- to medium-sized, stipitocarpic, agaricoid (telamonioid) with yellow-brown to red-brown colours, sparse to distinct universal veil and ellipsoid basidiospores. They can most easily be distinguished from the species of $H$. subgen. Hygronarius by the basidiospores: the basidiospores of Hygronarius species are smaller, 6-7×4.5-6 $\mu \mathrm{m}$ and subglobose to broadly ellipsoid.

Mystinarius Niskanen \& Liimat., gen. nov.

IndexFungorum IF552524

Current name of the type species: Mystinarius lustrabilis (Moënne-Locc.) Niskanen \& Liimat., comb. nov. IF552525. Basionym of the type species: Cortinarius lustrabilis Moënne-Locc., in Bidaud, Moënne-Loccoz, Reumaux \& Henry, Atlas des Cortinaires (Meyzieu) 10: 492 (2000). Holotype: PC 1226.

Etymology: Derived from the latin word "mysticus" and the generic name Cortinarius.

Currently included subgenera: Mystinarius (Fig. 4).

Description: Basidiomata medium-sized, agaricoid (myxacioid/phlegmacioid), development type stipitocarpic. Pileus 3-6 cm, at first hemispherical, then low convex, rimy fibrillose, brownish yellow to reddish brown, somewhat viscid to almost dry. Lamellae crowded to medium spaced, emarginate, yellowish brown to brown. Stipe $5-10 \mathrm{~cm}$ long, $0.7-1.2 \mathrm{~cm}$ wide at the apex, cylindrical or tapering downwards to somewhat clavate, silky fibrillose, white to yellow, dry. Universal veil white, sparse, presumably somewhat viscid. Context yellow. Odour in lamellae indistinct or sweetish. Taste in pileus context somewhat bitter. Basidiospores 8.5-9.5 $\times 5-6 \mu \mathrm{m}$, ovoid to amygdaloid, finely to moderately verrucose. Pileipellis duplex, hypoderm developed.
Ecology and Distribution: In Northern and Southern Hemisphere in coniferous and Nothofagaceae forests.

Notes: The species of this small, bihemispheric genus have medium-sized, stipitocarpic, agaricoid (myxacioid/ phlegmacioid) basidiomata with a yellow to reddish brown, somewhat viscid to almost dry pileus and a white to yellow, dry stipe. The basidiospores are medium-sized and the pileipellis is duplex. The species of this genus resemble morphologically most of those in Thaxterogaster subgenus Multiformes, T. sect. Pinophili or T. sect. Vibratiles. However, they are not closely related to Thaxterogaster or other genera of Cortinariaceae and we here propose a new genus, Mystinarius, for them.

Phlegmacium (Fr.) Wünsche, Die Pilze: 87, 128 (1877) em. Niskanen \& Liimat.

Basionym: Agaricus trib. Phlegmacium Fr., Syst. mycol. (Lundae) 1: 10, 227 ['217’] (1821).

Sanctioning citation: Fr., Syst. mycol. 1: 10 (1821).

Current name of the type species. Phlegmacium saginum (Fr.) Niskanen \& Liimat., comb. nov. IF552795. Basionym of the type species: Agaricus saginus Fr., Syst. mycol. (Lundae) 1: 226 (1821). Neotype: IB 19770098, in Melot, Docum. Mycol. XVI (63-64): 130, (1986).

Synonyms: Bulbopodium Earle, Bull. New York Bot. Gard. 5: 441 (1909). Current name of the type species: Phlegmacium caerulescens (Schaeff.) Wünsche, Die Pilze: 131 (1877). Basionym of the type species: Agaricus caerulescens Schaeff., Fung. bavar. palat. nasc. (Ratisbonae) 4: 17 (1774).

Cyanicium Locq., Fl. Mycol., 3. Cortinariales-A.: 146 (1979) [1977]. Current name of the type species: Phlegmacium cyanites (Fr.) M.M. Moser, Die Gatt. Phlegm.: 337 (1960). Basionym of the type species: Cortinarius cyanites Fr., Epicr. syst. mycol. (Upsaliae): 279 (1838) [1836-1838].

Meliderma Velen., České Houby 2: 399 (1920). Current name of the type species: Phlegmacium mussivum (Fr.) Niskanen \& Liimat., comb. nov. IF552796. Basionym of the type species: Agaricus mussivus Fr., Epicr. syst. mycol. (Upsaliae): 178 (1838) [1836-1838].

Currently included subgenera: Phlegmacium, Bulbopodium, Carbonella and Cyanicium (Fig. 5).

Description: Basidiomata medium- to large-sized, rarely small, agaricoid (phlegmacioid, rarely telamonioid), some species sequestrate, development type stipitocarpic or pileocarpic. Pileus (1-)3-12(-20) cm, at first hemispherical to convex, low convex to almost plane when old, rarely with a broad umbo; surface in some species innately fibrillose or radially wrinkled, rarely scaly or with patches of veil; from white, pale ochraceous and yellow to dark brown and umber with yellow, orange, red, greyish, greenish or purplish tints, in some species completely purple; dry, viscid or glutinous. Lamellae in the vast majority of species crowded, in some 
species medium spaced, emarginate, at first pale greyish white to purple, later pale brown to purplish brown, darker in the species of subgenus Carbonella. Stipe 3-13(-20) cm long, (0.4-)0.8-2(-3) cm wide at the apex, up to $5 \mathrm{~cm}$ at base, clavate to bulbous with a rounded or a marginate bulb, or cylindrical to rooting, in the vast majority of the species more or less white, sometimes with purplish tints, in some species grey, dry. Universal veil white, grey, yellow, greenish yellow, more or less brown or purple, sparse to abundant, forming incomplete and complete girdles on the stipe. Context in many species in pileus and stipe white, sometimes with purplish colours, in some species grey, yellow-greenish, olive-grey, pale greyish purple to vinaceous brown, in the species of subgenus Cyanicium becoming vinaceous red on exposure. Odour in lamellae indistinct or in some species raphanoid, earthy, grassy, rubbery, sweetish, fruity or farinaceous. $\mathrm{KOH}$ reaction in pileus context negative, yellow, orange, reddish lilac, olivaceous or pale brown. Basidiospores 7-12.5(-17) $\times 4-8.5(-10) \mu \mathrm{m}$, amygdaloid, ellipsoid or citriform, in some species subglobose, finely to strongly verrucose. Pileipellis duplex, simplex in $P$. subgen. Cyanicium and some lineages of $P$. subgen. Phlegmacium, epicutis in many species \pm gelatinous.

Ecology and Distribution: In the Northern Hemisphere with the species of Fagales, Pinaceae and Tilia. In the Southern Hemisphere at least in Nothofagaceae forests. The centre of the diversity is in the Northern Hemisphere: two of the four subgenera, Bulbopodium and Cyanicium, are only know from the Northern Hemisphere and the vast majority of the species of the $P$. subgenus Bulbopodium are also boreal.

Notes: This genus includes many of the species traditionally placed in the Cortinarius subgenus Phlegmacium. Typical for the species are a dry stipe and viscid to glutinous pileus, or if dry, then the $\mathrm{KOH}$ reaction in the context of the pileus is usually yellow. Most species have a pileipellis duplex with a more or less developed hypoderm but the species of the subgenus Cyanicium and some lineages of $P$. subgen. Phlegmacium have a simplex pileipellis. The species of the genus Calonarius that were previously included in this group can be distinguished from the species of the genus Phlegmacium by the combination of pileocarpic basidiomata, a marginated bulb and simplex pileipellis. For the phlegmacioid species in the genus Thaxterogaster, a distinguishing combination of characters that would work for all groups is harder to give, but as a rule the phlegmacioid species encountered in the Southern Hemisphere mainly belong to the genus Thaxterogaster and the lineages in the Northern Hemisphere that can be confused with the species of the genus Phlegmacium are subgenera Multiformes, Riederorum, Scauri and Varieagati and sections Pinophili and Vespertini. Some phlegmacioid lineages also exist in the genus Cortinarius, namely Infracti and Subtorti, but they have stipitocarpic basidiomata and round spores. The species of the small Southern Hemispheric genus Volvanarius have a phlegmacioid appearance as well, but they are small in size and the majority of the species have a volva. Some species of the genus Cystinarius may also be confused with the species of the genus Phlegmacium, but Cystinarius species have distinct cheilo- and pleurocystidia and a dry pileus. Lastly, the basidiomata of the genus Austrocortinarius resemble those in P. subgenus Phlegmacium, sect. Arguta and clades/Obsoleti and Caligati but those lineages of Phlegmacium are only known from the Northern Hemisphere whereas the genus Austrocortinarius occurs in the South Pacific.

\section{Phlegmacium subgen. Phlegmacium}

Currently included sections: Phlegmacium, Arguta, Claricoloria, Elastica, Obsoleta, Phlegmacioida, Percomia, Rhizophora, Seraria, and Varia as well as clade/Caligata.

Notes: The centre of the diversity of this species-rich lineage is in the Northern Hemisphere but some members of the group are also encountered in the Southern Hemisphere. Basidiomata are medium- to large-sized, predominantly stipitocarpic, agaricoid (phlegmacioid). The stipe is dry, and the pileus is viscid to glutinous, or if dry then the $\mathrm{KOH}$ reaction in the context of the pileus is usually yellow. The pileipellis is either duplex or simplex. The members of the other species-rich subgenus, Bulbopodium, have mainly pileocarpic basidiomata.

\section{Phlegmacium subgen. Bulbopodium (Earle) Niskanen \& \\ Liimat., comb. \& stat. nov. \\ IndexFungorum IF552797 \\ Basionym: Bulbopodium Earle, Bull. New York Bot.} Gard. 5: 441 (1909).

Current name of the type species: Phlegmacium caerulescens (Schaeff.) Wünsche, Die Pilze: 131 (1877). Basionym of the type species: Agaricus caerulescens Schaeff., Fung. bavar. palat. nasc. (Ratisbonae) 4: 17 (1774). Lectotype: Schaeffer, Fung. Bav. 1: Tab. 34, figs I, II, III, 1762, in Brandrud et al., Cortinarius Flora Photographica II, pl. B11 (1992). Epitype: S F-44815, in Liimatainen et al., Persoonia 33:118 (2014).

Currently included sections: Amoenolentia, Arcifolia, Aureocistophila, Bulbopodium (=Caerulescentes ss. Soop et al. 2019), Caerulea (=/Eucaerulei ss. Soop et al. 2019), Caerulescentia (=/Camptori ss. Soop et al. 2019), Dionysae, Glaucocephala, Glaucopodes, Subhymenogaster, and Taura.

Notes: Representatives of this species-rich subgenus are thus far only known from the Northern Hemisphere. Basidiomata are medium- to large-sized, predominantly pileocarpic, agaricoid (phlegmacioid) or rarely sequestrate. The pileus is viscid to glutinous, and the stipe is dry. The 
members of the other species-rich subgenus, Phlegmacium, have mainly stipitocarpic basidiomata and some species also have a yellow to pale brown $\mathrm{KOH}$ reaction in the pileus context.

\section{Phlegmacium subgen. Carbonella (Soop) Niskanen \& Liimat., comb. \& stat. nov. IndexFungorum IF553054}

Basionym: Cortinarius sect. Carbonelli Soop, in Soop, Dima, Cooper, Park \& Oertel, Persoonia 42: 286 (2019). Current name of the type species: Phlegmacium carbonellum (Soop) Niskanen \& Liimat., comb. nov. IF552947. Basionym of the type species: Cortinarius carbonellus Soop, Bull. Soc. mycol. Fr. 117(2): 120 (2001). Holotype: PDD 70502.

Currently included sections: Carbonella.

Notes: The species of this subgenus occur in the Nothofagaceae forests of New Zealand. The species are characterized by small-sized, agaricoid (telamonioid), stipitocarpic basidiomata with dark grey-brown to bluish-grey, or purple-brown to umber colours and dry, hygrophanous pileus and dry stipe. The universal veil is pale grey-brown, purple to pale brownish-red and sparse. The alkaline reaction is orange to reddish-lilac in the context and red on lamellae (Soop 2017; Soop et al. 2019). Morphologically the species of this subgenus are most reminiscent of those in Cortinarius subgenus Telamonia (dry pileus and stipe, development type of the basiodiomata stipitocarpic) but phylogenetically the subgenus is most closely related to the genus Phlegmacium (pileus viscid to glutinous, or if dry then KOH-reaction usually yellow, stipe dry, development type of the basiodiomata stipito- or pileocarpic). Since they represent a well-supported lineage within the genus Phlegmacium and are morphologically distinct from their closest relatives we here recognize them in a subgeneric level.

\section{Phlegmacium subgen. Cyanicium (Locq.) Niskanen \& \\ Liimat., comb. \& stat. nov. \\ IndexFungorum IF553369}

Basionym: Cyanicium Locq., Fl. Mycol., 3. Cortinariales-A.: 146 (1979) [1977].

Current name of the type species: Phlegmacium cyanites (Fr.) M.M. Moser, Die Gatt. Phlegm.: 337 (1960). Basionym of the type species: Cortinarius cyanites Fr., Epicr. syst. mycol. (Upsaliae): 279 (1838) [1836-1838]. Neotype: S, Taylor 2005069, in Liimatainen et al., Persoonia 33:118 (2014).

Currently included sections: Cyanicium.

Notes: This small Northern Hemispheric subgenus includes species with a unique combination of characters: basidiomata are (medium- to) large-sized, agaricoid (phlegmacioid) and stipitocarpic with greyish-blue, greyish-brown to darker purplish-brown colors. The pileus is at first viscid but soon dry. A context that becomes vinaceous-red on exposure and lamellar trama hyphae with abundant small to large to worm-like blood red guttules in Melzer's reagent is typical. The $\mathrm{KOH}$ reaction is negative in the context and the pileipellis structure is simplex.

Thaxterogaster Singer, Mycologia 43(2): 216 (1951) em. Niskanen \& Liimat.

Current name and basionym of the type species: Thaxterogaster magellanicus Singer [as 'magellanicum'], Mycologia 43(2):219. 1951. Neotype: Argentina, Tierra del Fuego, Ushuaia, los Humedales, under Nothofagaceae, $16 \mathrm{Feb}$ 2015, L. Domínguez LSD2380b, CORDC00006504, GenBank no. MN855076 (ITS), in Nouhra et al., Mycologia 113: 1040 (2021).

Synonyms: Gigasperma E. Horak, N.Z. Jl Bot. 9(3): 491 (1971). Current name of the type species: Thaxterogaster crypticus (E. Horak) Niskanen \& Liimat.

Hygramaricium Locq., Fl. Mycol., 3. CortinarialesA.: 146 (1979) [1977]. Current name of the type species: Thaxterogaster causticus (Fr.) Niskanen \& Liimat., comb. nov. IF552948. Basionym of the type species: Cortinarius causticus Fr., Epicr. syst. mycol. (Upsaliae): 270 (1838) [1836-1838]. Neotype: $6031321(\mathrm{H})$, in Niskanen et al., Index Fungorum 477: 3 (2021).

Rapacea E. Horak, Kew Bull. 54(3): 789 (1999). Current name of the type species: Thaxterogaster mariae (E. Horak) Niskanen \& Liimat., comb. nov. IF552949. Basionym of the type species: Rapacea mariae E. Horak, Kew Bull. 54(3): 789 (1999). Holotype: PDD 69747.

Currently included subgenera: Thaxterogaster, Cretaces, Multiformes, Riederorum, Scauri, and Variegati (Fig. 5).

Description: Basidiomata small- to large-sized, agaricoid (phlegmacioid, myxacioid) or sequestrate, development type stipitocarpic to pileocarpic. Pileus $1-12 \mathrm{~cm}$, at first hemispherical, then convex to plano-convex; surface smooth, innately fibrillose or somewhat scaly; \pm white, \pm yellow, pale to dark brown with greyish, ochraceous or reddish tints, umber to blackish, \pm purple or with a purplish tint, some species with olivaceous colours; dry, viscid or glutinous, with hygrophanous spots or streaks or non-hygrophanous. Lamellae crowded to medium spaced, adnate, adnexed or emarginate; when young white, pale grey, pale brown, green, \pm purple or with a purplish tint. Stipe $4-13 \mathrm{~cm}$ long, $0.3-2.5 \mathrm{~cm}$ wide at the apex, up to $5 \mathrm{~cm}$ at the base; cylindrical, clavate, rooting or bulbous, bulb rounded to \pm marginate; white, pale brown, \pm purple, some species with greenish colours, in species of sect. Purpurascentes usually turning deeper purple when bruised, dry. Universal veil white, purplish white, purple, in some species turning pink; sparse to more abundant, in pileocarpic species at the bulb margin and pileus margin, in stipitocarpic species forming a 
thin sock-like sheet or incomplete and complete girdles on the stipe, usually dry but in some species viscid. Context in pileus white, pale brown, purple or dark blue/blackish green, in stipe white, \pm yellow, pale brown, \pm purple or with purplish or green/olivaceous colours. Odour in lamellae indistinct, in the context of the stipe indistinct, honey-like or sweet, garlic-like in $T$. crypticus. $\mathrm{KOH}$ reaction negative or red in pileus, context and/or stipital veil. Basidiospores $6-18 \times 3.5-9 \mu \mathrm{m}$, subglobose, amygdaloid, fusoid to ellipsoid, finely to strongly verrucose (subglobose, smooth and very large in T. crypticus $25-35 \mu \mathrm{m}$ in diam.). Cystidia absent. Pileipellis duplex, hypoderm present.

Ecology and Distribution: In the Northern Hemisphere with species of Fagaceae, Betulaceae, Tilia and Pinaceae. In the Southern Hemisphere in Nothofagaceae forests.

Notes: The species of this bihemispherical genus have traditionally been classified in phlegmacioid and myxacioid taxa in genus Cortinarius or in sequestrate genera/ taxa. The size of the basidiomata ranges from small to large and vary in coloration from white, ochraceous, greenish, brown to purple. Typical for all agaricoid species, however, is a pileipellis duplex and a negative or, more rarely, red (in pileus, context and/or stipital veil) KOH reaction. Several lineages of this genus have a honey-like or sweet smell in the context, not typical in other genera of the family Cortinariaceae and otherwise known only in Cortinarius subgenus Myxacium. The development type of basidiomata ranges from stipitocarpic to pileocarpic.

\section{Thaxterogaster subgen. Thaxterogaster}

Currently included sections: Alboaggregati, Thaxterogaster.

Description: Basidiomata medium- to large-sized, agaricoid (phlegmacioid) or sequestrate, development type stipitocarpic. Pileus 3.5-7.5(-12) cm, at first hemispherical, then convex to plano-convex, with an umbo, finely fibrillose, white, yellow-brown or with purplish tint, dry to viscid. Lamellae crowded, adnate to adnexed to emarginate, white to greyish white. Stipe 4-10 cm long, 1-2 cm wide at the apex, cylindrical to rooting; white. Universal veil white, rather abundant in agaricoid species, peronate, sometimes forming a small collar. Context white. Odour in lamellae indistinct. Basidiospores 10.5-17.5 ×5.5-9.5 $\mu \mathrm{m}$, fusoid-amygdaloid to ellipsoid, moderately verrucose. Cystidia absent.

Ecology and Distribution: In New Zealand and South America, in Nothofagaceae forests.

Notes: This small Southern Hemispheric subgenus includes medium- to large-sized, stipitocarpic, agaricoid (phlegmacioid) and sequestrate species. The pileus is viscid and the stipe is cylindrical to rooting. The species resemble those in South American T. subgenus Cretaces but the species of subgenus Cretaces have smaller basidiospores $(6-10 \times 3-5.5 \mu \mathrm{m})$ and a sparse universal veil.

Thaxterogaster subgen. Cretaces (Soop \& Dima) Niskanen \& Liimat., comb. et stat. nov.

IndexFungorum IF552950

Basionym: Cortinarius sect. Cretaces Soop \& Dima, in Soop, Dima, Cooper, Park \& Oertel, Persoonia 42:279. 2019. Current name of the type species: Thaxterogaster cretax (Soop) Niskanen \& Liimat., comb. nov. IF552951. Basionym of the type species: Cortinarius cretax Soop, Bull. Soc. Mycol. Fr. 118(3):185. 2003. (2002). Holotype: PDD 73148.

Currently included sections: Cretaces.

Notes: The representatives of this small subgenus are only encountered in the Southern Hemisphere. The basidiomata are medium- to large-sized, stipitocarpic, agaricoid (phlegmacoid) with a viscid pileus and a dry stipe. The colour of the pileus ranges from white to yellow-brown, lamellae are white to pale grey and crowded, the stipe is usually rooting and the universal veil is sparse. The odour in the lamellae is indistinct or marzipan-like. Basidiospores are fusoid-amygdaloid, 6-10×3-5.5 $\mu \mathrm{m}$ and weakly verrucose. The species are most reminiscent of those in $T$. subgen. Thaxterogaster but the agaricoid species in subgenus Thaxterogaster have larger basidiospores and more abundant universal veil.

\section{Thaxterogaster subgen. Multiformes Niskanen \& Liimat.,} subgen. nov.

IndexFungorum IF552952

Current name of the type species: Thaxterogaster caesiophylloides (Kytöv., Liimat., Niskanen, Brandrud \& Frøslev) Niskanen \& Liimat., comb. nov. IF552953. Basionym of the type species: Cortinarius caesiophylloides Kytöv., Liimat., Niskanen, Brandrud \& Frøslev, in Liimatainen, Niskanen, Dima, Kytövuori, Ammirati \& Frøslev, Persoonia 33: 130. 2014. Holotype: H 6029792.

Etymology: Named after C. multiformis, a species belonging to this subgenus.

Currently included sections: Multiformes.

Description: Basidiomata medium- to large-sized, agaricoid (phlegmacioid), development type pileocarpic. Pileus 4-12 cm, at first hemispherical, then convex to plano-convex, in some species innately fibrillose, white, cream-coloured, pale yellow, ochraceous yellow, orange-yellow, greybrown or red brown, rarely bluish brown, viscid to glutinous, with hygrophanous spots or streaks. Lamellae crowded to almost crowded, emarginate, at first greyish white, later very pale greyish brown, in some species with a bluish tint. Stipe $4-13 \mathrm{~cm}$ long, $0.7-2 \mathrm{~cm}$ wide at the apex, up to $3.5 \mathrm{~cm}$ at the base, clavate to bulbous, bulb rounded to slightly marginate, rarely almost cylindrical, at first white, later pale brown, in some species with a bluish tint at the apex, dry. Universal 
veil white, sparse, at the bulb margin, rarely somewhat viscid. Context in pileus white or pale brown to brown near the pileus surface, in stipe white, in some species with a bluish tint at the apex of the stipe. Odour in the flesh of the bulb and/or stipe honey-like. $\mathrm{KOH}$ reaction negative. Basidiospores 7.5-11 $\times 4.5-6.5 \mu \mathrm{m}$, ovoid-amygdaloid, amygdaloid, fusoid to ellipsoid, finely to rather strongly verrucose. Cystidia absent. Pileipellis duplex, epicutis with a glutinous layer on the top, hypoderm present.

Ecology and Distribution: In the Northern Hemisphere with coniferous (Pinaceae) and deciduous trees (Fagaceae, Betulaceae).

Notes: The species of this Northern Hemispheric subgenus are medium- to large-sized and phlegmacioid with a viscid to glutinous pileus and a dry stipe. They are characterised by having a pileocarpic development type of the basidiomata, pileipellis duplex, greyish-white lamellae when young and a honey-like smell in the context. In addition, the colour of the pileus ranges from cream-coloured to yellowochraceous to red-brown and the stipe is white. Some species have bluish tints in their basidiomata. The phylogenetic analysis of Soop et al. (2019) indicated that morphologically similar species of $T$. sect. Cremeolini could also belong to this subgenus as well as species of sect.Malvacei Moser, but the group did not receive strong support.

\section{Thaxterogaster subgen. Riederorum Niskanen \& Liimat.,} subgen. nov.

\section{IndexFungorum IF553567}

Current name of the type species: Thaxterogaster malachioides (P.D. Orton) Niskanen \& Liimat., comb. nov. IF553568. Basionym of the type species: Cortinarius malachioides P.D. Orton, Naturalist, Leeds (Suppl.): 148. 1958. Holotype: K(M) 94426.

Etymology: Named after $C$. riederi, a species belonging to this subgenus.

\section{Currently included sections: Riederorum.}

Description: Basidiomata medium- to large-sized, agaricoid (phlegmacioid), development type pileocarpic. Pileus 2.5-12 cm, at first hemispherical, then convex to planoconvex, innately fibrillose; cream-coloured, greyish white, pale grey, yellow ochraceous, ochraceous brown, fulvous brown or grey-brown, sometimes with an olivaceous tint; viscid to glutinous, in some species with hygrophanous spots or streaks. Lamellae crowded, emarginate, at first violetblue, later greyish brown. Stipe 5-12 cm long, 0.7-2.5 cm wide at the apex, up to $5 \mathrm{~cm}$ at the base; clavate to bulbous, bulb rounded to \pm marginate; at first white with a bluish tint to completely bluish violet, later greyish white to pale ochraceous brown, becoming \pm brown if damaged, bruised or with age, dry. Universal veil bluish white, very sparse, remnants, if visible, near the bulb margin and on the pileus margin. Context in pileus and bulb bluish white to white, in stipe bluish white to bluish violet, violet colour fading with age. Odour in lamellae indistinct. $\mathrm{KOH}$ reaction negative. Basidiospores 10-14.5×6-9 $\mu \mathrm{m}$, ellipsoid to amygdaloid, moderately to strongly verrucose. Cystidia absent. Pileipellis duplex, epicutis with a glutinous layer on the top, hypoderm present, well to somewhat developed.

Ecology and Distribution: In the Northern Hemisphere with coniferous (Pinaceae) and deciduous trees (Fagaceae, Betulaceae, Tilia).

Notes: The species of this small Northern Hemispheric subgenus are characterized by having medium- to largesized, agaricoid (phlegmacioid), pileocarpic basidiomata with a viscid to glutinous, innately fibrillose pileus, dry stipe and bluish-violet colours in the lamellae and stipe. Typical are also large ( $>10 \mu \mathrm{m}$ long) ellipsoid to amygdaloid basidiospores, a negative $\mathrm{KOH}$-reaction and pileipellis duplex. For a recent morpho-genetic revision of the group see Brandrud et al. (2018).

Thaxterogaster subgen. Scauri Niskanen \& Liimat., subgen. nov.

IndexFungorum IF553569

Current name of the type species: Thaxterogaster herpeticus (Fr.) Niskanen \& Liimat., comb. nov. IF553570. Basionym of the type species: Cortinarius herpeticus Fr., Epicr. syst. mycol. (Upsaliae): 268. 1838 (1836-1838). Neotype: S F-44759, in Liimatainen et al., Persoonia 33:119 (2014).

Etymology: Named after C. scaurus, a species belonging to this subgenus.

Currently included sections: Scauri and Purpurascentes.

Description: Basidiomata medium- to large-sized, agaricoid (phlegmacioid), in T. sect. Purpurascentes some species sequestrate, development type pileocarpic (Scauri) or somewhat stipitocarpic to stipitocarpic (Purpurascentes). Pileus $1-10 \mathrm{~cm}$, at first hemispherical, then convex to plano-convex; surface innately fibrillose or not; greyish white, pale (greyish) ochraceous, pale ochraceous brown, olivaceous brown, red brown, dark brown, blackish brown, purplish grey or pale purple; viscid to glutinous, many species with hygrophanous spots or veins. Lamellae crowded to medium spaced, emarginate, greyish brown, green to olivaceous, soon brown, in part of the species with a purplish tint, completely purple or bluish grey. Stipe 3-12 cm long, $0.3-2 \mathrm{~cm}$ wide at the apex, up to $3.5 \mathrm{~cm}$ at the base; cylindrical, clavate or more or less bulbous, bulb usually \pm marginate; at first pale greyish purple/blue, pale purple to purplish green, later yellowish grey, yellow-brown or purple, in species of sect. Purpurascentes usually turning deeper purple when bruised, dry. Universal veil green, purple, ochraceous yellow or white, sparse to more abundant, in pileocarpic species at the bulb and pileus margin, in stipitocarpic species forming a sock/like sheet or incomplete and/or complete girdles on the stipe. Context in pileus white, brownish white, 
pale brown, purple or dark blue/blackish green, in stipe pale purple, greenish purple, pale olivaceous to yellow-green. Odour in the context of the stipe honey-like or sweet in many species. $\mathrm{KOH}$ reaction negative, in a few species blood red on pileus and/or stipital veil (Soop 2017). Basidiospores 7-12 $\times 4.5-7 \mu \mathrm{m}$, broadly ellipsoid, ellipsoid to amygdaloid, moderately to coarsely verrucose. Cystidia absent. Pileipellis duplex, epicutis with a glutinous layer on the top, hypoderm present.

Ecology and Distribution: In the Northern Hemisphere with coniferous (Pinaceae) and deciduous trees (Fagaceae, Betulaceae, Tilia), and in the Southern Hemisphere in Nothofagaceae forests.

Notes: Typical for the species of this bihemispheric subgenus are medium- to large-sized, agaricoid (phlegmacioid) basidiomata with purplish and/or greenish tints/colours and a pileipellis duplex. The pileus is viscid to glutinous, and the stipe is dry, and many species have a honey-like or sweet smell in the context. The iodine (lugol) reaction is positive in the context and lamellae (Garnica et al. 2005; Soop et al. 2019). The development type of the basidiomata is pileocarpic or stipitocarpic, or for at least 14 Australian species sequestrate..

\section{Thaxterogaster subgen. Variegati Niskanen \& Liimat.,} subgen. nov.

IndexFungorum IF553571

Current name of the type species: Thaxterogaster variegatus (Bres.) Niskanen \& Liimat., comb. nov. IF553573. Basionym of the type species: Cortinarius variegatus Bres., Fung. trident. 1(4-5):56. 1884. Lectotype: Bresadola, Fung. trident. 1(4-5): tab. LXII, 1884 (lectotypus hic designatus, IF553574). Epitype: Finland, Kuusamo; Oulanka biological station, dry pine heath forest (Pinus sylvestris) on sandy soil, 20 Sept. 2005, coll. K. Liimatainen \& T. Niskanen, 05-182, H 6031519 (epitypus hic designatus IF553602), GenBank No. OL985940 (ITS).

Currently included sections: Variegati.

Description: Basidiomata medium- to large-sized, agaricoid (phlegmacioid), development type \pm stipitocarpic. Pileus $3.5-10 \mathrm{~cm}$, at first hemispherical then plano-convex; surface rimy at least when young: red-brown, darker from the centre; viscid to glutinous, with some hygrophanous spots. Lamellae crowded, adnexed to emarginate, greyish white to pale grey. Stipe $5-15 \mathrm{~cm}$ long, $1-1.5 \mathrm{~cm}$ wide at the apex, up to $2 \mathrm{~cm}$ at the base; cylindrical, clavate to bulbous, bulb marginate or not; silky-fibrillose, white, dry. Universal veil at first white, later pink to purplish pink, forming a thin sheet or some girdles on the $1 / 3$ lowest part of the stipe. Context white. Odour in lamellae indistinct. $\mathrm{KOH}$ reaction negative. Basidiospores 6-8 $\times 3-4 \mu \mathrm{m}$, amygdaloid-fusoid, smooth to finely verrucose. Cystidia absent. Pileipellis duplex, hypoderm present.
Ecology and Distribution: In the Northern Hemisphere with coniferous (Pinaceae) and more rarely with deciduous trees (Fagaceae).

Notes: The most characteristic features of this monotypic boreal subgenus are the initially white universal veil that becomes pinkish with age and small, almost smooth amygdaloid-fusoid spores. In addition, the basidiomata are medium- to large-sized, the development type is \pm stipitocarpic and the pileipellis has a well-developed hypoderm. The pileus is red-brown, and the stipe is white. Our phylogenetic analysis also suggests that $T$. sect. Turmales could be included in this subgenus, but the relationship is not wellsupported. Section Turmales includes morphologically similar species with small ( $<9 \mu \mathrm{m}$ long), amygdaloid-fusoid, finely verrucose spores, and in at least one species of the section, $C$. turmalis, the mycelium becomes rose-coloured after exposure to air.

\section{Volvanarius Niskanen \& Liimat., gen. nov.}

\section{IndexFungorum IF553603}

Current name of the type species: Volvanarius chlorosplendidus (Furci, Niskanen, San-Fabian, Liimat. \& Salgado Salomón) Niskanen \& Liimat., comb nov. IF553604. Basionym of the type species: Cortinarius chlorosplendidus Furci, Niskanen, San-Fabian, Liimat. \& Salgado Salomón, in Liimatainen, Niskanen, San-Fabian, Mujic, Peintner, Dresch, Furci, Nouhra, Matheny \& Smith, Mycologia 112(2): 335. 2020. Holotype: K(M) 235086.

Etymology: Derived from the word volva, that many species of this genus have, and the generic name Cortinarius.

Currently included subgenera: Thaumasti, Volvanarius (Fig. 4).

Description: Basidiomata small- to rather small-sized, agaricoid (phlegmacioid) or rarely sequestrate, development type pileocarpic. Pileus $1.5-6 \mathrm{~cm}$, at first hemispherical, then low convex to almost plane, yellow, ochraceous, ochraceous brown, orange-brown, olive brown to greenish, dry or viscid. Lamellae medium crowded to almost crowded, adnate, at first very pale brownish grey, later pale greyish brown. Stipe 3-8.5 cm long, $0.4-1.2 \mathrm{~cm}$ wide at the apex, cylindrical, with a bulbous base (up to $2.5 \mathrm{~cm}$ ), with silky fibrillose surface, white, pale yellow, or pale greenish. Universal veil white or ochraceous, in some species with orange spots, often forming a volva at the base of the stipe. Context in most species white with ochraceous, greenish or brownish tints, in some species context in pileus brown. Odour in lamellae indistinct. Chemical reactions: context of the bulb turns red with ammonia (Moser and Horak 1975; Soop et al. 2019). Basidiospores 7-11.5 $\times 4-6.5 \mu \mathrm{m}$, citriform to amygdaloid, rarely ellipsoid, finely to strongly verrucose. Cystidia (cheilocystidia) balloon-shaped, present in some species. Pileipellis duplex, hypoderm developed. 
Ecology and Distribution: In the Southern Hemisphere with species of Nothofagaceae.

Notes: This small genus is only known from the Southern Hemispheric Nothofagaceae forests. Members of this group can easily be identified in the field by the small and Phlegmacium-like basidiomata with a bulbous stipe, and the universal veil that in most species forms a distinct volva at the base of the stipe. Typical are also citriform to amygdaloid, rarely ellipsoid basidiospores and pileipellis duplex. A few species have balloon-shaped cheilocystidia. For a recent morphogenetic revision of $C$. sect. Thaumasti see Liimatainen et al. (2020b).

\section{Discussion}

\section{Which criteria make a good genus?}

The primary criterion for recognizing a taxonomic rank such as genus is a natural, monophyletic group of species that is supported, for a given phylogenetic analysis. However, the rank and what other criteria should be used to delimit it are more or less subjective. Ultimately, the aim is to find a community consensus for practical solution to describing diversity. At least in species-rich fungal groups, monophyletic clades with good support often exist at different nested levels for a given phylogeny and there are, therefore, multiple ways in which generic limits could be drawn.

A genus is usually also defined by its morphological, chemical, or ecological characteristics that distinguish it from its relatives. Our proposed classification is largely inline with circumscription of other genera in the same order based on a combination of phylogenetic, morphological, chemical, and ecological traits. Although a universal set of objective criteria is not realistic for classifying all life with its multitudes of variation, the objective of achieving both coherence and practicality in recognizing evolutionary uniqueness of the generic rank within a higher taxon could be applied at approximately the same level of inclusiveness. This ideal exists not only because a basic assumption is that a certain taxonomic rank reflects a level of cohesion around a similar set of traits and phylogenetic patterns, but also because in practice it makes comparisons between different genera across different groups of organisms (e.g., in ecological, evolutionary, and conservation studies) more meaningful.

One additional aspect to take into consideration when delimiting genera is the amount of diversity to be included. Within reason, monotypic genera should be avoided, since the general aim of classification above the species level is to group closely related units together towards increasingly larger units, so that each taxonomic level, with cumulative inclusiveness, would deliver information that is something more than the previous unit. In practise, however, monotypic entities are hard to completely avoid since some clades are just less diverse than others. On the opposite end, if made possible by the other criteria above, we also try to avoid overly diverse entities in which we run out of infrageneric taxonomic ranks, i.e., subgenera and sections, to classify the distinct monophyletic groups identified within the genus. When delimiting genera, we aim to find a balance between the number of genera and the amount of diversity they include.

The trend in fungal taxonomy, after the introduction of molecular tools, has in many cases been towards smaller and natural genera (e.g., Buyck et al. 2008, Sánchez-García et al. 2014, Matheny et al. 2020). The work is still ongoing and it would be important that all genera would go through the same re-evaluation so that, in the end, we would be applying a similar set of criteria for recognizing genera across higher fungal taxa. This process has and will, without a doubt, lead to nomenclatural changes, but the end result should be improvement-a natural, more meaningful, and stable classification that will provide a good framework for understanding and classifying fungal diversity in an evolutionary context.

\section{Generic delimitation within Cortinariaceae}

\section{Current delimitation of the genus Cortinarius and associated problems}

The size of genus Cortinarius with thousands of species and tremendous morphological variation among them have contributed to a poor understanding of their true diversity and evolutionary relationships. Even at local scales, Cortinarius has often been too diverse to manage accurately as a whole and taxonomists have tended to specialize on certain groups. For example, in Funga Nordica (Niskanen et al. 2008) Cortinarius is the only genus in which different authors have written different subkeys of the genus.

The idea of splitting the genus Cortinarius into several genera is not a new one. Based on morphological data, different genera-i.e., Dermocybe, Phlegmacium, and Rozites - have been recognized in the past (e.g., Moser 1960; Moser and Horak 1975). The main issue with all previous classifications, however, has been that they were either unnatural or keeping them would have led to the splitting of the genus into far too many, upractical entities. Alternative solutions on how to divide the genus into natural units have not been possible until now, because the phylogenetic studies done so far have not been able to resolve the deeper nodes of the phylogeny, beyond the section level (e.g., Peintner et al 2004; Garnica et al. 2005; Soop et al. 2019).

If we look at how the current situation lines with other families in the suborder Agaricineae, the ectomycorrhizal 
family Inocybaceae provides a good point of reference for a comparison. It is a species-rich family, around 2600 species are recognized based on ITS sequence data using an SH threshold of $1.5 \%$ in UNITE (2021). Before its most recent molecular revisions (Matheny and Bougher 2006; Alvarado et al. 2010; Matheny et al. 2020), it used to be a monotypic family including one genus, Inocybe. Now, the family is delimited into seven genera based on morpho-genetic data.

If the current system to delimit genus Cortinarius is neither practical nor does it align well with comparable genera in the suborder, the reasonable conclusion would be to split the genus. It is hard to see a reason, other than keeping nomenclatoric stability, to maintain Cortinarius as a single genus.

\section{New classification proposed and justification for the new generic delimitations}

Here we propose the classification of family Cortinariaceae into ten genera-Aureonarius, Austrocortinarius, Calonarius, Cortinarius, Cystinarius, Hygronarius, Mystinarius, Phlegmacium, Thaxterogaster, and Volvanariusbased on the phylogenomic analysis of 75 single-copy nuclear orthologs from 19 species, complemented with a wider 5-locus analysis of 245 recognized species. There are names already in existance for the three largest genera, as well as three to eleven generic level synonyms. Where several names of a genus are possible, the most ancient synonym must be chosen (Art. 11.4, 52.1), which explains why a name like Thaxterogaster now applies to a large taxon with only some gastroid members. Seven genera are described as new to science. The position of Stephanopus within suborder Agaricineae, for which no sequence data exist, remains to be studied. The genera have been delimited (i) to be the largest monophyletic units with statistical support, (ii) to be supported by morphological traits, (iii) to facilitate classification of Cortinariaceae diversity into infrageneric ranks, (iv) to avoid oversplitting, and (v) to be in line with other genera of gilled macrofungi.

To strike a balance between the number of genera and the amount of morphological and species diversity they include, a few exceptions to the principles above have been made. For example, we propose that the small telamonioid subgenus Carbonella should be included in an otherwise rather uniform genus Phlegmacium, because treating Carbonella as a separate genus would have required the division of the genus Phlegmacium into four separate genera. Also, the genus Cortinarius s. str. has been kept as one unit, rather than further split it into several smaller genera, even though morphologically it still is quite a variable genus (and six out of eleven entities currently recognized as subgenera already have a generic level name), because many relationships still remain unresolved and many species are not currently included in any well-supported group.

Based just on monophyly, the phylogeny would have allowed us to propose also other solutions for the generic classification within family Cortinariaceae. We could have delimited just two genera, Thaxterogaster and Cortinarius, but that would not have led to any major taxonomic improvements that accurately capture the morphological variation contained within a single genus. Also, having five genera-Thaxterogaster, Hygronarius, Austrocortinarius, Cortinarius, and Phlegmacium — could have been an option. However, in this scenario, the species-rich genera Phlegmacium and Calochroi, as well as the smaller Aureonarius, Cystinarius, and Mystinarius (all entities with morphological characteristics that make them easily distinguishable from one another) would have been grouped together.

All genera recognized have a combination of morphological traits that distinguish them from their closely related taxa. The smaller genera are more uniform morphologically and thus more easily defined and recognized. Additionally, one of the four species-rich genera, Calonarius, is also morphologically very uniform. However, the three largest genera contain clades that differ morphologically from the others within that genus. This broadens the infrageneric variation and affects the diagnostic value of the generic descriptions, although the vast majority of the species in those genera can still be distinguished based on morphology from members of other genera.

An estimation of the species diversity in the ten putative genera of Cortinariaceae is given in Table 3. Genus Cortinarius s. str. still remains the largest genus in the family, with $\geq 2000$ species estimated worldwide, classified into eleven subgenera and more than a hundred sections. In the Northern Hemisphere, the next most species-rich genera are Phlegmacium (four subgenera, 15 sections) and Calonarius (three subgenera), while in the Southern Hemisphere (where Calonarius does not occur and where the diversity of Phlegmacium is low) the second largest genus is Thaxterogaster (six subgenera, 18 sections). All these three genera are estimated to have more than or $\sim 200$ species. The remaining six genera are smaller, containing $\leq 25$ species.

Thus, how does the suggested delimitation of genera compare to other groups of gilled fungi? When comparing our proposal to the new Inocybaceae classification the new proposal and its justifcation are very similar. In both cases, after careful examination of global morpho-genetic data, the previously monotypic family has been divided into several genera to better recognize and communicate the amount of morphological, ecological, and biological diversity observed within each of them. We propose four larger and six smaller genera, whereas the current framework for Inocybaceae includes four larger ( $>50$ species) and three smaller genera of which one is monotypic. In both cases the genus on 
which the family name is based remains the largest one with hundreds of species. The refined classification will be more practical to use for comparative studies and is more appropriate for conservation studies and for identification of diversity hotspots than the previous, more inclusive one (Matheny et al. 2020).

When comparing the sizes of the four most species-rich genera-Cortinarius, Phlegmacium, Thaxterogaster, and Calonarius - to other genera of gilled fungi, the new classification still retains the size signature of the old classification, only now with more segregated units that are better refined. Because comparison at a global scale is challenging since, for many genera, data are still lacking and/or can be strongly biased, and because local keys or checklists from the most intensively studied areas of the world can provide a better basis for a more accurate comparison, we here use species numbers from Funga Nordica (Niskanen et al. 2008) to give an idea of the sizes of the new genera. Based on the proposed classification, Cortinarius would still be at least the second largest genus (206 species) after Entoloma (232 species) in Northern Europe and, most likely even remain the largest when all species from the region are recorded. The size of Calonarius ( $~ 80$ species) would be equal with Psathyrella, while the size of Phlegmacium ( 60 species) with Tricholoma and the size of Thaxterogaster ( 30 species) with Amanita although for the latter the comparison does not strictly apply, since Thaxterogaster has its centre of the diversity in the Southern Hemisphere and, globally, the size of this genus is equal to that of Phlegmacium.

To maintain nomenclatural stability as much as possible, we have kept the currently accepted sectional framework that has been created based on molecular data. In addition, the new generic names have been designed to have the same ending -narius as in Cortinarius, to keep the species epithets as they currently are, whenever possible.

In ecological and conservation studies, the go-to operational taxonomic unit is the species rank. Under current usage, the next rank used is the genus level, since no information on infrageneric ranks are associated with a name in fungal DNA barcoding databases. Therefore, the new classification proposed here will benefit ecological and other research by providing more biologically relevant categories. For example, the recognition of genus Calonarius, with many rare representatives that have narrow ecological preferences, will help highlight its uniqueness. Moreover, this classification will also advance communication of conservation priorities, as many of the species in Calonarius are included on national red lists across Europe (e.g. Stoltze and Pihl 1998; SLU Artdatabanken 2020) with C. meinhardii also making it into the global red list (Brandrud 2019). Having Calonarius as a separate genus will help draw focus into this group and provide a tool to better recognize it by ecologists and conservation biologists.

\section{Previous phylogenetic studies in Cortinariaceae}

Genera recognized in this study have also been recovered in the two previous multi-gene studies of Cortinariaceae that included data from the RPB1 region, in addition to the traditionally used ITS and LSU regions (Garnica et al. 2016; Soop et al 2019). Garnica et al. (2016) recognized the following clades: Phlegmacioid clade 1 (= Phlegmacium), Phlegmacioid clade 2 (= Thaxterogaster), Phlegmacioid clade 3 (=Calonarius), Renidentes (= Hygronarius), and Coleopodes (=Volvanarius). Also, Aureonarius, Cortinarius, Cystinarius, and Mystinarius were included in their analysis and formed their own respective clades, although they were not named in the tree. The only genus not represented in this earlier study is Austrocortinarius, but it was included in the phylogeny of Soop et al. (2019), which also recovered the same clades inferred by Garnica et al. (2016). Although many lineages in Garnica et al. (2016) received good support, they were unsupported in the analysis of Soop et al. (2019) and, therefore, were not recognized as formally named taxa.

The phylogenies based on ITS and LSU alone can recover the proposed genera to some extent, but these two gene regions do not suffice to resolve all of the infrafamilial relationships correctly. Particularly, they fail in recovering the monophyly of genera Cortinarius s. str. and Aureonarius (Garnica et al. 2005; Stensrud et al. 2014). Rather, the ITS and LSU regions are most suitable for shallow level classification, i.e., species and sections. To get a better idea on the higher level classification of Cortinariaceae, at least RPB1 would be needed, in addition to ITS and LSU. For optimal resolution, genome-wide data should be used.

\section{How does the new proposed classification differ from the existing one?}

Moving from one to ten genera is a big change, but our proposal is not a large leap in circumscribing the known diversity. First, most of the diversity belongs to four large genera, Cortinarius (species-rich in the Northern and Southern Hemispheres), Phlegmacium (species-rich in the Northern Hemisphere, but far fewer species in the Southern Hemisphere), Thaxterogaster (species-rich in the Southern Hemisphere, but far fewer species in the Northern Hemisphere) and Calonarius (restricted to the Northern Hemisphere). Secondly, most of the species-level diversity remains within genus Cortinarius s. str., which includes most of the species with telamonioid, cortinarioid (including dermocyboid and leprocyboid) or myxacioid habits, and all species with 
rozitoid or cuphocyboid habits (Table 3). Third, except for Aureonarius and Hygronarius, the small genera Austrocortinarius, Cystinarius, Mystinarius, and Volvanarius have long been enigmatic and difficult to confidently place within the previous classifications based on morphological traits only.

The main difference to the previous classification is the transfer of most phlegmacioid species to three separate genera: Phlegmacium, Calonarius, and Thaxterogaster. Of these, Calonarius is the easiest one to distinguish based solely on morphology. It has been recognized as a separate lineage from very early phylogenetic studies onwards (Peintner et al. 2004; Garnica et al. 2005) and several molecular studies have focused on it (e.g., Frøslev et al. 2007; Garnica et al. 2009, 2011). In the Northern Hemisphere, genus Phlegmacium contains most of the species traditionally included in $C$. subgenus Phlegmacium, except for sections Multiformes, Scauri/Purpurascentes, Riederorum, Lustrati, Pinophili, Turmales, and C. variegatus which instead belong to genus Thaxterogaster. In the Southern Hemisphere Nothofagaceae forests, however, the default genus for phlegmacioid species is Thaxterogaster. So far, no Calonarius species have been found in the Southern Hemisphere and far fewer species of Phlegmacium occur in the Southern than in the Northern Hemisphere. The peculiar species of Southern Hemisphere $C$. sect. Thaumasti, which look like miniature, volvate Phlegmacium, are treated in their own genus, Volvanarius; whereas the two distinctive, big, white species that occur in Australia and New Zealand are placed in genus Austrocortinarius. In addition, sections Crassi and Rubicunduli, traditionally classified with either phlegmacioid or cortinarioid species, are treated in their own genus, Cystinarius. Consequently, few stipitocarpic lineages with a phlegmacioid appearance-sections Subtorti, Infracti, Dulciolentes, Cuphocybe, and Vinaceolamellati-are kept in genus Cortinarius.

The myxacioid species mostly remain in genus Cortinarius and only sections Vibratiles and Austrocyanites are moved into Thaxterogaster, while $C$. lustrabilis and $C$. badiohepaticus are placed in the genus Mystinarius. Also, cortinarioid species mainly remain in genus Cortinarius and the only changes are the placement of sections Callistei and Limoni in their own genus Aureonarius, and the placement of section Rubicunduli in genus Cystinarius. In addition, most telamonioid species belong to genus Cortinarius and only some tens of species are placed in other lineages: genus Hygronarius and $P$. subgenus Carbonella. All rozitoid and cuphocypoid species belong to genus Cortinarius.

Sequestrate species have already been shown to belong to different lineages of Cortinariaceae (Peintner et al. 2001; Nouhra et al. 2021). Although most of them belong to either Cortinarius or Thaxterogaster, they are found in all four of the largest Cortinariaceae genera (Cortinarius,
Phlegmacium, Calonarius, and Thaxterogaster), as well as in the small genus Volvanarius.

\section{Infrageneric classification}

Our main goal for this study, was to produce a revised generic framework for family Cortinariaceae based on a robust phylogeny derived from genomic data. Futhermore, a base for subgeneric classification is also proposed by recognizing clades with strong to full support, while indicating the possible limits of the already existing subgenera. In some genera, i.e., Aureonarius and Phlegmacium, for which single-copy gene data from a wide range of species already exist, all species were placed in moderately to fully supported groups (Fig. 2). Elsewhere, e.g., the two species-rich genera Cortinarius and Thaxterogaster, further multi-gene studies will be needed to clarify the infrageneric relationships and, at present, only the morphologically and genetically most distinct groups are here recognized. A total of 30 subgenera are recognized of which 10 are here described as new to science.

For the most species-rich genus, Cortinarius, 11 subgenera and 130 sections are currently recognized, although most of these sections (80) belong to the most species-rich subgenus of Cortinariaceae, C. subgen. Telamonia. Morphological variation in the genus is broad but correlates rather well with the phylogeny. The vast majority of cortinarioid (dermocyboid, leprocyboid) and telamonioid species are placed in the strongly supported (BS 97\%) crown group of Cortinarius. The group includes the cortinarioid subgenera Dermocybe, Leprocybe, and Orellani, and the telamonioid subgenera Iodolentes, Illumini, and Telamonia, plus several sections and species whose relationships were not wellresolved (Fig. 2). The small phlegmacioid subgenus Infracti and the New Zealand endemic C. pholiotellus form a fully supported (BS 100\%) sister group to the crown group. Leading to this crown clade, we find a grade comprised mainly myxacioid, rozitoid, cuphocypoid, and sequestrate species, together with $C$. sect. Anomali, which was previously placed in $C$. subgen. Telamonia. Tentative limits of the previously described subgenera are marked in the tree (Fig. 2). Subgenus Cortinarius, which includes the type species of the genus $C$. violaceus, is tentatively placed in an unsupported clade sister to all other Cortinarius species. It is a morphologically unique group characterized by dark purple to blackish-purple species with dry velvety-squamulose pileus and cheilocystidia (Harrower et al. 2015a, b).

In the genus Phlegmacium, four subgenera and $22 \mathrm{sec}-$ tions are recognized. The subgenera are all moderately to fully supported in the phylogenetic analysis and are also supported by morphological traits. The two large groups, $P$. subgen. Phlegmacium and $P$. subgen. Bulbopodium, are 
characterized by different basidiomata development types: the basidiomata of Phlegmacium are stipitocarpic and those of Bulbopodium pileocarpic. The small subgenus Cyanicium includes species with bluish to violet (brownish)grey basidiomata and reddening context. They are phlegmacioid in appearance but have previously also been placed in Telamonia and Sericeocybe (Soop et al. 2019). Also, Carbonella is placed with moderate support in genus Phlegmacium in our analysis. It differs from all other lineages of Phlegmacium by having telamonioid basidiomata and is thus recognized here as its own subgenus.

Thaxterogaster includes phlegmacioid, myxacioid and a few telamonioid species. At present, five new subgenera, in addition to the autonym, are proposed to describe the morphologically most distinct units and to serve as anchors for further studies. Twenty-eight sections are recognized. More sampling of species from the Southern Hemisphere is needed to better understand the infrageneric relationships and evolution of the genus.

In Calonarius, three subgenera and 11 sections are recognized. In the smaller genera Aureonarius, Cystinarius, and Hygronarius, two subgenera are recognized for each genus, and this division is also supported by morphological traits. In Austrocortinarius, Mystinarius, and Volvanarius, which only contain a few species, no further infrageneric classification is proposed.

\section{Fungariomics}

Two approaches were used to create genomic data for our phylogenomic study: shallow WGS and targeted capture sequencing. For the shallow WGS, the goal was to produce sufficient sequence data representative of the whole genome to assemble into contiguous sequences and then fish our targets from the resulting assemblies. For the targeted capture sequencing, the baits are first designed for the chosen targets, then genomic libraries of chosen samples are enriched, via in solution hybridization with our baits, so that only the targets will be sequenced. We wanted to compare the performance of these two methods in fungi, for which the genome size is relatively small and thus producing low cost WGS data is possible.

Results obtained from targeted capture sequencing were remarkably better than those achieved via shallow WGS. With targeted capture sequencing, over $85 \%$ of the 75 targets used for the phylogenomics analysis were recovered, for nine out of 11 specimens. Whereas with WGS, the same percentage was only achieved for three out of nine specimens. The same specimen of Cystinarius crassus was processed with both methods and $33 \%$ of the targets were recovered with WGS, compared to $99 \%$ with targeted capture sequencing. The advantage of the targeted capture sequencing approach is that only the targeted regions of the systematic group studied are sequenced whereas in WGS the whole genome is sequenced, including possible contaminants present in the basidiomata collected from the wild or gained during the preservation process (Dentinger et al. 2016). Thus, prior knowledge of the genome size of the studied species might help optimize the number of specimens to be pooled for WGS; although, even then, some of the capacity might be lost to sequencing accompanying organisms. Somewhat better results could potentially have also been achieved by improved assembly quality through assembly refinement and it could also be possible that differences in the preservation state and molecular processing of sampled Cortinariaceae species might as well have had some impact in the results (Brewer et al. 2019; Forrest et al. 2019). However, a thorough comparison and evaluation of the effects of these different factors to the success rate is beyond the scope of this study and overall, they would not entirely explain the differences observed in performance.

The age of the fungarium specimens sampled ranged from one to 21 year for the WGS and from four to 13 year for the targeted capture sequencing. Targeted capture sequencing studies in plants have used herbarium specimens 50-200 years old (Brewer et al. 2019; Shee et al. 2020), and even thousands of years old aDNA in archaeogenomic studies (Kistler et al. 2020). Therefore, targeted capture sequencing is also a very promising approach for fungariomics and provides a way to unlock the full potential of specimens stored in fungaria worldwide for phylogenetic analysis. In our study we generated genomic libraries with medium sized inserts, which we chose to sequence in a MiSeq using the Nano chemistry $(250 \times 250 \mathrm{bp})$, due to the small number of specimens processed in total. However, especially for the older specimens, where the DNA is likely to be more degraded, the Illumina platforms (i.e., HiSeq, NextSeq, NovaSeq), taking shorter sized fragments as template, would be more suitable.

Our results join the existing evidence (Dodsworth et al. 2019) showing that targeted capture sequencing provides a cost-efficient approach (Hale et al. 2020) to produce data for phylogenomic analyses for species-rich groups, like Cortinariaceae, in which one can use the same set of baits for a large range of species (e.g., see Liu et al. 2019, mosses; Johnson et al. 2019, angiosperms; or Widhelm et al. 2021, peltigeralean lichens). The initial bait design and capture reactions add costs compared to the WGS and therefore the latter approach can be more appropriate for smaller taxonomic groups, unless an enrichment panel is already available. It is difficult to provide a precise threshold on the number of species for which targeted capture sequencing becomes cheaper than WGS in fungi, since costs of genomic data are in constant flux and costs also depend 
on the genome size and intended sequencing coverage, as well as the number of baits to be included in the enrichment panel. Nonetheless, to give some idea of the difference in volume between these two methods, for Cortinariaceae we estimated that about 200 specimens could be pooled into a single Illumina MiSeq $2 \times 300$ bp paired end run, when using targeted capture sequencing, compared to five to six specimens in total for the WGS approach. On the other hand, in some cases it might be justified to choose the WGS approach for other reasons, e.g., its potential added value of providing data on other genomic features or other loci, not included for a given enrichment panel, for analyses at different taxonomic levels.

\section{Conclusions}

This study is the first family revision in Agaricales based on genomic data and hopefully many others will soon follow. We have come a long way from the time of Fries when all gilled fungi were in one genus, Agaricus (Fries 1821). Since then, mycologists have, in most cases, created smaller and smaller genera due to the increased understanding of the diversity and enhanced ability to collect data of the organisms for taxonomic studies. The same phenomenon has happened in plants and animals. The genus Cortinarius has been an especially difficult group for taxonomists, because it includes an enormous amount of morphological and species diversity. While there have been previous efforts to divide the genus into more manageable, practical, and natural units, none have achieved a natural classification for the whole group. Our proposed classification for Cortinariaceae is more equilevant to contemporary concepts in other genera of gilled fungi and we hope that our framework will be more user-friendly, facilitating the identification, conservation and ecological studies on these fascinating organisms.

\section{Additional new combinations of the species and sections belonging to the different genera of family Cortinariaceae}

\section{Aureonarius}

Aureonarius armiae (Soop) Niskanen \& Liimat., comb. nov.

IF553605

Basionym: Cortinarius armiae Soop, Bresadoliana 1(2): 19. 2013.
Aureonarius aurantiobrunneus (Ammirati, Halling \& Garnica) Niskanen \& Liimat., comb. nov.

\section{IF553606}

Basionym: Cortinarius aurantiobrunneus Ammirati, Halling \& Garnica, in Ammirati, Garnica, Halling, Mata, Mueller \& Carranza, Can. J. Bot. 85(9): 801. 2007.

Aureonarius austrolimonius (M.M. Moser \& E. Horak) Liimat. \& Niskanen, comb. nov.

IF553607

Basionym: Cortinarius austrolimonius M.M. Moser \& E. Horak, Beih. Nova Hedwigia 52: 454. 1975.

Aureonarius callisteus (Fr.) Niskanen \& Liimat., comb. nov.

IF553608

Basionym: Agaricus callisteus Fr., Observ. mycol. (Havniae) 2: 51.1818 .

Aureonarius caryotis (Soop) Niskanen \& Liimat., comb. nov.

\section{IF553621}

Basionym: Cortinarius caryotis Soop, Bull. Soc. mycol. Fr. 117(2): 97. 2001.

Aureonarius caryotoides (Soop) Niskanen \& Liimat., comb. nov.

\section{IF553622}

Basionym: Cortinarius caryotoides Soop, in Soop, Wallace \& Dima, N.Z. Jl Bot. 56(2): 166. 2018.

Aureonarius controversus (Gasparini) Niskanen \& Liimat., comb. nov.

IF553623

Basionym: Cortinarius controversus Gasparini, in Gasparini \& Soop, Australas. Mycol. 27(3): 190. 2008. 
Aureonarius eucollybianus (Soop) Niskanen \& Liimat., comb. nov.

IF553624

Basionym: Cortinarius eucollybianus Soop, in Soop, Wallace \& Dima, N.Z. J1 Bot. 56(2): 171. 2018.

Aureonarius infucatus (Fr.) Niskanen \& Liimat., comb. nov.

IF553625

Basionym: Cortinarius infucatus Fr., Öfvers. K. Svensk. Vetensk.-Akad. Förhandl. 18(1): 26. 1861.

Aureonarius limonius (Fr.) Niskanen \& Liimat., comb. nov.

IF553626

Basionym: Agaricus limonius Fr., Observ. mycol. (Havniae) 2: 56. 1818.

Aureonarius neocallisteus (Kranab., Ammirati, Liimat. \& Niskanen) Niskanen \& Liimat., comb. nov.

IF553640

Basionym: Cortinarius neocallisteus Kranab., Ammirati, Liimat. \& Niskanen, in Niskanen, Liimatainen, Kytövuori, Lindström, Dentinger \& Ammirati, Mycologia 108(5): 1024. 2016.

Aureonarius rubrimarginatus (Soop) Niskanen \& Liimat., comb. nov.

\section{IF553641}

Basionym: Cortinarius rubrimarginatus Soop, in Soop, Wallace \& Dima, N.Z. Jl Bot. 56(2): 169. 2018.

Aureonarius rubrocastaneus (Soop) Niskanen \& Liimat., comb. nov.

IF553643

Basionym: Gymnopilus rubrocastaneus Soop, Bull. Soc. mycol. Fr. 117(2): 128. 2001.

Aureonarius rubrodactylus (Soop) Niskanen \& Liimat., comb. nov.

IF553644
Basionym: Cortinarius rubrodactylus Soop, Australas. Mycol. 31: 3. 2013.

Aureonarius tofaceus (Fr.) Niskanen \& Liimat., comb. nov.

IF553645

Basionym: Cortinarius tofaceus Fr., Epicr. syst. mycol. (Upsaliae): 281. 1838. [1836-1838].

Aureonarius viscilaetus (Soop) Niskanen \& Liimat., comb. nov.

IF553777

Basionym: Cortinarius viscilaetus Soop, Bull. Soc. mycol. Fr. 117(2): 114. 2001.

\section{Austrocortinarius}

Austrocortinarius australiensis (Cleland \& Cheel) Liimat. \& Niskanen, comb. nov.

IF553778

Basionym: Rozites australiensis Cleland \& Cheel, Trans. \& Proc. Roy. Soc. S. Australia 42: 90. 1918.

\section{Calonarius}

Calonarius sect. Atrovirentes (Bidaud, Moënne-Locc. \& Reumaux) Niskanen \& Liimat., comb. \& stat. nov.

\section{IF553779}

Basionym: Cortinarius ser. Atrovirens Bidaud, MoënneLocc. \& Reumaux, in Bidaud, Carteret, Eyssartier, MoënneLoccoz \& Reumaux, Atlas des Cortinaires (Meyzieu) 14: 958. 2004.

Calonarius sect. Aureopulverulenti (Brandrud \& Melot) Niskanen \& Liimat., comb. \& stat. nov.

IF553780

Basionym: Cortinarius subsect. Aureopulverulenti Brandrud \& Melot, Nordic J1 Bot. 10(5): 535. 1990.

Calonarius sect. Dibaphi (Brandrud \& Melot) Niskanen \& Liimat., comb. \& stat. nov.

IF553781 
Basionym: Cortinarius subsect. Dibaphi Brandrud \& Melot, Nordic J1 Bot. 10(5): 537. 1990.

Calonarius sect. Flavovirentes (Bidaud, Moënne-Locc. \& Reumaux) Niskanen \& Liimat., comb. \& stat. nov.

\section{IF553782}

Basionym: Cortinarius ser. Flavovirens Bidaud, MoënneLocc. \& Reumaux, in Bidaud, Carteret, Eyssartier, MoënneLoccoz \& Reumaux, Atlas des Cortinaires (Meyzieu) 14: 958. 2004.

Calonarius sect. Osmophori (Bidaud \& Reumaux) Niskanen \& Liimat., comb. \& stat. nov.

\section{IF553783}

Basionym: Cortinarius stirps Osmophorus Bidaud \& Reumaux, in Bidaud, Moënne-Loccoz, Reumaux, Carteret \& Eyssartier, Atlas des Cortinaires (Meyzieu) 16: 1097. 2006.

Calonarius sect. Platypodes (Bidaud, Moënne-Locc. \& Reumaux) Niskanen \& Liimat., comb. \& stat. nov.

IF553784

Basionym: Cortinarius ser. Platypodes Bidaud, MoënneLocc. \& Reumaux, in Bidaud, Moënne-Loccoz, Reumaux, Carteret \& Eyssartier, Atlas des Cortinaires (Meyzieu) 11: 611. 2001.

Calonarius sect. Rufoolivacei (Brandrud \& Melot) Niskanen \& Liimat., comb. \& stat. nov.

\section{IF553785}

Basionym: Cortinarius subsect. Rufoolivacei Brandrud \& Melot, Nordic Jl Bot. 10(5): 538. 1990.

Calonarius sect. Sodagniti (Bidaud, Moënne-Locc. \& Reumaux) Niskanen \& Liimat., comb. \& stat. nov.

IF553786

Basionym: Cortinarius ser. Sodagniti Bidaud, MoënneLocc. \& Reumaux, Docums Mycol. 24(no. 95): 43. 1994.

Calonarius sect. Splendentes (Kühner \& Romagn. ex Brandrud \& Melot) Niskanen \& Liimat., comb. \& stat. nov.
Basionym: Cortinarius subsect. Splendentes Kühner \& Romagn. ex Brandrud \& Melot, Nordic J. Bot. 10(5): 538. 1990.

Calonarius adonis (Bojantchev \& Ammirati) Niskanen \& Liimat., comb. nov.

\section{IF553788}

Basionym: Cortinarius adonis Bojantchev \& Ammirati, in Bojantchev, Index Fungorum 247: 1. 2015.

Calonarius albertii (Dima, Frøslev \& T.S. Jeppesen) Niskanen \& Liimat., comb. nov.

IF553789

Basionym: Cortinarius albertii Dima, Frøslev \& T.S. Jeppesen, in Frøslev, Jeppesen \& Læssøe, Mycol. Res. 110(9): 1050. 2006.

Calonarius albidolilacinus (Ammirati, Bojantchev, Beug, Liimat., Niskanen \& Garnica) Niskanen \& Liimat., comb. nov.

IF553790

Basionym: Cortinarius albidolilacinus Ammirati, Bojantchev, Beug, Liimat., Niskanen \& Garnica, in Liimatainen, Index Fungorum 241: 1. 2015.

Calonarius alcalinophilus (Rob. Henry) Niskanen \& Liimat., comb. nov.

IF553791

Basionym: Cortinarius alcalinophilus Rob. Henry, Bull. trimest. Soc. mycol. Fr. 67(3): 301. 1952. (1951).

Calonarius alnobetulae (Kühner) Niskanen \& Liimat., comb. nov.

IF553792

Basionym: Cortinarius alnobetulae Kühner, Docums Mycol. 20(77): 92. 1989.

Calonarius amabilis (Bojantchev, Ammirati \& Pastorino) Niskanen \& Liimat., comb. nov.

IF553793

IF553787 
Basionym: Cortinarius amabilis Bojantchev, Ammirati \& Pastorino, in Bojantchev, Index Fungorum 247: 1. 2015.

Calonarius amnicola (A.H. Sm.) Niskanen \& Liimat., comb. nov.

\section{IF553794}

Basionym: Cortinarius amnicola A.H. Sm., Bull. Torrey bot. Club 69(1): 48. 1942.

Calonarius anaunianus (Fellin \& R.J. Ferrari) Niskanen \& Liimat., comb. nov.

\section{IF553795}

Basionym: Cortinarius anaunianus Fellin \& R.J. Ferrari, in Fellin, Ercole, Ferrari \& Vizzini, Phytotaxa 520(3): 230. 2021.

Calonarius anetholens (Ammirati, Garnica, Bojantchev, Beug, Liimat. \& Niskanen) Niskanen \& Liimat., comb. nov.

IF553800

Basionym: Cortinarius anetholens Ammirati, Garnica, Bojantchev, Beug, Liimat. \& Niskanen, in Liimatainen, Index Fungorum 241: 1. 2015.

Calonarius arcuatorum (Rob. Henry) Niskanen \& Liimat., comb. nov.

\section{IF553801}

Basionym: Cortinarius arcuatorum Rob. Henry, Bull. trimest. Soc. mycol. Fr. 55(1): 80. 1939.

Calonarius arenicola (A.H. Sm.) Niskanen \& Liimat., comb. nov.

\section{IF553802}

Basionym: Cortinarius arenicola A.H. Sm., Bull. Torrey bot. Club 69(1): 49. 1942.

Calonarius atrovirens (Kalchbr.) Niskanen \& Liimat., comb. nov.

\section{IF553803}

Basionym: Cortinarius atrovirens Kalchbr., Icon. Sel. Hymenomyc. Hung. (Budapest) 2: tab. 19. 1874.
Calonarius aureocalceolatus (M.M. Moser \& Peintner) Niskanen \& Liimat., comb. nov.

IF553804

Basionym: Cortinarius aureocalceolatus M.M. Moser \& Peintner, Journal des JEC, Journées Européenes du Cortinaire 5(no. 4): 30. 2002.

Calonarius aureofulvus (M.M. Moser) Niskanen \& Liimat., comb. nov.

IF553851

Basionym: Cortinarius aureofulvus M.M. Moser, Sydowia 6(1-4): 154. 1952.

Calonarius aureopulverulentus (M.M. Moser) Niskanen \& Liimat., comb. nov.

IF553852

Basionym: Cortinarius aureopulverulentus M.M. Moser, Sydowia 6(1-4): 152. 1952.

Calonarius aurora (M.M. Moser \& Ammirati) Niskanen \& Liimat., comb. nov.

IF553853

Basionym: Cortinarius aurora M.M. Moser \& Ammirati, in Moser, McKnight \& Ammirati, Mycotaxon 55: 305. 1995.

Calonarius barbaricus (Brandrud) Niskanen \& Liimat., comb. \& stat. nov.

\section{IF553854}

Basionym: Cortinarius callochrous var. barbaricus Brandrud, Cortinarius, Flora Photographica (Matfors) 3: 27. 1994.

Calonarius barbarorum (Bidaud, Moënne-Locc. \& Reumaux) Niskanen \& Liimat., comb. nov.

\section{IF553855}

Basionym: Cortinarius barbarorum Bidaud, Moënne-Locc. \& Reumaux, in Bidaud, Moënne-Loccoz, Reumaux, Carteret \& Eyssartier, Atlas des Cortinaires (Meyzieu) 11: 612. 2001.

Calonarius bigelowii (Thiers \& A.H. Sm.) Niskanen \& Liimat., comb. nov. 
IF554100

Basionym: Cortinarius bigelowii Thiers \& A.H. Sm., Mycologia 61: 531. 1969.

Calonarius cacodes (M.M. Moser \& Ammirati) Niskanen \& Liimat., comb. nov.

IF554101

Basionym: Cortinarius cacodes M.M. Moser \& Ammirati, Mycotaxon 74(1): 6. 2000.

Calonarius caesiocinctus (Kühner) Niskanen \& Liimat., comb. nov.

IF554102

Basionym: Cortinarius caesiocinctus Kühner, Docums Mycol. 20(77): 92. 1989.

Calonarius caesiolatens (Rob. Henry ex Bidaud \& Reumaux) Niskanen \& Liimat., comb. nov.

IF554103

Basionym: Cortinarius caesiolatens Rob. Henry ex Bidaud \& Reumaux, in Bidaud, Carteret, Eyssartier, Moënne-Loccoz \& Reumaux, Atlas des Cortinaires (Meyzieu) 14: 960. 2004.

Calonarius callochrous (Pers.) Niskanen \& Liimat., comb. nov.

\section{IF554104}

Basionym: Agaricus callochrous Pers., Syn. meth. fung. (Göttingen) 2: 282. 1801.

Calonarius calojanthinus (M.M. Moser \& Ammirati) Niskanen \& Liimat., comb. nov.

IF559246

Basionym: Cortinarius calojanthinus M.M. Moser \& Ammirati, Mycotaxon 72: 291. 1999.

Calonarius caroviolaceus (P.D. Orton) Niskanen \& Liimat., comb. nov.

IF554105
Basionym: Cortinarius caroviolaceus P.D. Orton, Trans. Br. mycol. Soc. 43(2): 208. 1960.

Calonarius catharinae (Consiglio) Niskanen \& Liimat., comb. nov.

IF554106

Basionym: Cortinarius catharinae Consiglio, Riv. Micol. 39(3): 199. 1997. [1996].

Calonarius cedretorum (Maire) Niskanen \& Liimat., comb. nov.

IF554107

Basionym: Cortinarius cedretorum Maire, Bull. Soc. mycol. Fr. 30(2): 210. 1914.

Calonarius chailluzii (Frøslev \& T.S. Jeppesen) Niskanen \& Liimat., comb. nov.

IF554108

Basionym: Cortinarius chailluzii Frøslev \& T.S. Jeppesen, in Frøslev, Jeppesen \& Læssøe, Mycol. Res. 110(9): 1051. 2006.

Calonarius cisticola (Frøslev \& T.S. Jeppesen) Niskanen \& Liimat., comb. nov.

\section{IF554109}

Basionym: Cortinarius cisticola Frøslev \& T.S. Jeppesen, in Frøslev, Jeppesen \& Læssøe, Mycol. Res. 110(9): 1051. 2006.

Calonarius citrinipedes (A.H. Sm.) Niskanen \& Liimat., comb. nov.

IF554400

Basionym: Cortinarius citrinipedes A.H. Sm., Bull. Torrey bot. Club 69(1): 54. 1942.

Calonarius citrinus (J.E. Lange ex P.D. Orton) Niskanen \& Liimat., comb. nov.

IF554401

Basionym: Cortinarius citrinus J.E. Lange ex P.D. Orton, Bull. trimest. Soc. mycol. Fr. 55(2): 176. 1960. 
Calonarius claroflavus (Rob. Henry) Niskanen \& Liimat., comb. nov.

IF554402

Basionym: Cortinarius claroflavus Rob. Henry, Bull. trimest. Soc. mycol. Fr. 67(3): 297. 1952. (1951).

Calonarius cobaltinus (Kytöv., Liimat. \& Niskanen) Niskanen \& Liimat., comb. nov.

IF554403

Basionym: Cortinarius cobaltinus Kytöv., Liimat. \& Niskanen, in Liimatainen, Index Fungorum 22: 1. 2013.

Calonarius coniferarum (M.M. Moser) Niskanen \& Liimat., comb. \& stat. nov.

IF554404

Basionym: Phlegmacium multiforme var. coniferarum M.M. Moser, Gatt. Phlegm.: 349. 1960.

Calonarius corrosus (Fr.) Niskanen \& Liimat., comb. nov.

IF554405

Basionym: Cortinarius corrosus Fr., Epicr. syst. mycol. (Upsaliae): 266. 1838. [1836-1838].

Calonarius cupreorufus (Brandrud) Niskanen \& Liimat., comb. nov.

\section{IF554406}

Basionym: Cortinarius cupreorufus Brandrud, in Brandrud, Lindström, Marklund, Melot \& Muskos, Cortinarius, Flora Photographica (Matfors) 3: 27. 1994.

Calonarius dalecarlicus (Brandrud) Niskanen \& Liimat., comb. nov.

IF554407

Basionym: Cortinarius dalecarlicus Brandrud, in Brandrud, Lindström, Marklund, Melot \& Muskos, Cortinarius, Flora Photographica vol. 2 (Sweden): 33. 1992.

Calonarius dibaphus (Fr.) Niskanen \& Liimat., comb. nov.

IF554408
Basionym: Cortinarius dibaphus Fr., Epicr. syst. mycol. (Upsaliae): 266. 1838. [1836-1838].

Calonarius elegantiomontanus (Garnica \& Ammirati) Niskanen \& Liimat., comb. nov.

IF554409

Basionym: Cortinarius elegantiomontanus Garnica \& Ammirati, in Garnica, Spahn, Oertel, Ammirati \& Oberwinkler, BMC Evol. Biol. 11(213 [reprint]): 13 + Additional file 3: 20. 2011.

Calonarius elegantior (Fr.) Niskanen \& Liimat., comb. \& stat. nov.

IF554410

Basionym: Agaricus multiformis $\beta$ elegantior Fr., Observ. mycol. (Havniae) 2: 64. 1818.

Calonarius elegantissimus (Rob. Henry) Niskanen \& Liimat., comb. nov.

IF554411

Basionym: Cortinarius elegantissimus Rob. Henry, Docums Mycol. 20(77): 69. 1989.

Calonarius elotoides (M.M. Moser \& McKnight) Niskanen \& Liimat., comb. nov.

IF554412

Basionym: Cortinarius elotoides M.M. Moser \& McKnight, in Moser, McKnight \& Ammirati, Mycotaxon 55: 311. 1995.

Calonarius elotus (Fr.) Niskanen \& Liimat., comb. nov.

\section{IF554413}

Basionym: Cortinarius elotus Fr., Epicr. syst. mycol. (Upsaliae): 264. 1838. (1836-1838).

Calonarius evosmus (Joachim ex Bidaud \& Reumaux) Niskanen \& Liimat., comb. nov.

\section{IF554414}

Basionym: Cortinarius evosmus Joachim ex Bidaud \& Reumaux, in Bidaud, Moënne-Loccoz, Reumaux, Carteret \& Eyssartier, Atlas des Cortinaires (Meyzieu) 16: 1097. 2006. 
Calonarius flavaurora (M.M. Moser \& McKnight) Niskanen \& Liimat., comb. nov.

\section{IF554415}

Basionym: Cortinarius flavaurora M.M. Moser \& McKnight, in Moser, McKnight \& Ammirati, Mycotaxon 55: 321. 1995.

Calonarius flavoaurantians (Boccardo, Cleric. \& Vizzini) Niskanen \& Liimat., comb. nov.

IF554416

Basionym: Cortinarius flavoaurantians Boccardo, Cleric. \& Vizzini, in Vizzini, Clericuzio, Boccardo \& Ercole, Mycologia 104(6): 1504. 2012.

Calonarius flavobulbus (Ammirati \& M.M. Moser) Niskanen \& Liimat., comb. nov.

IF554417

Basionym: Cortinarius flavobulbus Ammirati \& M.M. Moser, in Moser \& Ammirati, Sydowia 49(1): 34. 1997.

Calonarius flavovirens (Rob. Henry) Niskanen \& Liimat., comb. nov.

IF554418

Basionym: Cortinarius flavovirens Rob. Henry, Bull. trimest. Soc. mycol. Fr. 55(2): 182. 1939.

Calonarius frondosophilus (Bidaud) Niskanen \& Liimat., comb. nov.

IF554419

Basionym: Cortinarius frondosophilus Bidaud, in Bidaud, Moënne-Loccoz, Reumaux, Carteret \& Eyssartier, Atlas des Cortinaires (Meyzieu) 11: 612. 2001.

Calonarius fulvoarcuatorum (Garnica \& Ammirati) Niskanen \& Liimat., comb. nov.

IF554420

Basionym: Cortinarius fulvoarcuatorum Garnica \& Ammirati, in Garnica, Spahn, Oertel, Ammirati \& Oberwinkler, BMC Evol. Biol. 11(213 [reprint]): 13+ Additional file 3: 5. 2011.
Calonarius fulvocitrinus (Brandrud) Niskanen \& Liimat., comb. nov.

IF554421

Basionym: Cortinarius fulvocitrinus Brandrud, in Brandrud, Lindström, Marklund, Melot \& Muskos, Cortinarius, Flora Photographica (Matfors) 4: 20. 1998.

Calonarius fulvoincarnatus (Joachim ex Bidaud, MoënneLocc. \& Reumaux) Niskanen \& Liimat., comb. nov.

IF554422

Basionym: Cortinarius fulvoincarnatus Joachim ex Bidaud, Moënne-Locc. \& Reumaux, in Bidaud, Moënne-Loccoz, Reumaux, Carteret \& Eyssartier, Atlas des Cortinaires (Meyzieu) 11: 613. 2001.

Calonarius glaucescens (Jul. Schäff.) Niskanen \& Liimat., comb. nov.

IF554423

Basionym: Phlegmacium glaucescens Jul. Schäff., Die Gattung Phlegmacium (Schleimköpfe). Die Pilze Mitteleuropas 4: 359. 1960.

Calonarius glaucoelotus (Brandrud, Dima, Krisai, Ballarà \& Peintner) Niskanen \& Liimat., comb. nov.

IF554427

Basionym: Cortinarius glaucoelotus Brandrud, Dima, Krisai, Ballarà \& Peintner, in Crous et. al., Persoonia 45: 405. 2020 .

Calonarius haasii (M.M. Moser) Niskanen \& Liimat., comb. \& stat. nov.

IF554428

Basionym: Phlegmacium arquatum var. haasii M.M. Moser, Gatt. Phlegm.: 353. 1960.

Calonarius hildegardiae (Schmidt-Stohn, Brandrud \& Dima) Niskanen \& Liimat., comb. nov.

IF554429

Basionym: Cortinarius hildegardiae Schmidt-Stohn, Brandrud \& Dima, in Brandrud, Schmidt-Stohn \& Dima, Sydowia 71: 119. 2019. 
Calonarius insignibulbus (Bidaud \& Moënne-Locc.) Niskanen \& Liimat., comb. nov.

IF554430

Basionym: Cortinarius insignibulbus Bidaud \& MoënneLocc., in Bidaud, Moënne-Loccoz, Reumaux, Carteret \& Eyssartier, Atlas des Cortinaires (Meyzieu) 11: 613. 2001.

Calonarius intricatus (Bojantchev, Ammirati \& N. Siegel)

Niskanen \& Liimat., comb. nov.

\section{IF554431}

Basionym: Cortinarius intricatus Bojantchev, Ammirati \& N. Siegel, in Bojantchev, Index Fungorum 247: 1. 2015.

Calonarius ionochlorus (Maire) Niskanen \& Liimat., comb. nov.

\section{IF554432}

Basionym: Cortinarius ionochlorus Maire, Publ. Inst. Bot. Barcelona 3(no. 4): 113. 1937.

Calonarius jardinensis (Garnica, Ammirati \& Halling) Niskanen \& Liimat., comb. nov.

IF554433

Basionym: Cortinarius jardinensis Garnica, Ammirati \& Halling, in Garnica, Spahn, Oertel, Ammirati \& Oberwinkler, BMC Evol. Biol. 11(213 [reprint]): 13+Additional file 3: 7. 2011.

Calonarius juxtadibaphus (Rob. Henry) Niskanen \& Liimat., comb. nov.

\section{IF554434}

Basionym: Cortinarius juxtadibaphus Rob. Henry, Bull. trimest. Soc. mycol. Fr. 99(1): 11. 1983.

Calonarius kristinae (Brandrud) Niskanen \& Liimat., comb. nov.

\section{IF554435}

Basionym: Cortinarius kristinae Brandrud, in Frøslev, Brandrud \& Dima, Mycol. Progr. 16(2): 151. 2017.

Calonarius laberiae (Münzmay, B. Oertel \& Saar) Niskanen \& Liimat., comb. nov.

\section{IF554436}

Basionym: Cortinarius laberiae Münzmay, B. Oertel \& Saar, Journal des JEC, Journées Européenes du Cortinaire 12(11): 36. 2009.

Calonarius langeorum (Frøslev \& T.S. Jeppesen) Niskanen \& Liimat., comb. nov.

IF554437

Basionym: Cortinarius langeorum Frøslev \& T.S. Jeppesen, in Frøslev, Jeppesen \& Læssøe, Mycol. Res. 110(9): 1052. 2006.

Calonarius lavandulochlorus (Eyssart.) Niskanen \& Liimat., comb. nov.

\section{IF554438}

Basionym: Cortinarius lavandulochlorus Eyssart., Journal des JEC, Journées Européenes du Cortinaire 14(no. 13): 53. 2011.

Calonarius lentus (Boccardo, Cleric., Dovana \& Vizzini) Niskanen \& Liimat., comb. nov.

IF554439

Basionym: Cortinarius lentus Boccardo, Cleric., Dovana \& Vizzini, in Dovana, Boccardo, Clericuzio \& Vizzini, Phytotaxa 447(1): 35. 2020.

Calonarius lilacinovelatus (Reumaux \& Ramm) Niskanen \& Liimat., comb. nov.

IF554440

Basionym: Cortinarius lilacinovelatus Reumaux \& Ramm, in Bidaud, Moënne-Loccoz, Reumaux, Carteret \& Eyssartier, Atlas des Cortinaires (Meyzieu) 11: 613. 2001.

Calonarius lilaciotinctus (Garnica \& Ammirati) Niskanen \& Liimat., comb. nov.

IF554441

Basionym: Cortinarius lilaciotinctus Garnica \& Ammirati, in Garnica, Spahn, Oertel, Ammirati \& Oberwinkler, BMC Evol. Biol. 11(213 [reprint]): 13+Additional file 3: 10. 2011. 
Calonarius luteicolor (Ammirati, Bojantchev, Niskanen \&

Liimat.) Niskanen \& Liimat., comb. nov.

IF554442

Basionym: Cortinarius luteicolor Ammirati, Bojantchev, Niskanen \& Liimat., in Liimatainen, Niskanen, Dima, Kytövuori, Ammirati \& Frøslev, Persoonia 33: 126. 2014.

Calonarius luteolus (M.M. Moser) Niskanen \& Liimat., comb. nov.

IF554443

Basionym: Cortinarius luteolus M.M. Moser, in Moser \& Horak, Beih. Nova Hedwigia 52: 322. 1975.

Calonarius mariekristinae (Brandrud \& Dima) Niskanen \& Liimat., comb. nov.

IF554444

Basionym: Cortinarius mariekristinae Brandrud \& Dima, in Brandrud, Schmidt-Stohn \& Dima, Sydowia 71: 122. 2019.

Calonarius meinhardii (Bon) Niskanen \& Liimat., comb. nov.

IF554740

Basionym: Cortinarius meinhardii Bon, Docums Mycol. 16(63-64): 66. 1986.

Calonarius metarius (Kauffman) Niskanen \& Liimat., comb. nov.

\section{IF554741}

Basionym: Cortinarius metarius Kauffman, Pap. Mich. Acad. Sci. 1: 137. 1921.

Calonarius mikedavisii (Bojantchev) Niskanen \& Liimat., comb. nov.

IF554742

Basionym: Cortinarius mikedavisii Bojantchev, Mycotaxon 118: 267. 2011. (2012).

Calonarius moseri (E. Horak) Niskanen \& Liimat., comb. nov.

IF554743
Basionym: Phlegmacium moseri E. Horak, Schweiz. Z. Pilzk. 40: 93. 1962.

Calonarius murellensis (Cors. Gut., Ballarà, Cadiñanos, Palazón \& Mahiques) Niskanen \& Liimat., comb. nov.

IF554744

Basionym: Cortinarius murellensis Cors. Gut., Ballarà, Cadiñanos, Palazón \& Mahiques, Butll. Soc. Micol. Valenciana 10: 160. 2005.

Calonarius napus (Fr.) Niskanen \& Liimat., comb. nov.

IF554745

Basionym: Cortinarius napus Fr., Epicr. syst. mycol. (Upsaliae): 263. 1838. [1836-1838].

Calonarius natalis (D. Antonini \& M. Antonini) Niskanen \& Liimat., comb. nov.

IF554746

Basionym: Cortinarius natalis D. Antonini \& M. Antonini, Fungi Non Delineati, Raro vel Haud Perspecte et Explorate Descripti aut Definite Picti 22: 19. 2002.

Calonarius nymphicolor (Reumaux) Niskanen \& Liimat., comb. nov.

IF554747

Basionym: Cortinarius nymphicolor Reumaux, in Bidaud, Moënne-Loccoz, Reumaux \& Henry, Atlas des Cortinaires, Pars V (Annecy): 151. 1993.

Calonarius ochraceopallescens (Moënne-Locc. \& Reumaux) Niskanen \& Liimat., comb. nov.

IF554805

Basionym: Cortinarius ochraceopallescens Moënne-Locc. \& Reumaux, in Bidaud, Moënne-Loccoz, Reumaux, Carteret \& Eyssartier, Atlas des Cortinaires (Meyzieu) 11: 613. 2001.

Calonarius odoratus (Joguet ex M.M. Moser) Niskanen \& Liimat., comb. nov.

\section{IF554806}

Basionym: Phlegmacium odoratum Joguet ex M.M. Moser, Gatt. Phlegm.: 360. 1960. 
Calonarius odorifer (Britzelm.) Niskanen \& Liimat., comb. nov.

\section{IF554807}

Basionym: Cortinarius odorifer Britzelm., Ber. naturhist. Augsburg 28: 123. 1885.

Calonarius olearioides (Rob. Henry) Niskanen \& Liimat., comb. nov.

\section{IF554808}

Basionym: Cortinarius olearioides Rob. Henry, Docums Mycol. 17(no. 68): 36. 1987.

Calonarius oliveopetasatus (M.M. Moser) Niskanen \& Liimat., comb. nov.

IF555319

Basionym: Cortinarius oliveopetasatus M.M. Moser, in Moser \& Ammirati, Mycotaxon 74(1): 29. 2000.

Calonarius olympianus (A.H. Sm.) Niskanen \& Liimat., comb. nov.

IF555320

Basionym: Cortinarius olympianus A.H. Sm., Contr. Univ. Mich. Herb. 2: 13. 1939.

Calonarius osloensis (Brandrud, T.S. Jeppesen \& Frøslev) Niskanen \& Liimat., comb. nov.

IF555321

Basionym: Cortinarius osloensis Brandrud, T.S. Jeppesen \& Frøslev, in Frøslev, Brandrud \& Jeppesen, Mycotaxon 97: 369. 2006.

Calonarius osmophorus (P.D. Orton) Niskanen \& Liimat., comb. nov.

IF555322

Basionym: Cortinarius osmophorus P.D. Orton, Trans. Br. mycol. Soc. 43(2): 210. 1960.

Calonarius parasuaveolens (Bon \& Trescol) Niskanen \& Liimat., comb. \& stat. nov.

\section{IF555417}

Basionym: Cortinarius sodagnitus var. parasuaveolens Bon \& Trescol, Docums Mycol. 19(73): 36. 1988.

Calonarius piceae (Frøslev, T.S. Jeppesen \& Brandrud) Niskanen \& Liimat., comb. nov.

IF555418

Basionym: Cortinarius piceae Frøslev, T.S. Jeppesen \& Brandrud, in Frøslev, Brandrud \& Jeppesen, Mycotaxon 97: 372. 2006.

Calonarius platypus (M.M. Moser) Niskanen \& Liimat., comb. nov.

\section{IF556647}

Basionym: Phlegmacium platypus M.M. Moser, Die Gattung Phlegmacium (Schleimköpfe). Die Pilze Mitteleuropas 4: 353. 1960.

Calonarius praetermissus (Bergeron ex Reumaux) Niskanen \& Liimat., comb. nov.

IF556639

Basionym: Cortinarius praetermissus Bergeron ex Reumaux, in Bidaud, Moënne-Loccoz, Reumaux \& Henry, Atlas des Cortinaires, Pars V (Annecy): 151. 1993.

Calonarius prasinus (Schaeff.) Niskanen \& Liimat., comb. nov.

\section{IF558128}

Basionym: Agaricus prasinus Schaeff., Fung. bavar. palat. nasc. (Ratisbonae) 4: 51. 1774.

Calonarius pseudocisticola (Boccardo, Dovana, Dima, L. Albert, Borovička, Mikšík, Saar \& Vizzini) Niskanen \& Liimat., comb. nov.

IF557225

Basionym: Cortinarius pseudocisticola Boccardo, Dovana, Dima, L. Albert, Borovička, Mikšík, Saar \& Vizzini, in Dovana, Boccardo, Borovička, Vizzini, Saar, Albert, Mikšík, Clericuzio \& Dima, Phytotaxa 518(1): 17. 2021. 
Calonarius pseudocupreorufus (Niskanen, Liimat. \& Ammirati) Niskanen \& Liimat., comb. nov.

\section{IF558777}

Basionym: Cortinarius pseudocupreorufus Niskanen, Liimat. \& Ammirati, in Liimatainen, Niskanen, Dima, Kytövuori, Ammirati \& Frøslev, Persoonia 33: 127. 2014.

Calonarius pseudoglaucopus (Jul. Schäff. ex M.M. Moser) Niskanen \& Liimat., comb. nov.

\section{IF557992}

Basionym: Phlegmacium pseudoglaucopus Jul. Schäff. ex M.M. Moser, Die Gattung Phlegmacium (Schleimköpfe). Die Pilze Mitteleuropas 4: 354. 1960.

Calonarius pseudoparvus (Bidaud) Niskanen \& Liimat., comb. nov.

IF557993

Basionym: Cortinarius pseudoparvus Bidaud, in Bidaud, Moënne-Loccoz, Reumaux, Carteret \& Eyssartier, Atlas des Cortinaires (Meyzieu) 11: 614. 2001.

Calonarius quercus-ilicis (Chevassut \& Rob. Henry) Niskanen \& Liimat., comb. \& stat. nov.

\section{IF557864}

Basionym: Cortinarius elegantior var. quercus-ilicis Chevassut \& Rob. Henry, Docums Mycol. 5(no. 20): 34. 1975.

Calonarius rapaceoides (Bidaud, G. Riousset \& Riousset) Niskanen \& Liimat., comb. nov.

\section{IF558098}

Basionym: Cortinarius rapaceoides Bidaud, G. Riousset \& Riousset, Micologia 2000 (Trento): 68. 2000.

Calonarius rapaceotomentosus (Delaporte \& Eyssart.) Niskanen \& Liimat., comb. nov.

\section{IF558101}

Basionym: Cortinarius rapaceotomentosus Delaporte \& Eyssart., in Delaporte, Eyssartier \& Moënne-Loccoz, Bull. Soc. mycol. Fr. 118(1): 12. 2002.
Calonarius rufo-olivaceus (Pers.) Niskanen \& Liimat., comb. nov.

IF558102

Basionym: Agaricus rufo-olivaceus Pers., Syn. meth. fung. (Göttingen) 2: 285. 1801.

Calonarius sancti-felicis (Frøslev \& T.S. Jeppesen) Niskanen \& Liimat., comb. nov.

IF558109

Basionym: Cortinarius sancti-felicis Frøslev \& T.S. Jeppesen, in Frøslev, Jeppesen \& Læssøe, Mycol. Res. 110(9): 1053. 2006.

Calonarius sannio (M.M. Moser) Niskanen \& Liimat., comb. nov.

IF558111

Basionym: Cortinarius sannio M.M. Moser, in Moser \& Ammirati, Mycotaxon 72: 315. 1999.

Calonarius saporatus (Britzelm.) Niskanen \& Liimat., comb. nov.

IF558125

Basionym: Cortinarius saporatus Britzelm., Zur Hymenomycetenkunde 3: 5. 1897.

Calonarius saxamontanus (Fogel) Niskanen \& Liimat., comb. nov.

IF556154

Basionym: Cortinarius saxamontanus Fogel, Mycologia 86(6): 798. 1995. [1994].

Calonarius selandicus (Frøslev \& T.S. Jeppesen) Niskanen \& Liimat., comb. nov.

IF558324

Basionym: Cortinarius selandicus Frøslev \& T.S. Jeppesen, in Frøslev, Jeppesen \& Læssøe, Mycol. Res. 110(9): 1054. 2006.

Calonarius sodagnitus (Rob. Henry) Niskanen \& Liimat., comb. nov. 
IF557221

Basionym: Cortinarius sodagnitus Rob. Henry, Bull. trimest. Soc. mycol. Fr. 51(1): 44. 1935.

Calonarius spectabilis (M.M. Moser) Niskanen \& Liimat., comb. nov.

IF557719

Basionym: Cortinarius spectabilis M.M. Moser, Sydowia 6(1-4): 152. 1952.

Calonarius speculum (Moënne-Locc.) Niskanen \& Liimat., comb. nov.

IF558593

Basionym: Cortinarius speculum Moënne-Locc., in Bidaud, Moënne-Loccoz, Reumaux, Carteret \& Eyssartier, Atlas des Cortinaires (Meyzieu) 11: 614. 2001.

Calonarius splendens (Rob. Henry) Niskanen \& Liimat., comb. nov.

IF558848

Basionym: Cortinarius splendens Rob. Henry, Bull. trimest. Soc. mycol. Fr. 55(2): 178. 1939.

Calonarius splendidior (Bidaud) Niskanen \& Liimat., comb. nov.

\section{IF558849}

Basionym: Cortinarius splendidior Bidaud, in Bidaud, Moënne-Loccoz, Reumaux, Carteret \& Eyssartier, Atlas des Cortinaires (Meyzieu) 11: 614. 2001.

Calonarius splendificus (Chevassut \& Rob. Henry) Niskanen \& Liimat., comb. nov.

\section{IF558850}

Basionym: Cortinarius splendificus Chevassut \& Rob. Henry, Docums Mycol. 5(20): 33. 1975.

Calonarius suaveolens (Bat. \& Joachim) Niskanen \& Liimat., comb. nov.

IF558851
Basionym: Cortinarius suaveolens Bat. \& Joachim, Bull. Soc. mycol. Fr. 36(2): 85. 1920.

Calonarius subgracilis (Moënne-Locc.) Niskanen \& Liimat., comb. nov.

\section{IF558852}

Basionym: Cortinarius subgracilis Moënne-Locc., in Bidaud, Moënne-Loccoz, Reumaux, Carteret \& Eyssartier, Atlas des Cortinaires (Meyzieu) 11: 614. 2001.

Calonarius sublilacinopes (Bidaud, Moënne-Locc. \& Reumaux) Niskanen \& Liimat., comb. nov.

\section{IF558853}

Basionym: Cortinarius sublilacinopes Bidaud, MoënneLocc. \& Reumaux, in Bidaud, Moënne-Loccoz, Reumaux, Carteret \& Eyssartier, Atlas des Cortinaires (Meyzieu) 11: 614. 2001.

Calonarius subpurpureophyllus (A.H. Sm.) Niskanen \& Liimat., comb. nov.

\section{IF558854}

Basionym: Cortinarius subpurpureophyllus A.H. Sm., Contr. Univ. Mich. Herb. 2: 17. 1939.

Calonarius subsulfurinus (Ammirati, Dima, Liimat., Niskanen \& Garnica) Niskanen \& Liimat., comb. nov.

\section{IF558855}

Basionym: Cortinarius subsulfurinus Ammirati, Dima, Liimat., Niskanen \& Garnica, Index Fungorum 252: 1. 2015.

Calonarius sulfurinus (Quél.) Niskanen \& Liimat., comb. nov.

\section{IF558856}

Basionym: Cortinarius sulfurinus Quél., C. r. Assoc. Franç. Avancem. Sci. 12: 501. 1884.

Calonarius verrucisporus (Thiers \& A.H. Sm.) Niskanen \& Liimat., comb. nov.

IF558857 
Basionym: Cortinarius verrucisporus Thiers \& A.H. Sm., Mycologia 61: 533. 1969.

Calonarius vesterholtii (Frøslev \& T.S. Jeppesen) Niskanen \& Liimat., comb. nov.

IF558858

Basionym: Cortinarius vesterholtii Frøslev \& T.S. Jeppesen, in Frøslev, Jeppesen \& Læssøe, Mycol. Res. 110(9): 1055. 2006.

Calonarius violaceipes (Bidaud \& Consiglio) Niskanen \& Liimat., comb. nov.

\section{IF558859}

Basionym: Cortinarius violaceipes Bidaud \& Consiglio, in Bidaud, Moënne-Loccoz, Reumaux, Carteret \& Eyssartier, Atlas des Cortinaires (Meyzieu) 11: 615. 2001.

Calonarius viridirubescens (M.M. Moser \& Ammirati) Niskanen \& Liimat., comb. nov.

IF558860

Basionym: Cortinarius viridirubescens M.M. Moser \& Ammirati, Sydowia 49(1): 44. 1997.

Calonarius xanthochlorus (Rob. Henry) Niskanen \& Liimat., comb. nov.

\section{IF558861}

Basionym: Cortinarius xanthochlorus Rob. Henry, Bull. trimest. Soc. mycol. Fr. 82: 117. 1966.

Calonarius xanthodryophilus (Bojantchev \& R.M. Davis) Niskanen \& Liimat., comb. nov.

IF558862

Basionym: Cortinarius xanthodryophilus Bojantchev \& R.M. Davis, Mycotaxon 116: 321. 2011.

Calonarius xanthophyllus (Cooke) Niskanen \& Liimat., comb. \& stat. nov.

\section{IF558863}

Basionym: Cortinarius dibaphus var. xanthophyllus Cooke, Ill. Brit. Fung. (London) 5: pl.713 (753) 1886.

\section{Cystinarius}

Cystinarius crassus (Fr.) Niskanen \& Liimat., comb. nov.

\section{IF558864}

Basionym: Cortinarius crassus Fr., Epicr. syst. mycol. (Upsaliae): 257. 1838. [1836-1838].

Cystinarius paurigarhwalensis (Semwal, Dima \& Soop) Niskanen \& Liimat., comb. nov.

\section{IF558865}

Basionym: Cortinarius paurigarhwalensis Semwal, Dima \& Soop, in Yuan et al., Fungal Diversity: https://doi.org/10. 1007/s13225-020-00461-7, [108]. 2020.

Cystinarius rubicundulus (Rea) Niskanen \& Liimat., comb. nov.

IF558866

Basionym: Agaricus rubicundulus Rea, Grevillea 22(no. 102): 401893 .

Cystinarius subgemmeus (Soop) Niskanen \& Liimat., comb. nov.

\section{IF558867}

Basionym: Cortinarius subgemmeus Soop, Bull. Soc. mycol. Fr. 118(3): 182. 2003. [2002].

\section{Hygronarius}

Hygronarius sect. Austroduracini (Soop \& Dima) Niskanen \& Liimat., comb. nov.

IF553403

Basionym: Cortinarius sect. Austroduracini Soop \& Dima, in Soop, Dima, Cooper, Park \& Oertel, Persoonia 42: 285. 2019.

Hygronarius austroduracinus (M.M. Moser) Liimat. \& Niskanen, comb. nov.

\section{IF558868}

Basionym: Cortinarius austroduracinus M.M. Moser, in Moser \& Horak, Beih. Nova Hedwigia 52: 400. 1975. 
Hygronarius parahumilis (Garnica) Liimat. \& Niskanen, comb. nov.

IF558869

Basionym: Cortinarius parahumilis Garnica, Mycologia 94(1): 142. 2002.

Hygronarius viridibasalis (M.M. Moser) Liimat. \& Niskanen, comb. nov.

IF558870

Basionym: Cortinarius viridibasalis M.M. Moser, in Moser \& Horak, Beih. Nova Hedwigia 52: 321. 1975.

\section{Phlegmacium}

Phlegmacium sect. Amoenolentia (Brandrud \& Melot) Niskanen \& Liimat., comb. nov.

IF558871

Basionym: Cortinarius sect. Amoenolentes Brandrud \& Melot, Nord. J. Bot. 10: 535 (1990).

Phlegmacium sect. Arcifolia (Bidaud \& Reumaux) Niskanen \& Liimat., comb. \& stat. nov.

IF558872

Basionym: Cortinarius subsect. Arcifolii Bidaud \& Reumaux, in Bidaud, Moënne-Loccoz, Reumaux, Carteret \& Eyssartier, Atlas des Cortinaires (Meyzieu) 17(2): 1235. 2008.

Phlegmacium sect. Arguta (Brandrud \& Melot) Niskanen \& Liimat., comb. \& stat. nov.

\section{IF558873}

Basionym: Cortinarius subsect. Arguti Brandrud \& Melot in Nord. J. Bot. 10: 535. 1990.

Phlegmacium sect. Aureocistophila (Fernàndez-Brime ex Soop, B. Oertel \& Dima) Niskanen \& Liimat., comb. nov.

\section{IF558874}

Basionym: Cortinarius sect. Aureocistophili Soop, B. Oertel \& Dima, in Soop, Dima, Cooper, Park \& Oertel, Persoonia 42: 277. 2019.
Phlegmacium sect. Caerulescentia (Rob. Henry ex MoënneLocc. \& Reum) Niskanen \& Liimat., comb. nov.

IF558875

Basionym: Cortinarius sect. Caerulescentes Rob. Henry ex Moënne-Locc. \& Reum, in Atlas des Cortinaires, Pars I (Annecy): 16. 1990.

Phlegmacium sect. Caesiocortinata (Frøslev \& T.S. Jeppesen) Niskanen \& Liimat., comb. nov.

\section{IF558876}

Basionym: Cortinarius sect. Caesiocortinati Frøslev \& T.S. Jeppesen, in Frøslev, Matheny \& Hibbett, Mol. Phylogen. Evol. 37(2): 616. 2005.

Phlegmacium sect. Carbonella (Soop) Niskanen \& Liimat., comb. nov.

\section{IF558877}

Basionym: Cortinarius sect. Carbonelli Soop, in Soop, Dima, Cooper, Park \& Oertel, Persoonia 42: 286. 2019.

Phlegmacium sect. Claricoloria (Kühner \& Romagn. ex Moënne-Locc. \& Reumaux) Niskanen \& Liimat., comb. nov.

IF558878

Basionym: Cortinarius sect. Claricolores Kühner \& Romagn. ex Moënne-Locc. \& Reumaux, Atlas des Cortinaires, Pars 1 (Annecy): 17. 1990.

Phlegmacium sect. Elastica (Fr.) Niskanen \& Liimat., comb. \& stat. nov.

\section{IF558879}

Basionym: Cortinarius $\dagger \dagger \dagger \dagger$ Elastici Fr., Epicr. syst. mycol. (Upsaliae): 269. 1838 (1836-1838).

Phlegmacium sect. Glaucopodes (Kühner \& Romagn. ex Moënne-Locc. \& Reumaux) Niskanen \& Liimat., comb. nov.

\section{IF558880}

Basionym: Cortinarius sect. Glaucopodes Kühner \& Romagn. ex Moënne-Locc. \& Reumaux, Atlas des Cortinaires, Pars 1 (Annecy): 16. 1990. 
Phlegmacium sect. Percomia (M. M. Moser ex MoënneLocc. \& Reumaux) Niskanen \& Liimat., comb. \& stat. nov.

IF558881

Basionym: Cortinarius subsect. Percomes M. M. Moser ex Moënne-Locc. \& Reumaux, Atlas des Cortinaires, Pars 1 (Annecy): 17. 1990.

Phlegmacium sect. Phlegmacioida (Fr.) Niskanen \& Liimat., comb. \& stat. nov.

\section{IF558882}

Basionym: Agaricus $\dagger \dagger$ Phlegmacioidea Fr., Syst. mycol. (Lundae) 1: 222. 1821.

Phlegmacium sect. Seraria (Brandrud) Niskanen \& Liimat., comb. \& stat. nov.

\section{IF558884}

Basionym: Cortinarius subsect. Serarii Brandrud, Edinb. J. Bot. 54(1): 115. 1997.

Phlegmacium sect. Subhymenogaster (Soop, B. Oertel \& Dima) Niskanen \& Liimat., comb. nov.

\section{IF558885}

Basionym: Cortinarius sect. Subhymenogaster Soop, B. Oertel \& Dima, in Soop, Dima, Cooper, Park \& Oertel, Persoonia 42: 281. 2019.

Phlegmacium sect. Varia (Soop, Brandrud, Saar \& Dima) Niskanen \& Liimat., comb. \& stat. nov.

\section{IF558886}

Basionym: Cortinarius subsect. Varii Soop, Brandrud, Saar \& Dima, in Schmidt-Stohn, Saar, Soop, Brandrud \& Dima, Journal des J.E.C 22: 37. 2020.

Phlegmacium acidophilum (Brandrud) Niskanen \& Liimat., comb. nov.

\section{IF558887}

Basionym: Cortinarius acidophilus Brandrud, Edinb. J. Bot. 54(1): 114. 1997.

Phlegmacium acystidiosum (Thiers) Niskanen \& Liimat., comb. nov.
IF558888

Basionym: Cortinarius acystidiosus Thiers, Mycologia 51(4): 530. 1960.

Phlegmacium albescens (A.H. Sm.) Niskanen \& Liimat., comb. nov.

IF558889

Basionym: Cortinarius albescens A.H. Sm., Lloydia 7(3): 180. 1944.

Phlegmacium albofragrans (Ammirati \& M.M. Moser) Niskanen \& Liimat., comb. nov.

IF558890

Basionym: Cortinarius albofragrans Ammirati \& M.M. Moser, in Moser \& Ammirati, Sydowia 49(1): 27. 1997.

Phlegmacium alticaudum (Reumaux) Niskanen \& Liimat., comb. nov.

IF558891

Basionym: Cortinarius alticaudus Reumaux, in Bidaud, Moënne-Loccoz, Reumaux, Carteret \& Eyssartier, Atlas des Cortinaires (Meyzieu) 17(2): 1236. 2008.

Phlegmacium americanomussivum (Liimat. \& Niskanen) Niskanen \& Liimat., comb. nov.

\section{IF558892}

Basionym: Cortinarius americanomussivus Liimat. \& Niskanen, in Niskanen \& Liimatainen, Index Fungorum 487: 6. 2021.

Phlegmacium amoenolens (Rob. Henry ex P.D. Orton) Niskanen \& Liimat., comb. nov.

\section{IF558893}

Basionym: Cortinarius amoenolens Rob. Henry ex P.D. Orton, Trans. Br. mycol. Soc. 43(2): 206. 1960.

Phlegmacium aquilanum (T.S. Jeppesen \& Frøslev) Niskanen \& Liimat., comb. nov.

IF558894 
Basionym: Cortinarius aquilanus T.S. Jeppesen \& Frøslev, Mycotaxon 106: 470. 2009. (2008).

Phlegmacium areni-silvae (Brandrud) Niskanen \& Liimat., comb. \& stat. nov.

\section{IF558895}

Basionym: Cortinarius balteatoalbus var. areni-silvis Brandrud, Edinb. J. Bot. 54(1): 114. 1997.

Phlegmacium areolatoimbricatum (Cleland) Niskanen \& Liimat., comb. nov.

\section{IF558896}

Basionym: Cortinarius areolatoimbricatus Cleland, Trans. \& Proc. Roy. Soc. S. Australia 57: 191. 1933.

Phlegmacium argutum (Fr.) Niskanen \& Liimat., comb. nov.

\section{IF558897}

Basionym: Cortinarius argutus Fr., Epicr. syst. mycol. (Upsaliae): 278. 1838. (1836-1838).

Phlegmacium artosum (Soop) Niskanen \& Liimat., comb. nov.

\section{IF558898}

Basionym: Cortinarius artosus Soop, N.Z. Jl Bot. 52: 338. 2014.

Phlegmacium atrochalybaeum (Ammirati \& M.M. Moser) Niskanen \& Liimat., comb. nov.

\section{IF553525}

Basionym: Cortinarius atrochalybaeus Ammirati \& M.M. Moser, Mycotaxon 74(1): 19. 2000.

Phlegmacium aurantiobasalis (Bidaud) Niskanen \& Liimat., comb. nov.

\section{IF558899}

Basionym: Cortinarius aurantiobasalis Bidaud, in Bidaud, Moënne-Loccoz, Reumaux \& Henry, Atlas des Cortinaires, Pars V (Annecy): 150. 1993.

Phlegmacium aurantiopallidum (Bidaud) Niskanen \& Liimat., comb. nov.
IF558900

Basionym: Cortinarius aurantiopallidus Bidaud, in Bidaud, Moënne-Loccoz, Reumaux, Carteret \& Eyssartier, Atlas des Cortinaires (Meyzieu) 16: 1100. 2006.

Phlegmacium aureocistophilum (Vila, Contu \& Llimona) Niskanen \& Liimat., comb. nov.

IF558901

Basionym: Cortinarius aureocistophilus Vila, Contu \& Llimona, Revta Catal. Micol. 28: 173. 2006.

Phlegmacium aurescens (Ammirati, Bojantchev, Garnica, Beug, Liimat. \& Niskanen) Niskanen \& Liimat., comb. nov.

\section{IF558902}

Basionym: Cortinarius aurescens Ammirati, Bojantchev, Garnica, Beug, Liimat. \& Niskanen, in Liimatainen, Index Fungorum 241: 1. 2015.

Phlegmacium aurilicis (Chevassut \& Trescol) Niskanen \& Liimat., comb. nov.

IF558903

Basionym: Cortinarius aurilicis Chevassut \& Trescol, Docums Mycol. 16(63-64): 71. 1986.

Phlegmacium balteatialutaceum (Kytöv., Liimat. \& Niskanen) Niskanen \& Liimat., comb. nov.

\section{IF558904}

Basionym: Cortinarius balteatialutaceus Kytöv., Liimat. \& Niskanen, in Liimatainen, Niskanen, Dima, Kytövuori, Ammirati \& Frøslev, Persoonia 33: 134. 2014.

Phlegmacium balteatibulbosum (Kytöv., Niskanen, Liimat., Bojantchev \& A.F.S. Taylor) Niskanen \& Liimat., comb. nov.

\section{IF558905}

Basionym: Cortinarius balteatibulbosus Kytöv., Niskanen, Liimat., Bojantchev \& A.F.S. Taylor, in Liimatainen, Niskanen, Dima, Kytövuori, Ammirati \& Frøslev, Persoonia 33: 134. 2014.

Phlegmacium balteaticlavatum (Kytöv., Liimat. \& Niskanen) Niskanen \& Liimat., comb. nov. 


\section{IF558906}

Basionym: Cortinarius balteaticlavatus Kytöv., Liimat. \& Niskanen, in Liimatainen, Niskanen, Dima, Kytövuori, Ammirati \& Frøslev, Persoonia 33: 135. 2014.

Phlegmacium balteatocumatile (Rob. Henry ex P.D. Orton) Niskanen \& Liimat., comb. nov.

IF558907

Basionym: Cortinarius balteatocumatilis Rob. Henry ex P.D. Orton, Trans. Br. mycol. Soc. 43(2): 207. 1960.

Phlegmacium balteatum (Fr.) Niskanen \& Liimat., comb. nov.

\section{IF558908}

Basionym: Cortinarius balteatus Fr., Epicr. syst. mycol. (Upsaliae): 257. 1838. (1836-1838).

Phlegmacium beugii (Ammirati, Bojantchev, Liimat., Niskanen \& Garnica) Niskanen \& Liimat., comb. nov.

IF558910

Basionym: Cortinarius beugii Ammirati, Bojantchev, Liimat., Niskanen \& Garnica, in Liimatainen, Index Fungorum 241: 2. 2015.

Phlegmacium bisporiger (Contu) Niskanen \& Liimat., comb. nov.

IF558911

Basionym: Cortinarius bisporiger Contu, Cryptog. Mycol. 13(2): 100. 1992.

Phlegmacium blattoi (R. Mazza) Niskanen \& Liimat., comb. nov.

IF558912

Basionym: Cortinarius blattoi R. Mazza, Boll. Circolo Micologico 'Giovanni Carini' 23: 15. 1992.

Phlegmacium boreicyanites (Kytöv., Liimat., Niskanen \& A.F.S. Taylor) Niskanen \& Liimat., comb. nov.

IF558913
Basionym: Cortinarius boreicyanites Kytöv., Liimat., Niskanen \& A.F.S. Taylor, in Liimatainen, Niskanen, Dima, Kytövuori, Ammirati \& Frøslev, Persoonia 33: 127. 2014.

Phlegmacium borgsjoeense (Brandrud) Niskanen \& Liimat., comb. nov.

\section{IF558914}

Basionym: Cortinarius borgsjoeensis Brandrud, in Brandrud, Lindström, Marklund, Melot \& Muskos, Cortinarius, Flora Photographica vol. 2 (Sweden): 33. 1992.

Phlegmacium brunneiaurantium (Kytöv., Liimat. \& Niskanen) Niskanen \& Liimat., comb. nov.

IF558915

Basionym: Cortinarius brunneiaurantius Kytöv., Liimat. \& Niskanen, in Liimatainen, Niskanen, Dima, Kytövuori, Ammirati \& Frøslev, Persoonia 33: 136. 2014.

Phlegmacium brunneocoerulescens (Rob. Henry) Niskanen \& Liimat., comb. nov.

IF558916

Basionym: Cortinarius brunneocoerulescens Rob. Henry, Bull. trimest. Soc. mycol. Fr. 73(1): 25. 1957.

Phlegmacium brunneolividum (Bidaud) Niskanen \& Liimat., comb. nov.

IF558917

Basionym: Cortinarius brunneolividus Bidaud, in Bidaud, Moënne-Loccoz, Reumaux \& Henry, Atlas des Cortinaires (Meyzieu) 8: 290. 1996.

Phlegmacium brunneoviolaceum (Bidaud) Niskanen \& Liimat., comb. nov.

IF558918

Basionym: Cortinarius brunneoviolaceus Bidaud, in Bidaud, Moënne-Loccoz, Reumaux \& Henry, Atlas des Cortinaires (Meyzieu) 8: 291. 1996.

Phlegmacium brunnescens (A.H. Sm.) Niskanen \& Liimat., comb. nov.

IF558919

Basionym: Hymenogaster brunnescens A.H. Sm., Mycologia 58(1): 111. 1966. 
Phlegmacium bulbolatens (Chevassut \& Rob. Henry) Niskanen \& Liimat., comb. nov.

IF558920

Basionym: Cortinarius bulbolatens Chevassut \& Rob. Henry, Docums Mycol. 16(63-64): 83. 1986.

Phlegmacium caesiocolor (Kytöv., Liimat. \& Niskanen) Niskanen \& Liimat., comb. nov.

IF558921

Basionym: Cortinarius caesiocolor Kytöv., Liimat. \& Niskanen, in Liimatainen, Niskanen, Dima, Kytövuori, Ammirati \& Frøslev, Persoonia 33: 136. 2014.

Phlegmacium caesiocortinatum (Jul. Schäff.) Niskanen \& Liimat., comb. nov.

IF558922

Basionym: Cortinarius caesiocortinatus Jul. Schäff., Sydowia 5(3-6): 359. 1951.

Phlegmacium caligatum (Malençon) Niskanen \& Liimat., comb. nov.

IF558923

Basionym: Cortinarius caligatus Malençon, in Malençon \& Bertault, Champignon Supérieurs du Maroc 1: 482. 1970.

Phlegmacium callimorphum (Bojantchev \& R.M. Davis) Niskanen \& Liimat., comb. nov.

\section{IF558924}

Basionym: Cortinarius callimorphus Bojantchev \& R.M. Davis, Mycotaxon 117: 3. 2011.

Phlegmacium calyptratum (A.H. Sm.) Niskanen \& Liimat., comb. nov.

IF558925

Basionym: Cortinarius calyptratus A.H. Sm., Contr. Univ. Mich. Herb. 2: 14. 1939.

Phlegmacium calyptrodermum (A.H. Sm.) Niskanen \& Liimat., comb. nov.

IF558926
Basionym: Cortinarius calyptrodermus A.H. Sm., Bull. Torrey bot. Club 69(1): 51. 1942.

Phlegmacium camptoros (Brandrud \& Melot) Niskanen \& Liimat., comb. nov.

IF558927

Basionym: Cortinarius camptoros Brandrud \& Melot, Bull. trimest. Soc. mycol. Fr. 99(2): 219. 1983.

Phlegmacium castaneicolor (A.H. Sm.) Niskanen \& Liimat., comb. nov.

IF558928

Basionym: Cortinarius castaneicolor A.H. Sm., Lloydia 7(3): 165. 1944.

Phlegmacium cephalixoides (M.M. Moser \& Thiers) Niskanen \& Liimat., comb. nov.

IF558929

Basionym: Cortinarius cephalixoides M.M. Moser \& Thiers, in Moser, McKnight \& Ammirati, Mycotaxon 55: 309. 1995.

Phlegmacium cephalixolargum (Rob. Henry) Niskanen \& Liimat., comb. nov.

IF558930

Basionym: Cortinarius cephalixolargus Rob. Henry, Bull. trimest. Soc. mycol. Fr. 93(3): 323. 1977.

Phlegmacium chromataphilum (Rob. Henry) Niskanen \& Liimat., comb. nov.

IF558931

Basionym: Cortinarius chromataphilus Rob. Henry, Bull. trimest. Soc. mycol. Fr. 105(1): 97. 1989.

Phlegmacium cinctipes (Bidaud, Eyssart. \& Hermitte) Niskanen \& Liimat., comb. nov.

IF558932

Basionym: Cortinarius cinctipes Bidaud, Eyssart. \& Hermitte, in Bidaud \& Eyssartier, Bulletin Semestriel de la Fédération des Associations Mycologiques Méditerranéennes 25: 32. 2004. 
Phlegmacium cistoglaucopus (A. Ortega, Vila, J.C. Campos \& Fern.-Brime) Niskanen \& Liimat., comb. nov.

IF558933

Basionym: Cortinarius cistoglaucopus A. Ortega, Vila, J.C. Campos \& Fern.-Brime, Mycologia 106(3): 499. 2014.

Phlegmacium citrinifolium (A.H. Sm.) Niskanen \& Liimat., comb. nov.

IF558934

Basionym: Cortinarius citrinifolius A.H. Sm., Contr. Univ. Mich. Herb. 2: 9. 1939.

Phlegmacium citriolens (Ammirati \& M.M. Moser) Niskanen \& Liimat., comb. nov.

IF558935

Basionym: Cortinarius citriolens Ammirati \& M.M. Moser, in Moser \& Ammirati, Mycotaxon 72: 296. 1999.

Phlegmacium clarobaltoides (Rob. Henry) Niskanen \& Liimat., comb. nov.

IF558936

Basionym: Cortinarius clarobaltoides Rob. Henry, Bull. trimest. Soc. mycol. Fr. 105(1): 97. 1989.

Phlegmacium clarum (Reumaux) Niskanen \& Liimat., comb. nov.

\section{IF558937}

Basionym: Cortinarius clarus Reumaux, in Bidaud, Moënne-Loccoz, Reumaux \& Henry, Atlas des Cortinaires (Meyzieu) 8: 291. 1996.

Phlegmacium cliduchus (Secr. ex Fr.) Niskanen \& Liimat., comb. nov.

\section{IF558938}

Basionym: Cortinarius cliduchus Secr. ex Fr., Epicr. syst. mycol. (Upsaliae): 260. 1838. (1836-1838).

Phlegmacium coalescens (Kärcher \& Seibt) Niskanen \& Liimat., comb. nov.
Basionym: Cortinarius coalescens Kärcher \& Seibt, Z. Mykol. 54(1): 78. 1988.

Phlegmacium coelopus (Gasparini) Niskanen \& Liimat., comb. nov.

IF558940

Basionym: Cortinarius coelopus Gasparini, N.Z. J1 Bot. 45(1): 177. 2007.

Phlegmacium coerulescentium (Rob. Henry) Niskanen \& Liimat., comb. nov.

IF558941

Basionym: Cortinarius coerulescentium Rob. Henry, Bull. trimest. Soc. mycol. Fr. 67(3): 282. 1952. (1951).

Phlegmacium concrescens (Secr. ex Bidaud, Moënne-Locc. \& Reumaux) Niskanen \& Liimat., comb. nov.

IF558942

Basionym: Cortinarius concrescens Secr. ex Bidaud, Moënne-Locc. \& Reumaux, in Bidaud, Moënne-Loccoz, Reumaux \& Henry, Atlas des Cortinaires (Meyzieu) 7: 228. 1995.

Phlegmacium congeminum (Moënne-Locc. \& Reumaux) Niskanen \& Liimat., comb. nov.

\section{IF558943}

Basionym: Cortinarius congeminus Moënne-Locc. \& Reumaux, in Bidaud, Moënne-Loccoz, Reumaux \& Henry, Atlas des Cortinaires (Meyzieu) 7: 228. 1995.

Phlegmacium cremeiamarescens (Kytöv., Liimat. \& Niskanen) Niskanen \& Liimat., comb. nov.

IF558944

Basionym: Cortinarius cremeiamarescens Kytöv., Liimat. \& Niskanen, in Liimatainen, Niskanen, Dima, Kytövuori, Ammirati \& Frøslev, Persoonia 33: 122. 2014.

Phlegmacium cruentipellis (Kytöv., Liimat., Niskanen \& Dima) Niskanen \& Liimat., comb. nov.

IF558945

IF558939 
Basionym: Cortinarius cruentipellis Kytöv., Liimat., Niskanen \& Dima, in Liimatainen, Niskanen, Dima, Kytövuori, Ammirati \& Frøslev, Persoonia 33: 128. 2014.

Phlegmacium cupreonatum (Soop) Niskanen \& Liimat., comb. nov

IF558946

Basionym: Cortinarius cupreonatus Soop, Bull. Soc. mycol. Fr. 117(2): 99. 2001.

Phlegmacium cupreoviolaceum (Bidaud \& Reumaux) Niskanen \& Liimat., comb. nov.

\section{IF558947}

Basionym: Cortinarius cupreoviolaceus Bidaud \& Reumaux, in Bidaud, Moënne-Loccoz, Reumaux \& Henry, Atlas des Cortinaires (Meyzieu) 8: 292. 1996.

Phlegmacium daulnoyae (Quél.) Niskanen \& Liimat., comb. \& stat. nov.

\section{IF558948}

Basionym: Cortinarius cumatilis var. daulnoyae Quél., C. r. Assoc. Franç. Avancem. Sci. 18(2): 510. 1890. (1889).

Phlegmacium decolorans (Pers.) Niskanen \& Liimat., comb. nov.

\section{IF558952}

Basionym: Agaricus decolorans Pers., Observ. mycol. (Lipsiae) 1: 52. 1796.

Phlegmacium delaportei (Rob. Henry) Niskanen \& Liimat., comb. nov.

IF558949

Basionym: Cortinarius delaportei Rob. Henry, Docums Mycol. 19(no. 73): 70. 1988.

Phlegmacium durus (P.D. Orton) Niskanen \& Liimat., comb. nov.

IF558950

Basionym: Cortinarius durus P.D. Orton, Trans. Br. mycol. Soc. 43(2): 209. 1960.
Phlegmacium eliae (Bidaud, Moënne-Locc. \& Reumaux) Niskanen \& Liimat., comb. nov.

IF558951

Basionym: Cortinarius eliae Bidaud, Moënne-Locc. \& Reumaux, in Bidaud, Moënne-Loccoz, Reumaux \& Henry, Atlas des Cortinaires (Meyzieu) 8: 292. 1996.

Phlegmacium eucaeruleum (Rob. Henry) Niskanen \& Liimat., comb. nov.

\section{IF558952}

Basionym: Cortinarius eucaeruleus Rob. Henry, Docums Mycol. 20(no. 77): 69. 1989.

Phlegmacium exlugubre (Soop) Niskanen \& Liimat., comb. nov.

\section{IF558953}

Basionym: Cortinarius exlugubris Soop, Bull. Soc. mycol. Fr. 117(2): 98. 2001.

Phlegmacium flavescentipes (Reumaux) Niskanen \& Liimat., comb. nov.

\section{IF558954}

Basionym: Cortinarius flavescentipes Reumaux, in Bidaud, Moënne-Loccoz, Reumaux \& Henry, Atlas des Cortinaires (Meyzieu) 8: 292. 1996.

Phlegmacium flavivelatum (Kytöv., Liimat. \& Niskanen) Niskanen \& Liimat., comb. nov.

\section{IF558955}

Basionym: Cortinarius flavivelatus Kytöv., Liimat. \& Niskanen, in Liimatainen, Niskanen, Dima, Kytövuori, Ammirati \& Frøslev, Persoonia 33: 123. 2014.

Phlegmacium fraudulosoides (Liimat. \& Niskanen) Niskanen \& Liimat., comb. nov.

\section{IF558956}

Basionym: Cortinarius fraudulosoides Liimat. \& Niskanen, in Niskanen, Index Fungorum 186: 1. 2014.

Phlegmacium fraudulosum (Britzelm.) Niskanen \& Liimat., comb. nov. 


\section{IF558957}

Basionym: Cortinarius fraudulosus Britzelm., Ber. naturhist. Augsburg 28: 122. 1885.

Phlegmacium gentianeum (Bidaud) Niskanen \& Liimat., comb. nov.

IF558958

Basionym: Cortinarius gentianeus Bidaud, in Bidaud, Moënne-Loccoz, Reumaux \& Henry, Atlas des Cortinaires, Pars V (Annecy): 150. 1993.

Phlegmacium georgiolens (Rob. Henry) Niskanen \& Liimat., comb. nov.

IF558959

Basionym: Cortinarius georgiolens Rob. Henry, Bull. trimest. Soc. mycol. Fr. 102(1): 76. 1986.

Phlegmacium glaucopoides (Kauffman) Niskanen \& Liimat., comb. nov.

IF558960

Basionym: Cortinarius glaucopoides Kauffman, Pap. Mich. Acad. Sci. 1: 133. 1921.

Phlegmacium griseocoeruleum (Ammirati \& M.M. Moser) Niskanen \& Liimat., comb. nov.

\section{IF558961}

Basionym: Cortinarius griseocoeruleus Ammirati \& M.M. Moser, in Moser \& Ammirati, Sydowia 49(1): 33. 1997.

Phlegmacium hedyaromaticum (C.L. Cripps \& O.K. Mill.) Niskanen \& Liimat., comb. nov.

\section{IF558962}

Basionym: Cortinarius hedyaromaticus C.L. Cripps \& O.K. Mill., Mycotaxon 50: 316. 1994.

Phlegmacium herculeum (Malençon) Niskanen \& Liimat., comb. nov.

\section{IF558963}

Basionym: Cortinarius herculeus Malençon, C. r. Seanc. mens. Soc. Sci. nat. phys. Maroc 23: 159. 1958.
Phlegmacium hysginicolor (Bidaud) Niskanen \& Liimat., comb. nov.

\section{IF558964}

Basionym: Cortinarius hysginicolor Bidaud, in Bidaud, Moënne-Loccoz, Reumaux \& Henry, Atlas des Cortinaires (Meyzieu) 7: 229. 1995.

Phlegmacium inexspectatum (Brandrud) Niskanen \& Liimat., comb. nov.

\section{IF558965}

Basionym: Cortinarius inexspectatus Brandrud, Docums Mycol. 20(no. 77): 110. 1989.

Phlegmacium inusitatum (A. Ortega, Bidaud, Suár.-Sant. \& Vila) Niskanen \& Liimat., comb. nov.

\section{IF558966}

Basionym: Cortinarius inusitatus A. Ortega, Bidaud, Suár.Sant. \& Vila, Fungal Diversity 36: 91. 2009.

Phlegmacium josephii (Reumaux) Niskanen \& Liimat., comb. nov.

IF558967

Basionym: Cortinarius josephii Reumaux, in Bidaud, Moënne-Loccoz, Reumaux, Carteret \& Eyssartier, Atlas des Cortinaires (Meyzieu) 16: 1099. 2006.

Phlegmacium kuehneri (M.M. Moser) Niskanen \& Liimat., comb. nov.

\section{IF558968}

Basionym: Cortinarius kuehneri M.M. Moser, Bull. mens. Soc. linn. Lyon 43(Num. spéc.): 288. 1974.

Phlegmacium kytoevuorii (Niskanen \& Liimat.) Niskanen \& Liimat., comb. nov.

\section{IF558969}

Basionym: Cortinarius kytoevuorii Niskanen \& Liimat., in Liimatainen, Niskanen, Dima, Kytövuori, Ammirati \& Frøslev, Persoonia 33: 124. 2014.

Phlegmacium langei (Rob. Henry) Niskanen \& Liimat., comb. nov. 


\section{IF558970}

Basionym: Cortinarius langei Rob. Henry, Docums Mycol. 16(61): 22. 1985.

Phlegmacium latoclaricolor (Rob. Henry) Niskanen \& Liimat., comb. nov.

IF558971

Basionym: Cortinarius latoclaricolor Rob. Henry, Bull. trimest. Soc. mycol. Fr. 105(1): 91. 1989.

Phlegmacium lavendulense (Cleland) Niskanen \& Liimat., comb. nov.

IF558972

Basionym: Cortinarius lavendulensis Cleland, Trans. \& Proc. Roy. Soc. S. Australia 52: 217. 1928.

Phlegmacium leonicolor (Reumaux) Niskanen \& Liimat., comb. nov.

IF558973

Basionym: Cortinarius leonicolor Reumaux, in Bidaud, Moënne-Loccoz, Reumaux, Carteret \& Eyssartier, Atlas des Cortinaires (Meyzieu) 11: 613. 2001.

Phlegmacium lepistoides (T.S. Jeppesen \& Frøslev) Niskanen \& Liimat., comb. nov.

\section{IF558974}

Basionym: Cortinarius lepistoides T.S. Jeppesen \& Frøslev, Mycotaxon 106: 474. 2009. (2008).

Phlegmacium lilacinoides (Soop, B. Oertel \& Dima) Niskanen \& Liimat., comb. nov.

IF558975

Basionym: Cortinarius lilacinoides Soop, B. Oertel \& Dima, in Soop, Dima, Cooper, Park \& Oertel, Persoonia 42: 281. 2019.

Phlegmacium luhmannii (Münzmay, Saar \& B. Oertel) Niskanen \& Liimat., comb. nov.

IF558976
Basionym: Cortinarius luhmannii Münzmay, Saar \& B. Oertel, Journal des JEC, Journées Européenes du Cortinaire 7(no. 6): 31. 2004.

Phlegmacium luteiaureum (Kytöv., Liimat. \& Niskanen) Niskanen \& Liimat., comb. nov.

IF558977

Basionym: Cortinarius luteiaureus Kytöv., Liimat. \& Niskanen, in Liimatainen, Niskanen, Dima, Kytövuori, Ammirati \& Frøslev, Persoonia 33: 129. 2014.

Phlegmacium luteoarmillatum (A.H. Sm.) Niskanen \& Liimat., comb. nov.

IF558978

Basionym: Cortinarius luteoarmillatus A.H. Sm., Bull. Torrey bot. Club 69(1): 59. 1942.

Phlegmacium luteobrunnescens (A.H. Sm.) Niskanen \& Liimat., comb. nov.

IF558979

Basionym: Cortinarius luteobrunnescens A.H. Sm., Lloydia 7(3): 170. 1944.

Phlegmacium luteocingulatum (Bidaud \& Fillion) Niskanen \& Liimat., comb. nov.

\section{IF558980}

Basionym: Cortinarius luteocingulatus Bidaud \& Fillion, Bull. trimest. Féd. Mycol. Dauphiné-Savoie 31(no. 124):9. 1992.

Phlegmacium luteoimmarginatum (Rob. Henry) Niskanen \& Liimat., comb. \& stat. nov.

IF558981

Basionym: Cortinarius multiformis var. luteoimmarginatus Rob. Henry, Bull. trimest. Soc. mycol. Fr. 55(1): 68 and 70. 1939.

Phlegmacium luteovaginans (Bidaud \& Faurite-Gendron) Niskanen \& Liimat., comb. nov.

IF558982 
Basionym: Cortinarius luteovaginans Bidaud \& FauriteGendron, in Bidaud, Moënne-Loccoz, Reumaux, Carteret \& Eyssartier, Atlas des Cortinaires (Meyzieu) 16: 1100. 2006.

Phlegmacium maculipes (Peck) Niskanen \& Liimat., comb. nov.

\section{IF558983}

Basionym: Cortinarius maculipes Peck, Ann. Rep. Reg. N.Y. St. Mus. 54: 150. 1902. (1901).

Phlegmacium maculosum (Pers.) Niskanen \& Liimat., comb. nov.

\section{IF558984}

Basionym: Agaricus maculosus Pers., Syn. meth. fung. (Göttingen) 2: 288. 1801 .

Phlegmacium mahiquesii (Vila, A. Ortega \& Suár.-Sant.) Niskanen \& Liimat., comb. nov.

\section{IF558985}

Basionym: Cortinarius mahiquesii Vila, A. Ortega \& Suár.Sant., Persoonia 21: 154. 2008.

Phlegmacium majoranae (Frøslev \& T.S. Jeppesen) Niskanen \& Liimat., comb. nov.

\section{IF558986}

Basionym: Cortinarius majoranae Frøslev \& T.S. Jeppesen, Mycotaxon 106: 472. 2009. (2008).

Phlegmacium mediterraneense (A. Ortega \& Vila) Niskanen \& Liimat., comb. nov.

\section{IF558987}

Basionym: Cortinarius mediterraneensis A. Ortega \& Vila, Mycologia 106(3): 494. 2014.

Phlegmacium memoria-annae (Gasparini) Niskanen \& Liimat., comb. nov.

\section{IF558988}

Basionym: Cortinarius memoria-annae Gasparini, N.Z. J1 Bot. 45(1): 195. 2007.
Phlegmacium misermontii (Chevassut \& Rob. Henry) Niskanen \& Liimat., comb. nov.

\section{IF558989}

Basionym: Cortinarius misermontii Chevassut \& Rob. Henry, Docums Mycol. 16(nos 63-64): 93. 1986.

Phlegmacium moenne-loccozii (Bidaud) Niskanen \& Liimat., comb. nov.

\section{IF558990}

Basionym: Cortinarius moenne-loccozii Bidaud, in Bidaud, Moënne-Loccoz, Reumaux \& Henry, Atlas des Cortinaires, Pars V (Annecy): 151. 1993.

Phlegmacium muricinicolor (Moënne-Locc.) Niskanen \& Liimat., comb. nov.

IF558991

Basionym: Cortinarius muricinicolor Moënne-Locc., in Bidaud, Moënne-Loccoz, Reumaux \& Henry, Atlas des Cortinaires (Meyzieu) 8: 295. 1996.

Phlegmacium myrtilliphilum (Kytöv., Liimat., Niskanen \& Brandrud) Niskanen \& Liimat., comb. nov.

IF558992

Basionym: Cortinarius myrtilliphilus Kytöv., Liimat., Niskanen \& Brandrud, in Liimatainen, Niskanen, Dima, Kytövuori, Ammirati \& Frøslev, Persoonia 33: 136. 2014.

Phlegmacium neotriumphans (Bidaud, Moënne-Locc. \& Reumaux) Niskanen \& Liimat., comb. nov.

\section{IF558993}

Basionym: Cortinarius neotriumphans Bidaud, MoënneLocc. \& Reumaux, in Bidaud, Moënne-Loccoz, Reumaux \& Henry, Atlas des Cortinaires (Meyzieu) 10: 372. 2000.

Phlegmacium norrlandicum (Brandrud) Niskanen \& Liimat., comb. nov.

\section{IF558994}

Basionym: Cortinarius norrlandicus Brandrud, Docums Mycol. 20(77): 110. 1989. 
Phlegmacium ochraceobrunneum (Rob. Henry ex Bidaud, Moënne-Locc. \& Reumaux) Niskanen \& Liimat., comb. nov.

\section{IF558995}

Basionym: Cortinarius ochraceobrunneus Rob. Henry ex Bidaud, Moënne-Locc. \& Reumaux, in Bidaud, MoënneLoccoz, Reumaux \& Henry, Atlas des Cortinaires (Meyzieu) 10: 372.2000.

Phlegmacium ochribubalinum (Kytöv., Liimat. \& Niskanen) Niskanen \& Liimat., comb. nov.

\section{IF558996}

Basionym: Cortinarius ochribubalinus Kytöv., Liimat. \& Niskanen, in Liimatainen, Niskanen, Dima, Kytövuori, Ammirati \& Frøslev, Persoonia 33: 124. 2014.

Phlegmacium ochroclarum (Rob. Henry) Niskanen \& Liimat., comb. nov.

\section{IF558997}

Basionym: Cortinarius ochroclarus Rob. Henry, in Bidaud, Moënne-Loccoz, Reumaux \& Henry, Atlas des Cortinaires (Meyzieu) 8: 295. 1996.

Phlegmacium olidoamarum (A. Favre) Niskanen \& Liimat., comb. nov.

\section{IF558998}

Basionym: Cortinarius olidoamarus A. Favre, in Favre, Moënne-Loccoz \& Trescol, Bull. trimest. Féd. Mycol. Dauphiné-Savoie 25(no. 100): 6. 1986.

Phlegmacium olidoamethysteum (Rob. Henry \& Ramm) Niskanen \& Liimat., comb. nov.

\section{IF558999}

Basionym: Cortinarius olidoamethysteus Rob. Henry \& Ramm, Bull. trimest. Féd. Mycol. Dauphiné-Savoie 29(no. 115): 11. 1989.

Phlegmacium olidovolvatum (Bon \& Trescol) Niskanen \& Liimat., comb. nov.

IF559000

Basionym: Cortinarius olidovolvatus Bon \& Trescol, Docums Mycol. 19(no. 73): 36. 1988.
Phlegmacium olidum (J.E. Lange) Niskanen \& Liimat., comb. nov.

IF559001

Basionym: Cortinarius olidus J.E. Lange, Fl. Agaric. Danic. 5(Taxon. Consp.): III. 1940.

Phlegmacium olivaceodionysae (A. Ortega, Vila \& Fern.Brime) Niskanen \& Liimat., comb. nov.

IF559002

Basionym: Cortinarius olivaceodionysae A. Ortega, Vila \& Fern.-Brime, Mycologia 106(3): 500. 2014.

Phlegmacium ophiopus (Peck) Niskanen \& Liimat., comb. nov.

\section{IF559003}

Basionym: Cortinarius ophiopus Peck, Ann. Rep. N.Y. St. Mus. nat. Hist. 30: 43. 1878. (1877).

Phlegmacium pallidifolium (A.H. Sm.) Niskanen \& Liimat., comb. nov.

\section{IF559004}

Basionym: Cortinarius pallidifolius A.H. Sm., Contr. Univ. Mich. Herb. 2: 8. 1939.

Phlegmacium palazonianum (Vila, A. Ortega \& Fern.Brime) Niskanen \& Liimat., comb. nov.

\section{IF559005}

Basionym: Cortinarius palazonianus Vila, A. Ortega \& Fern.-Brime, Mycologia 106(3): 501. 2014.

Phlegmacium pansa (Fr.) Niskanen \& Liimat., comb. nov.

IF559006

Basionym: Agaricus pansa Fr., Observ. mycol. (Havniae) 2: 67.1818 .

Phlegmacium pansicolor (Soop) Niskanen \& Liimat., comb. nov.

IF559007 
Basionym: Cortinarius pansicolor Soop, Bresadoliana 1(2): 23. 2013.

Phlegmacium papulosum (Fr.) Niskanen \& Liimat., comb. nov.

\section{IF559008}

Basionym: Cortinarius papulosus Fr., Epicr. syst. mycol. (Upsaliae): 271. 1838. (1836-1838).

Phlegmacium paracephalixum (Bohus) Niskanen \& Liimat., comb. nov.

\section{IF559009}

Basionym: Cortinarius paracephalixus Bohus, Annls hist.nat. Mus. natn. hung. 68: 51. 1978.

Phlegmacium pardinum (Reumaux) Niskanen \& Liimat., comb. nov.

IF559010

Basionym: Cortinarius pardinus Reumaux, in Bidaud, Moënne-Loccoz, Reumaux \& Henry, Atlas des Cortinaires (Meyzieu) 7: 230. 1995.

Phlegmacium patrickense (M.M. Moser) Niskanen \& Liimat., comb. \& stat. nov.

\section{IF559011}

Basionym: Cortinarius fraudulosus var. patrickensis M.M. Moser, in Moser \& Ammirati, Mycotaxon 74(1): 10. 2000.

Phlegmacium patibile (Brandrud \& Melot) Niskanen \& Liimat., comb. nov.

\section{IF559011}

Basionym: Cortinarius patibilis Brandrud \& Melot, Bull. trimest. Soc. mycol. Fr. 99(2): 228. 1983.

Phlegmacium percome (Fr.) Niskanen \& Liimat., comb. nov.

\section{IF559013}

Basionym: Cortinarius percomis Fr., Epicr. syst. mycol. (Upsaliae): 260. 1838. (1836-1838).

Phlegmacium perstrenuus (Chevassut \& Rob. Henry) Niskanen \& Liimat., comb. nov.
IF559014

Basionym: Cortinarius perstrenuus Chevassut \& Rob. Henry, Docums Mycol. 8(no. 32): 20. 1978.

Phlegmacium pini (Brandrud) Niskanen \& Liimat., comb. nov.

IF559015

Basionym: Cortinarius pini Brandrud, Edinb. J. Bot. 53(3): 360. 1996.

Phlegmacium piriodolens (Moënne-Locc.) Niskanen \& Liimat., comb. nov.

\section{IF559016}

Basionym: Cortinarius piriodolens Moënne-Locc., in Bidaud, Moënne-Loccoz, Reumaux \& Henry, Atlas des Cortinaires (Meyzieu) 8: 296. 1996.

Phlegmacium ponderosum (A.H. Sm.) Niskanen \& Liimat., comb. nov.

IF559017

Basionym: Cortinarius ponderosus A.H. Sm., Contr. Univ. Mich. Herb. 2: 6. 1939.

Phlegmacium populinum (Brandrud) Niskanen \& Liimat., comb. nov.

\section{IF559018}

Basionym: Cortinarius populinus Brandrud, in Brandrud, Lindström, Marklund, Melot \& Muskos, Cortinarius, Flora Photographica vol. 2 [Swedish version by Brandrud] (Sweden): 33. 1992.

Phlegmacium prasinocyaneum (Rob. Henry) Niskanen \& Liimat., comb. nov.

IF559019

Basionym: Cortinarius prasinocyaneus Rob. Henry, Bull. trimest. Soc. mycol. Fr. 55(1): 91. 1939.

Phlegmacium psalliotoides (Chevassut \& Rob. Henry) Niskanen \& Liimat., comb. nov.

IF559020 
Basionym: Cortinarius psalliotoides Chevassut \& Rob. Henry, Docums Mycol. 8(no. 32): 19. 1978.

Phlegmacium pseudocephalixum (Bidaud \& Moënne-Locc.) Niskanen \& Liimat., comb. nov.

IF559022

Basionym: Cortinarius pseudocephalixus Bidaud \& Moënne-Locc., in Bidaud, Moënne-Loccoz, Reumaux \& Henry, Atlas des Cortinaires (Meyzieu) 10: 372. 2000.

Phlegmacium pseudocyanopus (Rob. Henry) Niskanen \& Liimat., comb. nov.

\section{IF559023}

Basionym: Cortinarius pseudocyanopus Rob. Henry, in Bidaud, Moënne-Loccoz, Reumaux \& Henry, Atlas des Cortinaires (Meyzieu) 8: 296. 1996.

Phlegmacium pseudodaulnoyae (Rob. Henry \& Ramm) Niskanen \& Liimat., comb. nov.

\section{IF559024}

Basionym: Cortinarius pseudodaulnoyae Rob. Henry \& Ramm, Docums Mycol. 21(83): 54. 1991.

Phlegmacium pseudolargus (Rob. Henry) Niskanen \& Liimat., comb. nov.

\section{IF559025}

Basionym: Cortinarius pseudolargus Rob. Henry, in Chevassut \& Henry, Docums Mycol. 17(no. 68): 27. 1987.

Phlegmacium pseudonebulare (Moënne-Locc.) Niskanen \& Liimat., comb. nov.

\section{IF559026}

Basionym: Cortinarius pseudonebularis Moënne-Locc., in Bidaud, Moënne-Loccoz, Reumaux \& Henry, Atlas des Cortinaires (Meyzieu) 8: 296. 1996.

Phlegmacium pseudopimum (Rob. Henry) Niskanen \& Liimat., comb. nov.

IF559027
Basionym: Cortinarius pseudopimus Rob. Henry, in Bidaud, Moënne-Loccoz, Reumaux \& Henry, Atlas des Cortinaires (Meyzieu) 10: 373. 2000.

Phlegmacium pseudopansa (Bidaud) Niskanen \& Liimat., comb. nov.

IF559028

Basionym: Cortinarius pseudopansa Bidaud, in Bidaud, Moënne-Loccoz, Reumaux \& Henry, Atlas des Cortinaires (Meyzieu) 10: 373. 2000.

Phlegmacium pseudoturmale (Bidaud \& Moënne-Locc.) Niskanen \& Liimat., comb. nov.

\section{IF559029}

Basionym: Cortinarius pseudoturmalis Bidaud \& MoënneLocc., in Bidaud, Moënne-Loccoz, Reumaux \& Carteret, Atlas des Cortinaires (Meyzieu) 19: 1503. 2010.

Phlegmacium pseudovariegatum (M.M. Moser) Niskanen \& Liimat., comb. nov.

\section{IF559030}

Basionym: Cortinarius pseudovariegatus M.M. Moser, in Moser \& Ammirati, Mycotaxon 72: 302. 1999.

Phlegmacium pseudovarium (Moënne-Locc. \& Reumaux) Niskanen \& Liimat., comb. nov.

IF559031

Basionym: Cortinarius pseudovarius Moënne-Locc. \& Reumaux, in Bidaud, Moënne-Loccoz, Reumaux \& Henry, Atlas des Cortinaires (Meyzieu) 10: 373. 2000.

Phlegmacium pseudovulpinum (Rob. Henry \& Ramm) Niskanen \& Liimat., comb. nov.

IF559032

Basionym: Cortinarius pseudovulpinus Rob. Henry \& Ramm, Bull. trimest. Féd. Mycol. Dauphiné-Savoie 29(no. 115): 9. 1989.

Phlegmacium punctatisporum (Garnica) Niskanen \& Liimat., comb. nov.

IF559033 
Basionym: Cortinarius punctatisporus Garnica, Mycologia 94(1): 138. 2002.

Phlegmacium rattinum (Soop) Niskanen \& Liimat., comb. nov.

\section{IF559034}

Basionym: Cortinarius rattinus Soop, Bull. Soc. mycol. Fr. 117(2): 124. 2001.

Phlegmacium reverendissimum (Bidaud, Moënne-Locc. \& Reumaux) Niskanen \& Liimat., comb. nov.

\section{IF559035}

Basionym: Cortinarius reverendissimus Bidaud, MoënneLocc. \& Reumaux, in Bidaud, Moënne-Loccoz, Reumaux \& Henry, Atlas des Cortinaires (Meyzieu) 10: 373. 2000.

Phlegmacium rex-claricolorum (Bidaud, Carteret \& Reumaux) Niskanen \& Liimat., comb. nov.

IF559036

Basionym: Cortinarius rex-claricolorum Bidaud, Carteret \& Reumaux, in Bidaud, Moënne-Loccoz, Reumaux \& Carteret, Atlas des Cortinaires (Meyzieu) 19: 1504. 2010.

Phlegmacium rhizophorum (Bidaud \& Consiglio) Niskanen \& Liimat., comb. nov.

\section{IF559037}

Basionym: Cortinarius rhizophorus Bidaud \& Consiglio, Il Genere Cortinarius in Italia 6: F161. 2012.

Phlegmacium rioussetiae (Chevassut \& Rob. Henry) Niskanen \& Liimat., comb. nov.

IF559038

Basionym: Cortinarius rioussetiae Chevassut \& Rob. Henry, Docums Mycol. 16(nos 63-64): 103. 1986.

Phlegmacium rosargutum (Chevassut \& Rob. Henry) Niskanen \& Liimat., comb. nov.

IF559039

Basionym: Cortinarius rosargutus Chevassut \& Rob. Henry, Docums Mycol. 8(no. 32): 37. 1978.
Phlegmacium rubrivelatum (Garnica) Niskanen \& Liimat., comb. nov.

IF559040

Basionym: Cortinarius rubrivelatus Garnica, Mycologia 94(1): 140. 2002.

Phlegmacium rufior (Reumaux) Niskanen \& Liimat., comb. nov.

IF559041

Basionym: Cortinarius rufior Reumaux, in Bidaud, MoënneLoccoz, Reumaux \& Henry, Atlas des Cortinaires (Meyzieu) 10: 374. 2000.

Phlegmacium rufoaurantium (Soop) Niskanen \& Liimat., comb. nov.

IF559042

Basionym: Cortinarius rufoaurantius Soop, in Soop, Dima, Cooper, Park \& Oertel, Persoonia 42: 280. 2019.

Phlegmacium rufolatum (Moënne-Locc.) Niskanen \& Liimat., comb. nov.

IF559043

Basionym: Cortinarius rufolatus Moënne-Locc., in Bidaud, Moënne-Loccoz, Reumaux \& Henry, Atlas des Cortinaires (Meyzieu) 8: 297. 1996.

Phlegmacium russum (Fr.) Niskanen \& Liimat., comb. nov.

\section{IF559044}

Basionym: Cortinarius russus Fr., Epicr. syst. mycol. (Upsaliae): 261. 1838. (1836-1838).

Phlegmacium saginoides (Bidaud \& Reumaux) Niskanen \& Liimat., comb. nov.

\section{IF559045}

Basionym: Cortinarius saginoides Bidaud \& Reumaux, in Bidaud, Moënne-Loccoz, Reumaux \& Henry, Atlas des Cortinaires (Meyzieu) 10: 374. 2000.

Phlegmacium scaurocaninum (Chevassut \& Rob. Henry) Niskanen \& Liimat., comb. nov. 
IF559046

Basionym: Cortinarius scaurocaninus Chevassut \& Rob. Henry, Docums Mycol. 12(no. 47): 25. 1982.

Phlegmacium serariicolor (Rob. Henry) Niskanen \& Liimat., comb. nov.

\section{IF559047}

Basionym: Cortinarius serariicolor Rob. Henry, Bull. trimest. Soc. mycol. Fr. 82: 137. 1966.

Phlegmacium serarium (Fr.) Niskanen \& Liimat., comb. nov.

\section{IF559048}

Basionym: Cortinarius serarius Fr., Epicr. syst. mycol. (Upsaliae): 269. 1838. (1836-1838).

Phlegmacium sobrium (P. Karst.) Niskanen \& Liimat., comb. nov.

IF559049

Basionym: Cortinarius sobrius P. Karst., Hedwigia 29: 177. 1890.

Phlegmacium spurcum (Weinm.) Niskanen \& Liimat., comb. \& stat. nov.

\section{IF559050}

Basionym: Agaricus violaceocinereus var. spurcus Weinm., Hym. à Gast. Imp. Ross. Obs. (Petropoli): 165. 1836.

Phlegmacium squameoradicans (Bellivier ex Cheype) Niskanen \& Liimat., comb. nov.

\section{IF559051}

Basionym: Cortinarius squameoradicans Bellivier ex Cheype, Docums Mycol. 27(no. 106): 18. 1997.

Phlegmacium squamosocephalum (Bidaud, Moënne-Locc. \& Reumaux) Niskanen \& Liimat., comb. nov.

\section{IF559052}

Basionym: Cortinarius squamosocephalus Bidaud, MoënneLocc. \& Reumaux, Bull. trimest. Soc. mycol. Fr. 115(4): 417. 1999.
Phlegmacium stjernegaardii (Brandrud \& Frøslev) Niskanen \& Liimat., comb. nov.

\section{IF559053}

Basionym: Cortinarius stjernegaardii Brandrud \& Frøslev, in Frøslev, Brandrud \& Dima, Mycol. Progr. 16(2): 148. 2017.

Phlegmacium subaccedens (Rob. Henry) Niskanen \& Liimat., comb. nov.

\section{IF559054}

Basionym: Cortinarius subaccedens Rob. Henry, Bull. trimest. Soc. mycol. Fr. 105(1): 98. 1989.

Phlegmacium subalbescens (Reumaux) Niskanen \& Liimat., comb. nov.

IF559055

Basionym: Cortinarius subalbescens Reumaux, in Bidaud, Moënne-Loccoz, Reumaux \& Henry, Atlas des Cortinaires, Pars V (Annecy): 152. 1993.

Phlegmacium subamaricatum (Bidaud) Niskanen \& Liimat., comb. nov.

IF559056

Basionym: Cortinarius subamaricatus Bidaud, in Bidaud, Moënne-Loccoz, Reumaux, Carteret \& Eyssartier, Atlas des Cortinaires (Meyzieu) 17(2): 1238. 2008.

Phlegmacium subbalteatum (Kühner) Niskanen \& Liimat., comb. nov.

\section{IF559057}

Basionym: Cortinarius subbalteatus Kühner, Bull. mens. Soc. linn. Soc. Bot. Lyon 24(2): 40. 1955.

Phlegmacium subcaeruleum (A.H. Sm.) Niskanen \& Liimat., comb. nov.

\section{IF559058}

Basionym: Hymenogaster subcaeruleus A.H. Sm., Mycologia 58(1): 106. 1966.

Phlegmacium subcyanites (Bidaud) Niskanen \& Liimat., comb. nov. 
IF559059

Basionym: Cortinarius subcyanites Bidaud, in Bidaud, Moënne-Loccoz, Carteret, Reumaux \& Eyssartier, Atlas des Cortinaires (Meyzieu) 15: 1032. 2005.

Phlegmacium subdecolorans (M. Langl. \& Reumaux) Niskanen \& Liimat., comb. nov.

IF559060

Basionym: Cortinarius subdecolorans M. Langl. \& Reumaux, in Bidaud, Moënne-Loccoz, Reumaux \& Henry, Atlas des Cortinaires (Meyzieu) 10: 374. 2000.

Phlegmacium subdecoloratum (Reumaux) Niskanen \& Liimat., comb. nov.

IF559061

Basionym: Cortinarius subdecoloratus Reumaux, in Bidaud, Moënne-Loccoz, Reumaux \& Henry, Atlas des Cortinaires (Meyzieu) 10: 374. 2000.

Phlegmacium subfoetens (M.M. Moser \& McKnight) Niskanen \& Liimat., comb. nov.

\section{IF559062}

Basionym: Cortinarius subfoetens M.M. Moser \& McKnight, in Moser, McKnight \& Ammirati, Mycotaxon 55: 310. 1995.

Phlegmacium subfoetidum (A.H. Sm.) Niskanen \& Liimat., comb. nov.

\section{IF559063}

Basionym: Cortinarius subfoetidus A.H. Sm., Lloydia 7(3): 191. 1944.

Phlegmacium subfraudulosum (Kytöv., Liimat. \& Niskanen) Niskanen \& Liimat., comb. nov.

\section{IF559064}

Basionym: Cortinarius subfraudulosus Kytöv., Liimat. \& Niskanen, in Liimatainen, Niskanen, Dima, Kytövuori, Ammirati \& Frøslev, Persoonia 33: 125. 2014.

Phlegmacium subfuligineum (Bidaud) Niskanen \& Liimat., comb. nov.
IF559065

Basionym: Cortinarius subfuligineus Bidaud, in Bidaud, Moënne-Loccoz, Reumaux, Carteret \& Eyssartier, Atlas des Cortinaires (Meyzieu) 17(2): 1238. 2008.

Phlegmacium subhygrophanum (Bidaud) Niskanen \& Liimat., comb. nov.

\section{IF559066}

Basionym: Cortinarius subhygrophanus Bidaud, in Bidaud, Moënne-Loccoz, Reumaux \& Henry, Atlas des Cortinaires, Pars V (Annecy): 152. 1993.

Phlegmacium sublilacinum (A.H. Sm.) Niskanen \& Liimat., comb. nov.

IF559067

Basionym: Hymenogaster sublilacinus A.H. Sm., Mycologia 58(1): 108. 1966.

Phlegmacium subolivascens (A.H. Sm.) Niskanen \& Liimat., comb. nov.

IF559068

Basionym: Cortinarius subolivascens A.H. Sm., Lloydia 7(3): 183. 1944.

Phlegmacium subrubrovelatum (Bidaud) Niskanen \& Liimat., comb. \& stat. nov.

\section{IF559069}

Basionym: Cortinarius glaucopus var. subrubrovelatus Bidaud, in Bidaud, Moënne-Loccoz, Reumaux, Carteret \& Eyssartier, Atlas des Cortinaires (Meyzieu) 17(2): 1237. 2008.

Phlegmacium subrugulosum (Bidaud \& Armada) Niskanen \& Liimat., comb. nov.

IF559070

Basionym: Cortinarius subrugulosus Bidaud \& Armada, in Bidaud, Moënne-Loccoz, Reumaux, Carteret \& Eyssartier, Atlas des Cortinaires (Meyzieu) 16: 1096. 2006.

Phlegmacium subsolitarium (A.H. Sm.) Niskanen \& Liimat., comb. nov. 
IF559071

Basionym: Cortinarius subsolitarius A.H. Sm., Bull. Torrey bot. Club 69(1): 57.1942.

Phlegmacium subvariiforme (Bidaud) Niskanen \& Liimat., comb. nov.

IF559072

Basionym: Cortinarius subvariiformis Bidaud, in Bidaud, Moënne-Loccoz, Reumaux \& Henry, Atlas des Cortinaires (Meyzieu) 10: 374. 2000.

Phlegmacium superbum (A.H. Sm.) Niskanen \& Liimat., comb. nov.

IF559073

Basionym: Cortinarius superbus A.H. Sm., Lloydia 7(3): 195. 1944.

Phlegmacium tauri (Mahiques \& Reumaux) Niskanen \& Liimat., comb. nov.

IF559074

Basionym: Cortinarius tauri Mahiques \& Reumaux, Bull. Mycol. Bot. Dauphiné-Savoie 49(no. 193): 5. 2009.

Phlegmacium terpsichores (Melot) Niskanen \& Liimat., comb. nov.

IF559075

Basionym: Cortinarius terpsichores Melot, Docums Mycol. 20(no. 77): 96. 1989.

Phlegmacium tiliae (Brandrud) Niskanen \& Liimat., comb. nov.

\section{IF559076}

Basionym: Cortinarius tiliae Brandrud, Edinb. J. Bot. 53(3): 358. 1996.

Phlegmacium tirolianum (Bidaud, Moënne-Locc. \& Reumaux) Niskanen \& Liimat., comb. nov.

IF559077
Basionym: Cortinarius tirolianus Bidaud, Moënne-Locc. \& Reumaux, in Bidaud, Moënne-Loccoz, Carteret, Reumaux \& Eyssartier, Atlas des Cortinaires (Meyzieu) 15: 1033. 2005.

Phlegmacium tomentosum (Rob. Henry) Niskanen \& Liimat., comb. nov.

IF559078

Basionym: Cortinarius tomentosus Rob. Henry, Docums Mycol. 16(no. 61): 24. 1985.

Phlegmacium trachycystis (M.M. Moser) Niskanen \& Liimat., comb. nov.

\section{IF559079}

Basionym: Cortinarius trachycystis M.M. Moser, in Moser \& Horak, Beih. Nova Hedwigia 52: 469. 1975.

Phlegmacium triumphale (Bidaud, Moënne-Locc. \& Reumaux) Niskanen \& Liimat., comb. nov.

IF559080

Basionym: Cortinarius triumphalis Bidaud, Moënne-Locc. \& Reumaux, in Bidaud, Moënne-Loccoz, Reumaux \& Henry, Atlas des Cortinaires (Meyzieu) 9: 374. 1999.

Phlegmacium triumphans (Fr.) Niskanen \& Liimat., comb. nov.

\section{IF559081}

Basionym: Cortinarius triumphans Fr., Epicr. syst. mycol. (Upsaliae): 256. 1838. (1836-1838).

Phlegmacium turbinatorum (Cors. Gut. \& Vila) Niskanen \& Liimat., comb. nov.

\section{IF559082}

Basionym: Cortinarius turbinatorum Cors. Gut. \& Vila, Revta Catal. Micol. 23: 14. 2001.

Phlegmacium wiebeae (Thiers \& A.H. Sm.) Niskanen \& Liimat., comb. nov.

\section{IF559083}

Basionym: Cortinarius wiebeae Thiers \& A.H. Sm., Mycologia 61: 529. 1969. 
Phlegmacium vacciniophilum (Brandrud) Niskanen \& Liimat., comb. nov.

\section{IF559084}

Basionym: Cortinarius vacciniophilus Brandrud, Edinb. J. Bot. 54(1): 114. 1997.

Phlegmacium van-campiae (Consiglio) Niskanen \& Liimat., comb. nov.

\section{IF559085}

Basionym: Cortinarius van-campiae Consiglio, Micologia 2000 (Trento): 115. 2000.

Phlegmacium variiforme (Malençon) Niskanen \& Liimat., comb. nov.

\section{IF559086}

Basionym: Cortinarius variiformis Malençon, in Malençon \& Bertault, Champignon Supérieurs du Maroc 1: 526. 1970.

Phlegmacium variosimile (M.M. Moser \& Ammirati) Niskanen \& Liimat., comb. nov.

\section{IF559087}

Basionym: Cortinarius variosimilis M.M. Moser \& Ammirati, Mycotaxon 72: 306. 1999.

Phlegmacium velicopium (Kauffman) Niskanen \& Liimat., comb. nov.

\section{IF559088}

Basionym: Cortinarius velicopius Kauffman, Publications Mich. geol. biol. Surv., Biol. Ser. 5 26: 339. 1918.

Phlegmacium veneris (Bidaud, Moënne-Locc. \& Reumaux) Niskanen \& Liimat., comb. nov.

\section{IF559089}

Basionym: Cortinarius veneris Bidaud, Moënne-Locc. \& Reumaux, in Bidaud, Moënne-Loccoz, Reumaux \& Henry, Atlas des Cortinaires (Meyzieu) 8: 298. 1996.

Phlegmacium vernicifer (Soop) Niskanen \& Liimat., comb. nov.

IF559090
Basionym: Cortinarius vernicifer Soop, in Gasparini \& Soop, Australas. Mycol. 27(3): 199. 2008.

Phlegmacium violaceomaculatum (Brandrud) Niskanen \& Liimat., comb. nov.

IF559091

Basionym: Cortinarius violaceomaculatus Brandrud, Edinb. J. Bot. 54(1): 115. 1997.

Phlegmacium violaceorubens (Moënne-Locc. \& Reumaux) Niskanen \& Liimat., comb. nov.

IF559092

Basionym: Cortinarius violaceorubens Moënne-Locc. \& Reumaux, Atlas des Cortinaires, Pars II (Annecy): 27. 1990.

Phlegmacium viridocoeruleum (Chevassut \& Rob. Henry) Niskanen \& Liimat., comb. nov.

IF559093

Basionym: Cortinarius viridocoeruleus Chevassut \& Rob. Henry, Docums Mycol. 5(no. 20): 24. 1975.

Phlegmacium vixolivascens (Rob. Henry) Niskanen \& Liimat., comb. nov.

IF559094

Basionym: Cortinarius vixolivascens Rob. Henry, Bull. trimest. Soc. mycol. Fr. 108(4): 203. 1992.

Phlegmacium vulpinum (Velen.) Niskanen \& Liimat., comb. nov.

\section{IF559095}

Basionym: Inoloma vulpinum Velen., České Houby 3: 428. 1921.

Phlegmacium xantho-ochraceum (P.D. Orton) Niskanen \& Liimat., comb. nov.

\section{IF559096}

Basionym: Cortinarius xantho-ochraceus P.D. Orton, Trans. Br. mycol. Soc. 43(2): 216. 1960.

Phlegmacium xanthosuave (Bon \& Trescol) Niskanen \& Liimat., comb. nov. 
IF559097

Basionym: Cortinarius xanthosuavis Bon \& Trescol, Docums Mycol. 19(no. 73): 36. 1988.

\section{Thaxterogaster}

Thaxterogaster sect. Alboaggregati (Soop) Niskanen \& Liimat., comb. nov.

\section{IF559098}

Basionym: Cortinarius sect. Alboaggregati Soop, in Soop, Dima, Cooper, Park \& Oertel, Persoonia 42: 279. 2019.

Thaxterogaster sect. Austrocyanites (Soop) Niskanen \& Liimat., comb. nov.

IF559099

Basionym: Cortinarius sect. Austrocyanites Soop, in Soop, Dima, Cooper, Park \& Oertel, Persoonia 42: 281. 2019.

Thaxterogaster sect. Austrovaginati (Soop) Niskanen \& Liimat., comb. nov.

IF559100

Basionym: Cortinarius sect. Austrovaginati Soop, in Soop, Dima, Cooper, Park \& Oertel, Persoonia 42: 282. 2019.

Thaxterogaster sect. Caustici (Niskanen \& Liimat.) Niskanen \& Liimat., comb. nov.

\section{IF559101}

Basionym: Cortinarius sect. Caustici Niskanen \& Liimat., Index Fungorum 477: 1. 2021.

Thaxterogaster sect. Cremeolini (Soop) Niskanen \& Liimat., comb. nov.

IF559102

Basionym: Cortinarius sect. Cremeolinae Soop, in Soop, Dima, Cooper, Park \& Oertel, Persoonia 42: 276. 2019.

Thaxterogaster sect. Cretaces (Soop \& Dima) Niskanen \& Liimat., comb. nov.

IF559103
Basionym: Cortinarius sect. Cretaces Soop \& Dima, in Soop, Dima, Cooper, Park \& Oertel, Persoonia 42: 279. 2019.

Thaxterogaster sect. Gigasperma (E. Horak) Niskanen \& Liimat., comb. \& stat. nov.

IF559104

Basionym: Gigasperma E. Horak, New Zealand J. Bot. 9: 491. 1970.

Thaxterogaster sect. Laquelli (Soop) Niskanen \& Liimat., comb. nov.

IF559105

Basionym: Cortinarius sect. Laquelli Soop, in Soop, Dima, Cooper, Park \& Oertel, Persoonia 42: 279. 2019.

Thaxterogaster sect. Lustrati (Ammirati ex Soop, B. Oertel \& Dima) Niskanen \& Liimat., comb. nov.

IF559106

Basionym: Cortinarius sect. Lustrati Ammirati ex Soop, B. Oertel \& Dima, in Soop, Dima, Cooper, Park \& Oertel, Persoonia 42: 279. 2019.

Thaxterogaster sect. Malvacei (M.M. Moser) Niskanen \& Liimat., comb. nov.

\section{IF559107}

Basionym: Cortinarius sect. Malvacei M.M. Moser, Beih. Nova Hedwigia: 240. 1975.

Thaxterogaster sect. Olorinati (Soop \& Dima) Niskanen \& Liimat., comb. nov.

IF559247

Basionym: Cortinarius sect. Olorinati Soop \& Dima, in Dima \& Soop, Phytotaxa 438(4): 232. 2020.

Thaxterogaster sect. Pinophili (Niskanen \& Liimat.) Niskanen \& Liimat., comb. nov.

IF559108

Basionym: Cortinarius sect. Pinophili Niskanen \& Liimat., Index Fungorum 477: 2. 2021. 
Thaxterogaster sect. Purpurascentes (Kühner \& Romagn. ex Brandrud \& Melot) Niskanen \& Liimat., comb. \& stat. nov.

IF559109

Basionym: Cortinarius subsect. Purpurascentes Kühner \& Romagn. ex Brandrud \& Melot, Nordic J Bot. 10(5): 537. 1990.

Thaxterogaster sect. Rapacea (E. Horak) Niskanen \& Liimat., comb. \& stat. nov.

IF559110

Basionym: Rapacea E. Horak, Kew Bulletin 54: 789. 1999.

Thaxterogaster sect. Turmales (Soop, B. Oertel \& Dima) Niskanen \& Liimat., comb. nov.

IF559111

Basionym: Cortinarius sect. Turmales Soop, B. Oertel \& Dima, in Soop, Dima, Cooper, Park \& Oertel, Persoonia 42: 277.2019.

Thaxterogaster sect. Verniciori (Soop) Niskanen \& Liimat., comb. nov.

IF559112

Basionym: Cortinarius sect. Verniciori Soop, in Soop, Dima, Cooper, Park \& Oertel, Persoonia 42: 282. 2019.

Thaxterogaster sect. Vibratiles (Melot) Niskanen \& Liimat., comb. nov.

\section{IF559113}

Basionym: Cortinarius sect. Vibratiles Melot, Docums Mycol. 20(77): 99. 1989.

Thaxterogaster aggregatus (Kauffman) Niskanen \& Liimat., comb. nov.

IF559114

Basionym: Cortinarius aggregatus Kauffman, Publications Mich. geol. biol. Surv., Biol. Ser. 5 26: 346. 1918.

Thaxterogaster alboaggregatus (Soop) Niskanen \& Liimat., comb. nov.

IF559115
Basionym: Cortinarius alboaggregatus Soop, N.Z. J1 Bot. 43(2): 555. 2005.

Thaxterogaster alboamarescens (Kytöv., Niskanen \& Liimat.) Niskanen \& Liimat., comb. nov.

IF559116

Basionym: Cortinarius alboamarescens Kytöv., Niskanen \& Liimat., in Ariyawansa et al., Fungal Diversity: https://doi. org/10.1007/s13225-015-0346-5, [192] 2015.

Thaxterogaster anomalochrascens (Chevassut \& Rob. Henry) Niskanen \& Liimat., comb. nov.

IF559117

Basionym: Cortinarius anomalochrascens Chevassut \& Rob. Henry, Docums Mycol. 16(63-64): 84. 1986.

Thaxterogaster argenteolilacinus (M.M. Moser) Niskanen \& Liimat., comb. nov.

IF559118

Basionym: Cortinarius argenteolilacinus M.M. Moser, Sydowia 6(1-4): 151. 1952.

Thaxterogaster argyrionus (Danks, T. Lebel \& Vernes) Niskanen \& Liimat., comb. nov.

IF559119

Basionym: Cortinarius argyrionus Danks, T. Lebel \& Vernes, Persoonia 24: 113. 2010.

Thaxterogaster armenicorius (Soop \& Brandrud) Niskanen \& Liimat., comb. nov.

IF559120

Basionym: Cortinarius armenicorius Soop \& Brandrud, Journal des JEC, Journées Européenes du Cortinaire 16: 191. 2014.

Thaxterogaster aurantionapus (Bidaud \& Reumaux) Niskanen \& Liimat., comb. nov.

IF559121

Basionym: Cortinarius aurantionapus Bidaud \& Reumaux, in Bidaud, Moënne-Loccoz, Reumaux, Carteret \& Eyssartier, Atlas des Cortinaires (Meyzieu) 16: 1096. 2006. 
Thaxterogaster australis (Gasparini) Niskanen \& Liimat., comb. nov.

IF559122

Basionym: Cortinarius australis Gasparini, N.Z. Jl Bot. 45(1): 205. 2007.

Thaxterogaster austrocyanites (Soop) Niskanen \& Liimat., comb. nov.

IF559123

Basionym: Cortinarius austrocyanites Soop, Bull. Soc. mycol. Fr. 117(2): 108. 2001.

Thaxterogaster austrosaginus (Gasparini) Niskanen \& Liimat., comb. nov.

IF559124

Basionym: Cortinarius austrosaginus Gasparini, N.Z. J1 Bot. 45(1): 174. 2007.

Thaxterogaster austroturmalis (M.M. Moser \& E. Horak) Niskanen \& Liimat., comb. nov.

IF559125

Basionym: Cortinarius austroturmalis M.M. Moser \& E. Horak, Beih. Nova Hedwigia 52: 151. 1975.

Thaxterogaster austrovaginatus (Gasparini) Niskanen \& Liimat., comb. nov.

IF559126

Basionym: Cortinarius austrovaginatus Gasparini, N.Z. Jl Bot. 45(1): 189. 2007.

Thaxterogaster barbatus (Batsch) Niskanen \& Liimat., comb. nov.

IF559127

Basionym: Agaricus barbatus Batsch, Elench. fung. (Halle):39, t. 3: 11. 1783.

Thaxterogaster burlinghamiae (Bojantchev) Niskanen \& Liimat., comb. nov.

IF559128
Basionym: Cortinarius burlinghamiae Bojantchev, in Brandrud, Schmidt-Stohn, Liimatainen, Niskanen, Frøslev, Soop, Bojantchev, Kytövuori, Jeppesen, Bellù, Saar, Oertel, Ali, Thines \& Dima, Mycol. Progr. 17(12): 1350. 2018.

Thaxterogaster caesibulga (Vernes, Danks \& T. Lebel) Niskanen \& Liimat., comb. nov.

IF559129

Basionym: Cortinarius caesibulga Vernes, Danks \& T. Lebel, in Danks, Lebel \& Vernes, Persoonia 24: 116. 2010.

Thaxterogaster caesiolamellatus (Bidaud) Niskanen \& Liimat., comb. \& stat. nov.

\section{IF559130}

Basionym: Cortinarius rufoallutus var. caesiolamellatus Bidaud, in Bidaud, Moënne-Loccoz, Reumaux, Carteret \& Eyssartier, Atlas des Cortinaires (Meyzieu) 16: 1095. 2006.

Thaxterogaster caledoniensis (P.D. Orton) Niskanen \& Liimat., comb. nov.

IF559131

Basionym: Cortinarius caledoniensis P.D. Orton, Notes R. bot. Gdn Edinb. 26: 44. 1964.

Thaxterogaster castoreus (Soop) Niskanen \& Liimat., comb. nov.

\section{IF559132}

Basionym: Cortinarius castoreus Soop, N.Z. J1 Bot. 43(2): 552. 2005.

Thaxterogaster cervinus (M.M. Moser \& E. Horak) Niskanen \& Liimat., comb. nov.

\section{IF559133}

Basionym: Cortinarius cervinus M.M. Moser \& E. Horak, Beih. Nova Hedwigia 52: 148. 1975.

Thaxterogaster chalybeus (Soop) Niskanen \& Liimat., comb. nov.

IF559134

Basionym: Cortinarius chalybeus Soop, Bull. Soc. mycol. Fr. 118(3): 187.2003. 2002. 
Thaxterogaster chlorophyllus (Soop) Niskanen \& Liimat., comb. nov.

IF559135

Basionym: Cortinarius chlorophyllus Soop, N.Z. J1 Bot. 52: 337. 2014.

Thaxterogaster cinereoroseolus (Danks, T. Lebel \& Vernes) Niskanen \& Liimat., comb. nov.

IF559136

Basionym: Cortinarius cinereoroseolus Danks, T. Lebel \& Vernes, Persoonia 24: 118. 2010.

Thaxterogaster collocandoides (Reumaux) Niskanen \& Liimat., comb. nov.

IF559137

Basionym: Cortinarius collocandoides Reumaux, in Bidaud, Moënne-Loccoz, Reumaux \& Carteret, Atlas des Cortinaires (Meyzieu) 18(1-2): 1377. 2009.

Thaxterogaster columbinus (M.M. Moser \& E. Horak) Niskanen \& Liimat., comb. nov.

IF559138

Basionym: Cortinarius columbinus M.M. Moser \& E. Horak, Beih. Nova Hedwigia 52: 250. 1975.

Thaxterogaster comarostaphylidis (Ammirati, Halling \& Garnica) Niskanen \& Liimat., comb. nov.

\section{IF559139}

Basionym: Cortinarius comarostaphylidis Ammirati, Halling \& Garnica, in Ammirati, Garnica, Halling, Mata, Mueller \& Carranza, Can. J. Bot. 85(9): 803. 2007.

Thaxterogaster comparoides (Ammirati, Halling \& Garnica) Niskanen \& Liimat., comb. nov.

IF559140

Basionym: Cortinarius comparoides Ammirati, Halling \& Garnica, in Ammirati, Garnica, Halling, Mata, Mueller \& Carranza, Can. J. Bot. 85(9): 804. 2007.

Thaxterogaster corrugis (A.H. Sm.) Niskanen \& Liimat., comb. nov.
IF559141

Basionym: Cortinarius corrugis A.H. Sm., Lloydia 7(3): 189. 1944.

Thaxterogaster cremeolina (Soop) Niskanen \& Liimat., comb. nov.

IF559142

Basionym: Cortinarius cremeolina Soop, Bull. Soc. mycol. Fr. 117(2): 103. 2001.

Thaxterogaster cremeorufus (Soop) Niskanen \& Liimat., comb. nov.

IF559143

Basionym: Cortinarius cremeorufus Soop, N.Z. Jl Bot. 54(3): 347. 2016.

Thaxterogaster crenulatus (Rob. Henry ex Bidaud \& Reumaux) Niskanen \& Liimat., comb. nov.

IF559144

Basionym: Cortinarius crenulatus Rob. Henry ex Bidaud \& Reumaux, in Bidaud, Moënne-Loccoz, Reumaux, Carteret \& Eyssartier, Atlas des Cortinaires (Meyzieu) 16: 1097. 2006.

Thaxterogaster croceocoeruleus (Pers.) Niskanen \& Liimat., comb. nov.

\section{IF559145}

Basionym: Agaricus croceocoeruleus Pers., Icon. Desc. Fung. Min. Cognit. (Leipzig) 1: 2. 1798.

Thaxterogaster dulcamarus (Soop) Niskanen \& Liimat., comb. nov.

IF559146

Basionym: Cortinarius dulcamarus Soop, N.Z. Jl Bot. 54(3): 355. 2016.

Thaxterogaster dulciorum (Soop) Niskanen \& Liimat., comb. nov.

IF559147

Basionym: Cortinarius dulciorum Soop, in Gasparini \& Soop, Australas. Mycol. 27(3): 197. 2008. 
Thaxterogaster eburneus (Velen.) Niskanen \& Liimat., comb. nov.

IF559148

Basionym: Phlegmacium eburneum Velen., České Houby 2: 422.1920.

Thaxterogaster effundens (M.M. Moser, E. Horak \& Singer) Niskanen \& Liimat., comb. nov.

IF559149

Basionym: Cortinarius effundens M.M. Moser, E. Horak \& Singer, in Moser \& Horak, Beih. Nova Hedwigia 52: 144. 1975.

Thaxterogaster emollitoides (Bidaud, Moënne-Locc. \& Reumaux) Niskanen \& Liimat., comb. nov.

IF559150

Basionym: Cortinarius emollitoides Bidaud, MoënneLocc. \& Reumaux, in Bidaud, Moënne-Loccoz, Reumaux \& Henry, Atlas des Cortinaires (Meyzieu) 10: 491. 2000.

Thaxterogaster eumarginatus (Rob. Henry ex Bidaud, Carteret \& Reumaux) Niskanen \& Liimat., comb. nov.

IF559151

Basionym: Cortinarius eumarginatus Rob. Henry ex Bidaud, Carteret \& Reumaux, in Bidaud, Moënne-Loccoz, Reumaux \& Carteret, Atlas des Cortinaires (Meyzieu) 18(1-2): 1378. 2009.

Thaxterogaster fiordlandensis (Soop) Niskanen \& Liimat., comb. nov.

IF559152

Basionym: Cortinarius fiordlandensis Soop, Bresadoliana 1(2): 24.2013.

Thaxterogaster frondosomultiformis (Bellù, Brandrud \& Dima) Niskanen \& Liimat., comb. nov.

\section{IF559153}

Basionym: Cortinarius frondosomultiformis Bellù, Brandrud \& Dima, Journal des JEC, Journées Européenes du Cortinaire 16: 177. 2014.
Thaxterogaster fuligineofolius (M.M. Moser) Niskanen \& Liimat., comb. \& stat. nov.

IF559154

Basionym: Cortinarius montanus var. fuligineofolius M.M. Moser, Fungi Non Delineati, Raro vel Haud Perspecte et Explorate Descripti aut Definite Picti 15: 25. 2001.

Thaxterogaster fulvo-ochrascens (Rob. Henry) Niskanen \& Liimat., comb. nov.

\section{IF559155}

Basionym: Cortinarius fulvo-ochrascens Rob. Henry, Bull. trimest. Soc. mycol. Fr. 59: 55. 1943.

Thaxterogaster galeobdolon (Rob. Henry) Niskanen \& Liimat., comb. nov.

\section{IF559156}

Basionym: Cortinarius galeobdolon Melot, Acta Botanica Islandica 12: 91. 1995.

Thaxterogaster genuinus (Bidaud \& Carteret) Niskanen \& Liimat., comb. nov.

\section{IF559157}

Basionym: Cortinarius genuinus Bidaud \& Carteret, in Bidaud, Moënne-Loccoz, Reumaux \& Carteret, Atlas des Cortinaires (Meyzieu) 18(1-2): 1378. 2009.

Thaxterogaster glacialis (Bidaud \& Reumaux) Niskanen \& Liimat., comb. nov.

\section{IF559158}

Basionym: Cortinarius glacialis Bidaud \& Reumaux, in Bidaud, Moënne-Loccoz, Reumaux \& Henry, Atlas des Cortinaires (Meyzieu) 10: 491. 2000.

Thaxterogaster glaucocyanopus (Rob. Henry) Niskanen \& Liimat., comb. nov.

\section{IF559159}

Basionym: Cortinarius glaucocyanopus Rob. Henry, in Bidaud, Moënne-Loccoz, Reumaux \& Henry, Atlas des Cortinaires (Meyzieu) 10: 371. 2000. 
Thaxterogaster imbricatoides (Rob. Henry) Niskanen \& Liimat., comb. nov.

IF559160

Basionym: Cortinarius imbricatoides Rob. Henry, Bull. trimest. Soc. mycol. Fr. 105(1): 92. 1989.

Thaxterogaster iringa (Soop) Niskanen \& Liimat., comb. nov.

IF559161

Basionym: Cortinarius iringa Soop, Bull. Soc. mycol. Fr. 118(3): 183. 2003. (2002).

Thaxterogaster ixomolynus (Soop) Niskanen \& Liimat., comb. nov.

IF559162

Basionym: Cortinarius ixomolynus Soop, Australas. Mycol. 31: 2. 2013.

Thaxterogaster kaimanawa (Soop) Niskanen \& Liimat., comb. nov.

IF559163

Basionym: Cortinarius kaimanawa Soop, Bull. Soc. mycol. Fr. 118(3): 192. 2003. (2002).

Thaxterogaster laquellus (Soop) Niskanen \& Liimat., comb. nov.

\section{IF559164}

Basionym: Cortinarius laquellus Soop, N.Z. Jl Bot. 43(2): 560. 2005.

Thaxterogaster largoides (Rob. Henry ex Bidaud, Carteret \& Reumaux) Niskanen \& Liimat., comb. nov.

\section{IF559165}

Basionym: Cortinarius largoides Rob. Henry ex Bidaud, Carteret \& Reumaux, in Bidaud, Moënne-Loccoz, Reumaux $\&$ Carteret, Atlas des Cortinaires (Meyzieu) 18(1-2): 1378. 2009.

Thaxterogaster leucoluteolus (Rob. Henry) Niskanen \& Liimat., comb. nov.
IF559166

Basionym: Cortinarius leucoluteolus Rob. Henry, Bull. trimest. Soc. mycol. Fr. 99(1): 75. 1983.

Thaxterogaster leucophanes (P. Karst.) Niskanen \& Liimat., comb. nov.

IF559167

Basionym: Cortinarius leucophanes P. Karst., Symb. mycol. fenn. 7: 3. 1881.

Thaxterogaster lustratus (Fr.) Niskanen \& Liimat., comb. nov.

IF559168

Basionym: Cortinarius lustratus Fr., Epicr. syst. mycol. (Upsaliae): 258. 1838. (1836-1838).

Thaxterogaster luteofuscus (Peck) Niskanen \& Liimat., comb. nov.

IF559169

Basionym: Cortinarius luteofuscus Peck, Ann. Rep. Reg. N.Y. St. Mus. 23: 106. 1872. (1870).

Thaxterogaster magicus (Eichhorn) Niskanen \& Liimat., comb. nov.

IF559170

Basionym: Cortinarius magicus Eichhorn, in Gams, K1. Krypt.-Fl., Edn 3 (Stuttgart) 2b/2: 295. 1967.

Thaxterogaster malvaceus (E. Horak) Niskanen \& Liimat., comb. nov.

IF559171

Basionym: Cortinarius malvaceus E. Horak, in Moser \& Horak, Beih. Nova Hedwigia 52: 241. 1975.

Thaxterogaster medioscaurus (Soop) Niskanen \& Liimat., comb. nov.

IF559172

Basionym: Cortinarius medioscaurus Soop, N.Z. Jl Bot. 52: 338. 2014. 
Thaxterogaster melleicarneus (Kytöv., Liimat., Niskanen \& Brandrud) Niskanen \& Liimat., comb. nov.

\section{IF559173}

Basionym: Cortinarius melleicarneus Kytöv., Liimat., Niskanen \& Brandrud, in Liimatainen, Niskanen, Dima, Kytövuori, Ammirati \& Frøslev, Persoonia 33: 131. 2014.

Thaxterogaster mendax (Bidaud, Mahiques \& Reumaux) Niskanen \& Liimat., comb. nov.

\section{IF559174}

Basionym: Cortinarius mendax Bidaud, Mahiques \& Reumaux, in Bidaud, Journal des JEC, Journées Européenes du Cortinaire 14(no. 13): 18. 2011.

Thaxterogaster microspermus (J.E. Lange) Niskanen \& Liimat., comb. nov.

\section{IF559175}

Basionym: Cortinarius microspermus J.E. Lange, Fl. Agaric. Danic. 5(Taxon. Consp.): III. 1940.

Thaxterogaster montanus (Kauffman) Niskanen \& Liimat., comb. nov.

IF559176

Basionym: Cortinarius montanus Kauffman, N. Amer. Fl. (New York) 10(5): 299. 1932.

Thaxterogaster multiformis (Fr.) Niskanen \& Liimat., comb. nov.

\section{IF559177}

Basionym: Cortinarius multiformis Fr., Epicr. syst. mycol. (Upsaliae): 263. 1838. (1836-1838).

Thaxterogaster mutabilis (A.H. Sm.) Niskanen \& Liimat., comb. nov.

\section{IF559178}

Basionym: Cortinarius mutabilis A.H. Sm., Lloydia 7(3): 190. 1944.

Thaxterogaster myxenosma (Soop) Niskanen \& Liimat., comb. nov.
IF559179

Basionym: Cortinarius myxenosma Soop, in Gasparini \& Soop, Australas. Mycol. 27(3): 198. 2008.

Thaxterogaster myxoclaricolor (M.M. Moser) Niskanen \& Liimat., comb. nov.

IF559180

Basionym: Cortinarius myxoclaricolor M.M. Moser, in Moser \& Horak, Beih. Nova Hedwigia 52: 157. 1975.

Thaxterogaster nebulobrunneus (Danks, T. Lebel \& Vernes) Niskanen \& Liimat., comb. nov.

\section{IF559181}

Basionym: Cortinarius nebulobrunneus Danks, T. Lebel \& Vernes, Persoonia 24: 123. 2010.

Thaxterogaster occidentalis (A.H. Sm.) Niskanen \& Liimat., comb. nov.

IF559182

Basionym: Cortinarius occidentalis A.H. Sm., Contr. Univ. Mich. Herb. 1: 15. 1939.

Thaxterogaster ochroamarus (Niskanen, Kytöv. \& Liimat.) Niskanen \& Liimat., comb. nov.

IF559183

Basionym: Cortinarius ochroamarus Niskanen, Kytöv. \& Liimat., in Ariyawansa et al., Fungal Diversity: https://doi. org/10.1007/s13225-015-0346-5, [195] 2015.

Thaxterogaster ochroleucus (Schaeff.) Niskanen \& Liimat., comb. nov.

\section{IF559184}

Basionym: Agaricus ochroleucus Schaeff., Fung. bavar. palat. nasc. (Ratisbonae) 4: 24. 1774.

Thaxterogaster ochropudorinus (Rob. Henry ex Bidaud \& Reumaux) Niskanen \& Liimat., comb. nov.

\section{IF559185}

Basionym: Cortinarius ochropudorinus Rob. Henry ex Bidaud \& Reumaux, in Bidaud, Moënne-Loccoz, Reumaux, 
Carteret \& Eyssartier, Atlas des Cortinaires (Meyzieu) 16: 1097. 2006.

Thaxterogaster olivaceus (Peck) Niskanen \& Liimat., comb. nov.

\section{IF559186}

Basionym: Cortinarius olivaceus Peck, Ann. Rep. N.Y. St. Mus. 24: 72. 1872. (1871).

Thaxterogaster olorinatus (E. Horak) Niskanen \& Liimat., comb. nov.

\section{IF559187}

Basionym: Cortinarius olorinatus E. Horak, in Horak \& Wood, Sydowia 42: 92. 1990.

Thaxterogaster oregonensis (A.H. Sm.) Niskanen \& Liimat., comb. nov.

IF559188

Basionym: Cortinarius oregonensis A.H. Sm., Contr. Univ. Mich. Herb. 2: 9. 1939.

Thaxterogaster ovreboi (Ammirati, Halling \& Garnica) Niskanen \& Liimat., comb. nov.

\section{IF559189}

Basionym: Cortinarius ovreboi Ammirati, Halling \& Garnica, in Ammirati, Garnica, Halling, Mata, Mueller \& Carranza, Can. J. Bot. 85(9): 805. 2007.

Thaxterogaster pallidirimosus (Kytöv., Liimat. \& Niskanen) Niskanen \& Liimat., comb. nov.

IF559190

Basionym: Cortinarius pallidirimosus Kytöv., Liimat. \& Niskanen, in Liimatainen, Niskanen, Dima, Kytövuori, Ammirati \& Frøslev, Persoonia 33: 131. 2014.

Thaxterogaster pallidoriederi (Brandrud, Dima \& Bellù) Niskanen \& Liimat., comb. nov.

\section{IF559191}

Basionym: Cortinarius pallidoriederi Brandrud, Dima \& Bellù, in Brandrud, Schmidt-Stohn, Liimatainen, Niskanen, Frøslev, Soop, Bojantchev, Kytövuori, Jeppesen, Bellù, Saar,
Oertel, Ali, Thines \& Dima, Mycol. Progr. 17(12): 1339. 2018.

Thaxterogaster parapluvius (Bidaud \& Reumaux) Niskanen \& Liimat., comb. nov.

\section{IF559192}

Basionym: Cortinarius parapluvius Bidaud \& Reumaux, in Bidaud, Moënne-Loccoz, Reumaux \& Henry, Atlas des Cortinaires (Meyzieu) 10: 493. 2000.

Thaxterogaster parolivascens (Moënne-Locc. \& Reumaux) Niskanen \& Liimat., comb. nov.

\section{IF559193}

Basionym: Cortinarius parolivascens Moënne-Locc. \& Reumaux, in Bidaud, Moënne-Loccoz, Reumaux \& Carteret, Atlas des Cortinaires (Meyzieu) 18(1, 2): 1375. 2009.

Thaxterogaster parksianus (A.H. Sm.) Niskanen \& Liimat., comb. nov.

IF559194

Basionym: Cortinarius parksianus A.H. Sm., Contr. Univ. Mich. Herb. 2: 16. 1939.

Thaxterogaster periclymenus (Soop) Niskanen \& Liimat., comb. nov.

\section{IF559195}

Basionym: Cortinarius periclymenus Soop, Bull. Soc. mycol. Fr. 117(2): 122. 2001.

Thaxterogaster peristeris (Soop) Niskanen \& Liimat., comb. nov.

\section{IF559196}

Basionym: Cortinarius peristeris Soop, Bresadoliana 1(2): 22. 2013.

Thaxterogaster permagnificus (E. Horak) Niskanen \& Liimat., comb. nov.

\section{IF559197}

Basionym: Cortinarius permagnificus E. Horak, in Moser \& Horak, Beih. Nova Hedwigia 52: 169. 1975. 
Thaxterogaster persicanus (Soop) Niskanen \& Liimat., comb. nov.

IF559198

Basionym: Cortinarius persicanus Soop, Bull. Soc. mycol. Fr. 117(2): 104. 2001.

Thaxterogaster picoides (Soop) Niskanen \& Liimat., comb. nov.

IF559199

Basionym: Cortinarius picoides Soop, Bull. Soc. mycol. Fr. 117(2): 107. 2001.

Thaxterogaster pinophilus (Soop) Niskanen \& Liimat., comb. nov.

IF559200

Basionym: Cortinarius pinophilus Soop, Agarica 12(21): 114. 1993.

Thaxterogaster pluvialis (Kühner) Niskanen \& Liimat., comb. nov.

IF559201

Basionym: Cortinarius pluvialis Kühner, Docums Mycol. 20(77): 92.1989.

Thaxterogaster pluvius (Fr.) Niskanen \& Liimat., comb. nov.

IF559202

Basionym: Agaricus pluvius Fr., Syst. mycol. (Lundae) 1: 236. 1821

Thaxterogaster porphyropus (Alb. \& Schwein.) Niskanen \& Liimat., comb. nov.

IF559203

Basionym: Agaricus porphyropus Alb. \& Schwein., Consp. fung. (Leipzig): 153. 1805.

Thaxterogaster pseudoarquatus (A.H. Sm.) Niskanen \& Liimat., comb. nov.

IF559204
Basionym: Cortinarius pseudoarquatus A.H. Sm., Lloydia 7(3): 181.1944.

Thaxterogaster pseudominor (Rob. Henry ex Reumaux) Niskanen \& Liimat., comb. nov.

IF559205

Basionym: Cortinarius pseudominor Rob. Henry ex Reumaux, in Bidaud, Moënne-Loccoz, Reumaux, Carteret \& Eyssartier, Atlas des Cortinaires (Meyzieu) 16: 1098. 2006.

Thaxterogaster pseudotalus (Rob. Henry ex Bidaud \& Reumaux) Niskanen \& Liimat., comb. nov.

\section{IF559206}

Basionym: Cortinarius pseudotalus Rob. Henry ex Bidaud \& Reumaux, in Bidaud, Moënne-Loccoz, Reumaux, Carteret \& Eyssartier, Atlas des Cortinaires (Meyzieu) 16: 1098. 2006.

Thaxterogaster pseudotriumphans (M.M. Moser \& E. Horak) Niskanen \& Liimat., comb. nov.

IF559207

Basionym: Cortinarius pseudotriumphans M.M. Moser \& E. Horak, Beih. Nova Hedwigia 52: 135. 1975.

Thaxterogaster psilomorphus (Soop) Niskanen \& Liimat., comb. nov.

IF559208

Basionym: Cortinarius psilomorphus Soop, N.Z. Jl Bot. 54(3): 357. 2016.

Thaxterogaster pugionipes (M.M. Moser) Niskanen \& Liimat., comb. nov.

IF559209

Basionym: Cortinarius pugionipes M.M. Moser, in Moser \& Horak, Beih. Nova Hedwigia 52: 146. 1975.

Thaxterogaster purpurascens (Fr.) Niskanen \& Liimat., comb. nov.

IF559210

Basionym: Cortinarius purpurascens Fr., Epicr. syst. mycol. (Upsaliae): 265. 1838. (1836-1838). 
Thaxterogaster rhipiduranus (Soop) Niskanen \& Liimat., comb. nov.

\section{IF559211}

Basionym: Cortinarius rhipiduranus Soop, in Gasparini \& Soop, Australas. Mycol. 27(3): 197. 2008.

Thaxterogaster rhodophyllus (M.M. Moser \& E. Horak) Niskanen \& Liimat., comb. nov.

IF559212

Basionym: Cortinarius rhodophyllus M.M. Moser \& E. Horak, Beih. Nova Hedwigia 52: 161. 1975.

Thaxterogaster riederi (Weinm.) Niskanen \& Liimat., comb. nov.

IF559213

Basionym: Agaricus riederi Weinm., Hym. à Gast. Imp. Ross. Obs. (Petropoli): 161. 1836.

Thaxterogaster rufoallutus (Rob. Henry ex Bidaud \& Reumaux) Niskanen \& Liimat., comb. nov.

IF559214

Basionym: Cortinarius rufoallutus Rob. Henry ex Bidaud \& Reumaux, in Bidaud, Moënne-Loccoz, Reumaux, Carteret \& Eyssartier, Atlas des Cortinaires (Meyzieu) 16: 1095. 2006.

Thaxterogaster scaurus (Fr.) Niskanen \& Liimat., comb. nov.

\section{IF559215}

Basionym: Agaricus scaurus Fr., Observ. mycol. (Havniae) 2: 75.1818.

Thaxterogaster singularis (Soop) Niskanen \& Liimat., comb. nov.

IF559216

Basionym: Cortinarius singularis Soop, N.Z. J1 Bot. 43(2): 557. 2005.

Thaxterogaster sphagnophilus (Peck) Niskanen \& Liimat., comb. nov.

IF559217
Basionym: Cortinarius sphagnophilus Peck, Ann. Rep. N.Y. St. Mus. nat. Hist. 29: 42. 1878. (1876).

Thaxterogaster stilazureus (Rob. Henry) Niskanen \& Liimat., comb. nov.

\section{IF559218}

Basionym: Cortinarius stilazureus Rob. Henry, Bull. trimest. Soc. mycol. Fr. 105(2): 125. 1989.

Thaxterogaster subinops (Reumaux) Niskanen \& Liimat., comb. nov.

IF559219

Basionym: Cortinarius subinops Reumaux, in Bidaud, Moënne-Loccoz, Reumaux \& Carteret, Atlas des Cortinaires (Meyzieu) 18(1-2): 1379. 2009.

Thaxterogaster submagellanicus (Gasparini) Niskanen \& Liimat., comb. nov.

IF559220

Basionym: Cortinarius submagellanicus Gasparini, N.Z. J1 Bot. 45(1): 207. 2007.

Thaxterogaster subporphyropus (Pilát) Niskanen \& Liimat., comb. nov.

IF559221

Basionym: Cortinarius subporphyropus Pilát, Česká Mykol. 8(1): 6. 1954.

Thaxterogaster subpurpurascens (Batsch) Niskanen \& Liimat., comb. nov.

IF559222

Basionym: Agaricus subpurpurascens Batsch, Elench. fung. (Halle): 71, tab. 16, Fig. 74. 1786.

Thaxterogaster subsebaceus (Bidaud, Carteret \& Reumaux) Niskanen \& Liimat., comb. nov.

IF559223

Basionym: Cortinarius subsebaceus Bidaud, Carteret \& Reumaux, in Bidaud, Moënne-Loccoz, Reumaux \& Carteret, Atlas des Cortinaires (Meyzieu) 19: 1503. 2010. 
Thaxterogaster talimultiformis (Kytöv., Liimat., Niskanen, A.F.S. Taylor \& Sesli) Niskanen \& Liimat., comb. nov.

IF559224

Basionym: Cortinarius talimultiformis Kytöv., Liimat., Niskanen, A.F.S. Taylor \& Sesli, in Liimatainen, Niskanen, Dima, Kytövuori, Ammirati \& Frøslev, Persoonia 33: 133. 2014.

Thaxterogaster talus (Fr.) Niskanen \& Liimat., comb. nov.

IF559225

Basionym: Cortinarius talus Fr., Epicr. syst. mycol. (Upsaliae): 263. 1838. (1836-1838).

Thaxterogaster thalliopurpurascens (Rob. Henry) Niskanen \& Liimat., comb. nov.

IF559226

Basionym: Cortinarius thalliopurpurascens Rob. Henry, Docums Mycol. 25(97): 48. 1995.

Thaxterogaster turcopes (Soop) Niskanen \& Liimat., comb. nov.

IF559227

Basionym: Cortinarius turcopes Soop, Bresadoliana 1(2): 25. 2013.

Thaxterogaster turmalis (Fr.) Niskanen \& Liimat., comb. nov.

IF559228

Basionym: Cortinarius turmalis Fr., Epicr. syst. mycol. (Upsaliae): 257. 1838. (1836-1838).

Thaxterogaster urbiculus (Soop) Niskanen \& Liimat., comb. nov.

IF559229

Basionym: Cortinarius urbiculus Soop, N.Z. J1 Bot. 54(3): 361. 2016.

Thaxterogaster verniciorum (Soop) Niskanen \& Liimat., comb. nov.

IF559230
Basionym: Cortinarius verniciorum Soop, Australas. Mycol. 31: 8. 2013.

Thaxterogaster vespertinus (Fr.) Niskanen \& Liimat., comb. nov.

IF559231

Basionym: Agaricus vespertinus Fr., Syst. mycol. (Lundae) 1: 233. 1821 .

Thaxterogaster vibratilis (Fr.) Niskanen \& Liimat., comb. nov.

IF559232

Basionym: Agaricus vibratilis Fr., Syst. mycol. (Lundae) 1: 227. 1821.

Thaxterogaster violaceonitens (Rob. Henry) Niskanen \& Liimat., comb. \& stat. nov.

IF559233

Basionym: Cortinarius scaurus subsp. violaceonitens Rob. Henry, Docums Mycol. 7(25): 54. 1976.

Thaxterogaster virentophyllus (Kauffman) Niskanen \& Liimat., comb. nov.

IF559234

Basionym: Cortinarius virentophyllus Kauffman, Publications Mich. geol. biol. Surv., Biol. Ser. 5 26: 353. 1918.

Thaxterogaster xiphidipus (M.M. Moser \& E. Horak) Niskanen \& Liimat., comb. nov.

IF559235

Basionym: Cortinarius xiphidipus M.M. Moser \& E. Horak, Beih. Nova Hedwigia 52: 156. 1975.

\section{Volvanarius}

Volvanarius sect. Thaumasti (Soop) Niskanen \& Liimat., comb. nov.

IF555940

Basionym: Cortinarius sect. Thaumasti Soop, in Soop, Dima, Cooper, Park \& Oertel, Persoonia 42: 279. 2019. 
Volvanarius chlorophanus (M.M. Moser) Niskanen \& Liimat., comb. nov.

\section{IF559236}

Basionym: Cortinarius chlorophanus M.M. Moser, in Moser \& Horak, Beih. Nova Hedwigia 52: 197. 1975.

Volvanarius coleopus (M.M. Moser \& E. Horak) Niskanen \& Liimat., comb. nov.

\section{IF559237}

Basionym: Cortinarius coleopus M.M. Moser \& E. Horak, Beih. Nova Hedwigia 52: 191. 1975.

Volvanarius cosmoxanthus (M.M. Moser) Niskanen \& Liimat., comb. nov.

\section{IF559238}

Basionym: Cortinarius cosmoxanthus M.M. Moser, in Moser \& Horak, Beih. Nova Hedwigia 52: 196. 1975.

Volvanarius olivaceovaginatus (Niskanen, San-Fabian, Liimat. \& E. Horak) Niskanen \& Liimat., comb. nov.

IF559239

Basionym: Cortinarius olivaceovaginatus Niskanen, SanFabian, Liimat. \& E. Horak, in Liimatainen, Niskanen, SanFabian, Mujic, Peintner, Dresch, Furci, Nouhra, Matheny \& Smith, Mycologia 112(2): 337. 2020.

Volvanarius subcosmoxanthus (Liimat., San-Fabian \& Niskanen) Niskanen \& Liimat., comb. nov.

\section{IF559240}

Basionym: Cortinarius subcosmoxanthus Liimat., SanFabian \& Niskanen, in Liimatainen, Niskanen, San-Fabian, Mujic, Peintner, Dresch, Furci, Nouhra, Matheny \& Smith, Mycologia: 112(2): 337. 2020.

Volvanarius thaumastus (Soop) Niskanen \& Liimat., comb. nov.

\section{IF559241}

Basionym: Cortinarius thaumastus Soop, N.Z. Jl Bot. 43(2): 554. 2005.

Volvanarius vaginatus (E. Horak \& M.M. Moser) Niskanen \& Liimat., comb. nov.

\section{IF559242}

Basionym: Cortinarius vaginatus E. Horak \& M.M. Moser, in Moser \& Horak, Beih. Nova Hedwigia 52: 189. 1975.

Acknowledgements We thank Robyn Cowan, Sidonie Bellot, Niroshini Epitawalage, and Laura Martinez-Suz for help and support in the laboratory work, Alexandre Zuntini and Matt Clarke for help with molecular analyses, and Lee Davies for assistance with the fungarium specimens. The Sackler Phylogenomic Laboratory and the Jodrell Laboratory at RBGK are also thanked for facilitating access to molecular and computational resources. We are also grateful to Soop et al. (2019) for their recent, global section revision of family Cortinariaceae that was a valuable starting point for our study as well as the multi-gene phylogeny presented in Garnica et al. (2016). This study was partly supported by a Royal Botanic Gardens, Kew (RBGK) pilot study to TN, in collaboration with LP and BD. Lastly, we would like to thank the reviewers for their constructive comments, which helped us to improve the manuscript.

Open Access This article is licensed under a Creative Commons Attribution 4.0 International License, which permits use, sharing, adaptation, distribution and reproduction in any medium or format, as long as you give appropriate credit to the original author(s) and the source, provide a link to the Creative Commons licence, and indicate if changes were made. The images or other third party material in this article are included in the article's Creative Commons licence, unless indicated otherwise in a credit line to the material. If material is not included in the article's Creative Commons licence and your intended use is not permitted by statutory regulation or exceeds the permitted use, you will need to obtain permission directly from the copyright holder. To view a copy of this licence, visit http://creativecommons.org/licenses/by/4.0/.

\section{References}

Altschul SF, Gish W, Miller W, Myers EW, Lipman DJ (1990) Basic local alignment search tool. J Mol Biol 215:403-410. https://doi. org/10.1016/S0022-2836(05)80360-2

Alvarado P, Manjón JL, Matheny PB, Esteve-Raventós F (2010) Tubariomyces, a new genus of Inocybaceae. Mycologia 102(6):13891397. https://doi.org/10.3852/10-041

Ammirati JF, Liimatainen K, Bojantchev D, Peintner U, KuhnertFinkernagel R, Cripps C, Dentinger B, Niskanen T (2021) Cortinarius subgenus Leprocybe, unexpected diversity and significant differences in species compositions between western and eastern North America. Persoonia 46:216-239. https://doi.org/ 10.3767/persoonia.2021.46.08

Andrews S (2010) FastQC: a quality control tool for high throughput sequence data [WWW document]. http://www.bioinformatics. babraham.ac.uk/projects/fastqc/

Bankevich A, Nurk S, Antipov D, Gurevich AA, Dvorkin M, Kulikov AS, Lesin VM, Nikolenko SI, Pham S, Prjibelski AD, Pyshkin AV, Sirotkin AV, Vyahhi N, Tesler G, Alekseyev MA, Pevzner PA (2012) SPAdes: a new genome assembly algorithm and its applications to single-cell sequencing. J Comput Biol 19:455477. https://doi.org/10.1089/cmb.20120021

Bidaud A, Moënne-Loccoz P, Reumaux P (1994) Atlas des Cortinaires. Cle generale des sous-genres, sections et series, Èditions Fèdération mycologique Dauphiné-Savoie, France

Bidaud A, Loizides M, Armada F, de Dios RJ, Carteret X, Corriol G, Consiglio G, Reumaux P, Bellanger J-M (2021) Cortinarius 
subgenus Leprocybe in Europe: expanded Sanger and Next Generation Sequencing unveil unexpected diversity in the Mediterranean. Persoonia 46:188-215. https://doi.org/10.3767/perso onia.2021.46.07

Bolger AM, Lohse M, Usadel B (2014) Trimmomatic: a flexible trimmer for Illumina Sequence Data. Bioinformatics 30:2114-2120

Brandrud T-E (2019) Cortinarius meinhardii. The IUCN Red List of Threatened Species 2019: e.T147851191A147851218. https:// doi.org/10.2305/IUCN.UK.2019-2.RLTS.T147851191A1478 51218.en. Accessed 30 Jan 2021

Brandrud TE, Lindström H, Marklund H, Melot J, Muskos S (1989) Cortinarius Flora Photographica. Vol. I (Swedish version). Cortinarius HB, Matfors, Sweden

Brandrud TE, Schmidt-Stohn G, Liimatainen K, Niskanen T, Frøslev TG, Soop K, Bojantchev D, Kytövuori I, Jeppesen TS, Bellù F, Saar G, Oertel B, Ali T, Thines M, Dima B (2018) Cortinarius sect. Riederi: taxonomy and phylogeny of the new section with European and North American distribution. Mycol Prog 17:1323-1354. https://doi.org/10.1007/s11557-018-1443-0

Brandrud TE, Schmidt-Stohn G, Dima B (2019) Cortinarius hildegardiae and $C$. mariekristinae spp. nov., two new species in the phlegmacioid clade Humolentes (sect. Calochroi s. 1.). Sydowia 71:115-127. https://doi.org/10.12905/0380.sydow ia71-2019-0115

Brewer GE, Clarkson JJ, Maurin O, Zuntini AR, Barber V, Bellot S, Biggs N, Cowan RS, Davies NMJ, Dodsworth S, Edwards SL, Eiserhardt WL, Epitawalage N, Frisby S, Grall A, Kersey PJ, Pokorny L, Leitch IJ, Forest F, Baker WJ (2019) Factors affecting targeted sequencing of 353 nuclear genes from herbarium specimens spanning the diversity of angiosperms. Front Plant Sci 10:1102. https://doi.org/10.3389/fpls.2019.01102

Buyck B, Hofstetter V, Eberhardt U, Verbeken A, Kauff F (2008) Walking the thin line between Lactarius and Russula: the dilemma of Russula sect. Ochricompactae. Fungal Divers 28:15-40

Bödeker ITM, Clemmensen KE, de Boer W, Martin F, Olson Å, Lindahl BD (2014) Ectomycorrhizal Cortinarius species participate in enzymatic oxidation of humus in northern forest ecosystems. New Phytol 203:245-256. https://doi.org/10.1111/nph.12791

Chang Y, Rochon DA, Sekimoto S, Wang Y, Chovatia M, Sandor L, Salamov A, Grigoriev IV, Stajich JE, Spatafora JW (2021) Genome-scale phylogenetic analyses confirm Olpidium as the closest living zoosporic fungus to the non-flagellated, terrestrial fungi. Sci Rep 11(1):3217. https://doi.org/10.1038/ s41598-021-82607-4

Danel VC, Saviuc PF, Garon D (2001) Main features of Cortinarius spp. poisoning: a literature review. Toxicon 39:1053-1060. https:// doi.org/10.1016/S0041-0101(00)00248-8

Dentinger BTM, Gaya E, O'Brien H, Martinez-Suz L, Lachlan R, DiazValderrama JR, Koch RA, Aime MC (2016) Tales from the crypt: genome mining from fungarium specimens improves resolution of the mushroom tree of life. Biol J Linn Soc 117(1):11-32. https:// doi.org/10.1111/bij.12553

Dodsworth S, Pokorny L, Johnson MG, Kim JT, Maurin O, Wickett NJ, Forest F, Baker WJ (2019) Hyb-Seq for flowering plant systematics. Trends Plant Sci 24(10):887-891. https://doi.org/ 10.1016/j.tplants.2019.07.011

Faircloth BC (2017) Identifying conserved genomic elements and designing universal bait sets to enrich them. Methods Ecol Evol 8:1103-1112. https://doi.org/10.1111/2041-210X.12754

Fellin A, Ercole E, Ferrari RJ, Vizzini A (2021) Cortinarius anaunianus (Agaricales, Cortinariaceae): a new species of the Humolentes clade from Italy. Phytotaxa 520(3):225-240

Fernandez CW, See CR, Kennedy PG (2020) Decelerated carbon cycling by ectomycorrhizal fungi is controlled by substrate quality and community composition. New Phytol 226(2):569-582. https://doi.org/10.1111/nph.16269
Forrest LL, Hart ML, Hughes M, Wilson HP, Chung K-F, Tseng YH, Kidner CA (2019) The limits of Hyb-Seq for herbarium specimens: Impact of preservation techniques. Front Ecol Evol 7:439. https://doi.org/10.3389/fevo.2019.00439

Fries EM (1821) Systema mycologicum. Uppsala, Sweden

Frøslev TG, Matheny PB, Hibbett D (2005) Lower level relationships in the mushroom genus Cortinarius (Basidiomycota, Agaricales): a comparison of RBP1, RPB2, and ITS phylogenies. Mol Phylogenet Evol 37:602-618. https://doi.org/10.1016/j. ympev.2005.06.016

Frøslev TG, Jeppesen TS, Læssoe T, Kjøller R (2007) Molecular phylogenetics and delimitation of species in Cortinarius section Calochroi (Basidiomycota, Agaricales) in Europe. Mol Phylogenet Evol 44:217-227. https://doi.org/10.1016/j.ympev. 2006.11.013

Galtier N, Gouy M, Gautier C (1996) SEAVIEW and PHYLO_WIN: two graphic tools for sequence alignment and molecular phylogeny. Bioinformatics 12:543-548

Garnica S, Weiß M, Oertel B, Oberwinkler F (2005) A framework for a phylogenetic classification in the genus Cortinarius (Basidiomycota, Agaricales) derived from morphological and molecular data. Botany 83:1457-1477. https://doi.org/10.1139/b05-107

Garnica S, Weiß M, Oertel B, Ammirati J, Oberwinkler F (2009) Phylogenetic relationships in Cortinarius, section Calochroi, inferred from nuclear DNA sequences. BMC Evolut Biol 9:1. https://doi. org/10.1186/1471-2148-9-1

Garnica S, Spahn P, Oertel B, Ammirati J, Oberwinkler F (2011) Tracking the evolutionary history of Cortinarius species in section Calochroi, with transoceanic disjunct distributions. BMC Evolut Biol 11:213. http://www.biomedcentral.com/1471-2148/11/213

Garnica S, Schön ME, Abarenkov K, Riess K, Liimatainen K, Niskanen T, Dima B, Soop K, Frøslev TG, Jeppesen TS, Peintner U, Kuhnert R, Brandrud TE, Saar G, Oertel B, Ammirati JF (2016) Determining threshold values for barcoding fungi: lessons from Cortinarius (Basidiomycota), a highly diverse and widespread ectomycorrhizal genus. FEMS Microbiol Ecol 92(4):045. https://doi.org/10.1093/femsec/fiw045

Gómez AM, Cadiñanos AJ (2018) Historia taxonómica y nomenclatural de Cortinarius collinitus (Sowerby : Fr.) Gray y de especies próximas del subgénero Myxacium. J Des JEC 20:50-148

Grewe F, Ametrano C, Widhelm TJ, Leavitt S, Distefano I, Polyiam W, Pizarro D, Wedin M, Crespo A, Divakar PK, Lumbsch HT (2020) Using target enrichment sequencing to study the higherlevel phylogeny of the largest lichen-forming fungi family: Parmeliaceae (Ascomycota). IMA Fungus 11(1):27. https://doi.org/ 10.1186/s43008-020-00051-xs

Hale H, Gardner EM, Viruel J, Pokorny L, Johnson MG (2020) Strategies for reducing per-sample costs in target capture sequencing for phylogenomics and population genomics in plants. Appl Plant Sci 8(4):e11337. https://doi.org/10.1002/aps3.11337

Harrington TJ, Mitchell DT (2002) Colonization of root systems of Carex flacca and C. pilulifera by Cortinarius (Dermocybe) cinnamomeus. Mycol Res 106(4):452-459. https://doi.org/10. 1017/S0953756202005713

Harrower E, Ammirati JF, Cappuccino AA, Ceska O, Kranabetter JM, Kroeger P, Lim S, Taylor T, Berbee ML (2011) Cortinarius species diversity in British Columbia and molecular phylogenetic comparison with European specimen sequences. Botany 89(11):799-810. https://doi.org/10.1139/b11-065

Harrower E, Bougher NL, Henkel TW, Horak E, Matheny PB (2015a) Long-distance dispersal and speciation of Australasian and American species of Cortinarius sect. Cortinarius. Mycologia 107(4):697-709. https://doi.org/10.3852/14-182

Harrower E, Bougher NL, Winterbottom C, Henkel TW, Horak E, Matheny PB (2015b) New species in Cortinarius section 
Cortinarius (Agaricales) from the Americas and Australasia. MycoKeys 11:1-21. https://doi.org/10.3897/mycokeys.11.5409

Hill R, Leitch IJ, Gaya E (2021) Targeting Ascomycota genomes: what and how big? Fungal Biol Rev 36:52-59. https://doi.org/10. 1016/j.fbr.2021.03.003

Høiland K, Holst-Jensen A (2000) Cortinarius phylogeny and possible taxonomic implications of ITS rDNA sequences. Mycologia 92(4):694-710. https://doi.org/10.1080/00275514.2000.12061210

Index Fungorum (2021) www.indexfungorum.org. Accessed 6 Aug 2021

Jacquemyn H, Honnay O, Cammue BP, Brys R, Lievens B (2010) Low specificity and nested subset structure characterize mycorrhizal associations in five closely related species of the genus Orchis. Mol Ecol 19(18):4086-4095. https://doi.org/10.1111/j.1365-294x. 2010.04785.x

Johnson MG, Pokorny L, Dodsworth S, Botigué LR, Cowan RS, Devault A, Eiserhardt WL, Epitawalage N, Forest F, Kim JT, Leebens-Mack JH, Leitch IJ, Maurin O, Soltis DE, Soltis PS, Wong GK, Baker WJ, Wickett NJ (2019) A universal probe set for targeted sequencing of 353 nuclear genes from any flowering plant designed using k-medoids clustering. Syst Biol 68(4):594-606. https://doi.org/10.1093/sysbio/syy086

Kapusta A, Suh A, Feschotte C (2017) Dynamics of genome size evolution in birds and mammals. Proc Natl Acad Sci USA 114(8):E1460-E1469. https://doi.org/10.1073/pnas.1616702114

Katoh K, Standley DM (2013) MAFFT multiple sequence alignment software version 7: improvements in performance and usability. Mol Biol Evol 30:772-780

Kistler L, Bieker VC, Martin MD, Pedersen MW, Ramos Madrigal J, Wales N (2020) Ancient plant genomics in archaeology, herbaria, and the environment. Annu Rev Plant Biol 71:605-629. https:// doi.org/10.1146/annurev-arplant-081519-035837

Kohler A, Kuo A, Nagy LG, Morin E, Barry KW, Buscot F, Canbäck B, Choi C, Cichocki N, Clum A, Colpaert J, Copeland A, Costa MD, Doré J, Floudas D, Gay G, Girlanda M, Henrissat B, Herrmann S, Hess J, Högberg N, Johansson T, Khouja HR, LaButti K, Lahrmann U, Levasseur A, Lindquist EA, Lipzen A, Marmeisse R, Martino E, Murat C, Ngan CY, Nehls U, Plett JM, Pringle A, Ohm RA, Perotto S, Peter M, Riley R, Rineau F, Ruytinx J, Salamov A, Shah F, Sun H, Tarkka M, Tritt A, Veneault-Fourrey C, Zuccaro A, Tunlid A, Grigoriev IV, Hibbett DS, Martin F (2015) Convergent losses of decay mechanisms and rapid turnover of symbiosis genes in mycorrhizal mutualists. Nat Genet 47(4):410-415. https://doi.org/10.1038/ng.3223

Kullman B, Tamm H, Kullman K (2005) Fungal Genome Size Database [WWW Document]. http://www.zbi.ee/fungal-genomesize. Accessed 26 Sept 2021.

Li H, Handsaker B, Wysoker A, Fennell T, Ruan J, Homer N, Marth G, Abecasis G, Durbin R (2009) The sequence alignment/map format and SAMtools. Bioinformatics 25:2078-2079. https://doi.org/10. 1093/bioinformatics/btp352

Li H, Wu S, Ma X, Chen W, Zhang J, Duan S, Gao Y, Kui L, Huang W, Wu P, Shi R, Li Y, Wang Y, Li J, Guo X, Luo X, Li Q, Xiong C, Liu H, Gui M, Sheng J, Dong Y (2018) The genome sequences of 90 mushrooms. Sci Rep 8:9982. https://doi.org/10. 1038/s41598-018-28303-2

Li Y, Steenwyk JL, Chang Y, Wang Y, James TY, Stajich JE, Spatafora JW, Groenewald M, Dunn CW, Hittinger CT, Shen XX, Rokas A (2021) A genome-scale phylogeny of the kingdom Fungi. Curr Biol 31(8):P1653-P1665. https://doi.org/10.1016/j. cub.2021.01.074

Liimatainen K, Niskanen T, Dima B, Kytövuori I, Ammirati JF, Frøslev T (2014) The largest type study of Agaricales species to date: bringing identification and nomenclature of Phlegmacium (Cortinarius, Agaricales) into the DNA era. Persoonia 33:98-140
Liimatainen K, Niskanen T, Dima B, Ammirati JF, Kirk P, Kytövuori I (2020a) Mission impossible completed: unlocking the nomenclature of the largest and most complicated subgenus of Cortinarius, Telamonia. Fungal Divers 104:291-331. https://doi.org/10.1007/ s13225-020-00459-1

Liimatainen K, Niskanen T, San-Fabian B, Mujic AB, Peintner U, Dresch P, Furci G, Nouhra E, Matheny PB, Smith ME (2020b) Cortinarius section Thaumasti in South American Nothofagaceae forests. Mycologia 112(2):329-341. https://doi.org/10.1080/ 00275514.2019 .1689763

Lindahl BD, Kyaschenko J, Varenius K, Clemmensen KE, Dahlberg A, Karltun E, Stendahl J (2021) A group of ectomycorrhizal fungi restricts organic matter accumulation in boreal forest. Ecol Lett 24(7):1341-1351. https://doi.org/10.1111/ele.13746

Liu Y, Johnson MG, Cox CJ, Medina R, Devos N, Vanderpoorten A, Hedenäs L, Bell NE, Shevock JR, Aguero B, Quandt D, Wickett NJ, Shaw AJ, Goffinet B (2019) Resolution of the ordinal phylogeny of mosses using targeted exons from organellar and nuclear genomes. Nat Commun 10(1):1-11. https://doi.org/10.1038/ s41467-019-09454-w

Maddison WP, Maddison DR (2017) Mesquite: a modular system for evolutionary analysis. Version 3.2. http://www.mesquiteproject. org

Matheny PB, Bougher NL (2006) The new genus Auritella from Africa and Australia (Inocybaceae, Agaricales): molecular systematics, taxonomy and historical biogeography. Mycol Prog 5:2-17. https://doi.org/10.1007/s11557-005-0001-8

Matheny PB, Moreau P-A, Vizzini A, Harrower E, De Haan A, Contu M, Curti M (2015) Crassisporium and Romagnesiella: two new genera of dark-spored Agaricales. Syst Biodivers 13(1):28-41. https://doi.org/10.1080/14772000.2014.967823

Matheny PB, Hobbs AM, Esteve-Raventós F (2020) Genera of Inocybaceae: new skin for the old ceremony. Mycologia 112(1):83-120. https://doi.org/10.1080/00275514.2019.1668906

Miyauchi S, Kiss E, Kuo A, Drula E, Kohler A, Sánchez-García M, Morin E, Andreopoulos B, Barry KW, Bonito G, Buée M, Carver A, Chen C, Cichocki N, Clum A, Culley D, Crous PW, Fauchery L, Girlanda M, Hayes RD, Kéri Z, LaButti K, Lipzen A, Lombard V, Magnuson J, Maillard F, Murat C, Nolan M, Ohm RA, Pangilinan J, Pereira MF, Perotto S, Peter M, Pfister S, Riley R, Sitrit Y, Stielow JB, Szöllősi G, Žif̌ćáková L, Štursová M, Spatafora JW, Tedersoo L, Vaario L-M, Yamada A, Yan M, Wang P, Xu J, Bruns T, Baldrian P, Vilgalys R, Dunand C, Henrissat B, Grigoriev IV, Hibbett D, Nagy LG, Martin FM (2020) Large-scale genome sequencing of mycorrhizal fungi provides insights into the early evolution of symbiotic traits. Nat Commun 11:5125. https://doi. org/10.1038/s41467-020-18795-w

Mohanta TK, Bae H (2015) The diversity of fungal genome. Biol Proc Online 17:8. https://doi.org/10.1186/s12575-015-0020-z

Morrison DA (2006) Multiple sequence alignment for phylogenetic purposes. Aust Syst Bot 19:479-539. https://doi.org/10.1071/ SB06020s

Moser M (1960) Die Gattung Phlegmacium (Schleimköpfe). Die Pilze Mitteleuropas 4. Julius Klinkhardt, Bad Heilbrunn (Obb.), p 440

Moser M (1983) Die Röhrlinge und Blätterpilze. In: Gams H (ed) Kleine Kryptogamenflora, Band II b/2, 5th edn. Gustav Fischer Verlag, Stuttgart

Moser M, Horak E (1975) Cortinarius Fr. und nahe verwandte Gattungen in Südaamerika. Nova Hedwigia 52:1-628, 116 plts., 20 color plts

Niskanen T, Liimatainen K (2021) Nomenclatural novelties. Index Fungorum no. 477. http://www.indexfungorum.org/Publicatio ns/Index\%20Fungorum\%20no.477.pdf

Niskanen T, Kytövuori I, Bendiksen E, Bendiksen K, Brandrud TE, Frøslev TG, Høiland K, Jeppesen TS, Liimatainen K, Lindström H (2008) Cortinarius (Pers) Gray. In: Knudsen H, Vesterholt J 
(eds) Funga Nordica. Agaricoid, boletoid and cyphelloid genera. Nordsvamp, Copenhagen, pp 661-777

Nouhra E, Kuhar F, Truong C, Pastor N, Crespo E, Mujic A, Caiafa MF, Smith ME (2021) Thaxterogaster revisited: a phylogenetic and taxonomic overview of sequestrate Cortinarius from Patagonia. Mycologia 113(5):1022-1055. https://doi.org/10.1080/00275 514.2021.1894535

Peintner U, Bougher NL, Castellano MA, Moncalvo J-M, Moser MM, Trappe JM, Vilgalys R (2001) Multiple origins of sequestrate fungi related to Cortinarius (Cortinariaceae). Am J Bot 88(12):2168-2179. https://doi.org/10.2307/3558378s

Peintner U, Horak E, Moser MM, Vilgalys R (2002) Phylogeny of Rozites, Cuphocybe and Rapacea inferred from ITS and LSU rDNA sequences. Mycologia 94(4):620-629. https://doi.org/10. 1080/15572536.2003.11833190

Peintner U, Moncalvo J-M, Vilgalys R (2004) Towards a better understanding of the infrageneric relationships in Cortinarius (Agaricales, Basidiomycota). Mycologia 96(5):1042-1058. https://doi. org/10.1080/15572536.2005.11832904

Pellicer J, Hidalgo O, Dodsworth S, Leitch IJ (2018) Genome size diversity and its impact on the evolution of land plants. Genes 9(2):88. https://doi.org/10.3390/genes9020088

Sánchez-Garcia M, Matheny PB, Palfner G, Lodge DJ (2014) Deconstructing the Tricholomataceae (Agaricales) and introduction of the new genera Albomagister, Corneriella, Pogonoloma and Pseudotricholoma. Taxon 63:993-1007. https://doi.org/10.12705/ 635.635.3

Sánchez-García M, Ryberg M, Khan FK, Varga T, Nagy LG, Hibbett DS (2020) Fruiting body form, not nutritional mode, is the major driver of diversification in mushroom-forming fungi. Proc Natl Acad Sci 117(51):32528-32534. https://doi.org/10.1073/pnas. 1922539117

Schumacher T, Høiland K (1983) Mushroom poisoning caused by species of the genus Cortinarius Fries. Arch Toxicol 53:87-106. https://doi.org/10.1007/BF00302720

Shee ZQ, Frodin DG, Cámara-Leret R, Pokorny L (2020) Reconstructing the complex evolutionary history of the Papuasian Schefflera radiation through herbariomics. Front Plant Sci 11:258. https:// doi.org/10.3389/fpls.2020.00258

Simpson JT, Wong K, Jackman SD, Schein JE, Jones SJM, Birol I (2009) ABySS: a parallel assembler for short read sequence data. Genome Res 19:1117-1123

Slater GSC, Birney E (2005) Automated generation of heuristics for biological sequence comparison. BMC Bioinform 6:31

SLU Artdatabanken (2020) The Swedish Red List 2020. Checklist dataset https://doi.org/10.15468/jhwkpq accessed via GBIF.org. Accessed 12 Aug 2021

Soop K (2017) Cortinarioid Fungi of New Zealand. An Iconography and Key. Eleventh Revised Edition. Mora, Sweden. 57 pp. +40 plates

Soop K, Wallace M, Dima B (2018) New Cortinarius (Agaricales) species described from New Zealand. N Z J Bot 56(2):163-182. https://doi.org/10.1080/0028825X.2018.1436574

Soop K, Dima B, Cooper JA, Park D, Oertel B (2019) A phylogenetic approach to a global supraspecific taxonomy of Cortinarius (Agaricales) with an emphasis on the southern mycota. Persoonia 42:261-290. https://doi.org/10.3767/persoonia.2019.42.10

Soop K, Nilsen AR, Orlovich DA, Dima B (2021) An emended subgenus Myxacium in the light of a global Cortinarius (Agaricales) phylogeny. Mycol Prog 20:247-260. https://doi.org/10.1007/ s11557-020-01665-6

Stamatakis A (2014) RAxML Version 8: a tool for phylogenetic analysis and postanalysis of large phylogenies. Bioinformatics 30:1312-1313

Stefani F, Jones RH, May TW (2014) Concordance of seven gene genealogies compared to phenotypic data reveals multiple cryptic species in Australian dermocyboid Cortinarius (Agaricales). Mol Phylogenet Evol 71:249-260. https://doi.org/10.1016/j.ympev. 2013.10.019

Stensrud Ø, Orr RJS, Reier-Røberg K, Schumacher T, Høiland K (2014) Phylogenetic relationships in Cortinarius with focus on North European species. Karstenia 54:57-71. https://doi.org/10. 29203/ka.2014.464

Stoltze M, Pihl S (1998) Rødliste 1997 over planter og dyr i Danmark. Miljø- og Energiministeriet, Danmarks Miljø-undersøgelser og Skovog Naturstyrelsen

Tedersoo L, Bahram M, Jairus T, Bechem E, Chinoya S, Mpumba R, Leal M, Randrianjohany E, Razafimandimbison S, Sadam A, Naadel T, Koljalg U (2011) Spatial structure and the effects of host and soil environments on communities of ectomycorrhizal fungi in wooded savannas and rain forests of Continental Africa and Madagascar. Mol Ecol 20(14):3071-3080. https://doi.org/10. 1111/j.1365-294X.2011.05145.x

Thoen E, Aas AB, Vik U, Brysting AK, Skrede I, Carlsen T, Kauserud H (2019) A single ectomycorrhizal plant root system includes a diverse and spatially structured fungal community. Mycorrhiza 29:167-180. https://doi.org/10.1007/s00572-019-00889-z

UNITE (2021) https://unite.ut.ee/. Accessed 27 July 2021

Varga T, Krizsán K, Földi C, Dima B, Sánchez-García M, SánchezRamírez S, Szöllősi GJ, Szarkándi JG, Papp V, Albert L, Andreopoulos W, Angelini C, Antonín V, Barry KW, Bougher NL, Buchanan P, Buyck B, Bense V, Catcheside P, Chovatia M, Cooper J, Dämon W, Desjardin D, Finy P, Geml J, Haridas S, Hughes K, Justo A, Karasiński D, Kautmanova I, Kiss B, Kocsubé S, Kotiranta H, LaButti KM, Lechner BE, Liimatainen K, Lipzen A, Lukács Z, Mihaltcheva S, Morgado LN, Niskanen T, Noordeloos ME, Ohm RA, Ortiz-Santana B, Ovrebo C, Rácz N, Riley R, Savchenko A, Shiryaev A, Soop K, Spirin V, Szebenyi C, Tomšovský M, Tulloss RE, Uehling J, Grigoriev IV, Vágvölgyi C, Papp T, Martin FM, Miettinen O, Hibbett DS, Nagy LG (2019) Megaphylogeny resolves global patterns of mushroom evolution. Nat Ecol Evol 3:668-678. https://doi.org/10.1038/ s41559-019-0834-1

Widhelm TJ, Grewe F, Huang JP, Mercado-Díaz JA, Goffinet B, Lücking R, Moncada B, Mason-Gamer R, Lumbsch HT (2019) Multiple historical processes obscure phylogenetic relationships in a taxonomically difficult group (Lobariaceae, Ascomycota). Sci Rep 9(1):1-16. https://doi.org/10.1038/s41598-019-45455-x

Widhelm TJ, Grewe F, Goffinet B, Wedin M, Goward T, Coca LF, Distefano I, Košuthová A, Lumbsch HT (2021) Phylogenomic reconstruction addressing the Peltigeralean backbone (Lecanoromycetes, Ascomycota). Fungal Divers. https://doi.org/10.1007/ s13225-021-00476-8

Young AD, Gillung JP (2020) Phylogenomics-principles, opportunities, and pitfalls of big-data phylogenetics. Syst Entomol 45(2):225-247. https://doi.org/10.1111/syen.12406 